Portland State University

PDXScholar

Fall 11-14-2014

\title{
The Journey to Becoming Constructivist, Presidential Award for Excellence in Mathematics and Science Teaching, Secondary Mathematics Teacher
}

Gerald E. Young

Portland State University

Follow this and additional works at: https://pdxscholar.library.pdx.edu/open_access_etds

Part of the Secondary Education and Teaching Commons Let us know how access to this document benefits you.

\section{Recommended Citation}

Young, Gerald E., "The Journey to Becoming Constructivist, Presidential Award for Excellence in Mathematics and Science Teaching, Secondary Mathematics Teacher" (2014). Dissertations and Theses. Paper 2065.

https://doi.org/10.15760/etd.2064

This Dissertation is brought to you for free and open access. It has been accepted for inclusion in Dissertations and Theses by an authorized administrator of PDXScholar. Please contact us if we can make this document more accessible: pdxscholar@pdx.edu. 
The Journey to Becoming Constructivist, Presidential Award for Excellence in Mathematics and Science Teaching, Secondary Mathematics Teacher

by

Gerald Young

A dissertation submitted in partial fulfillment of the requirements for the degree of

Doctor of Education

in

Educational Leadership: Curriculum and Instruction

Dissertation Committee:

Ronald Narode, Chair

Christine Chaille

Samuel Henry

Jeanette Palmiter

Portland State University

2014 
C 2014 Gerald Young 


\begin{abstract}
The purpose of this research study is to describe and analyze the self-reported experiences of exemplary high school mathematics teachers who underwent personal and professional transformations in order to develop and use a standards-based, constructivist (SBC) teaching paradigm in their classrooms. These teachers were all past recipients of the Presidential Award for Excellence in Mathematics and Science Teaching (PAEMST), an award that required them to demonstrate that their mathematics instruction was rigorous in the manner described by the NCTM standards.
\end{abstract}

The following research questions are addressed: (a) What are the paths SBC secondary mathematics teachers who received the PAEMST pursued to become highly effective?, (b) What obstacles and challenges did they encounter and how were these obstacles overcome?, and (c) What sustained them on their journeys? The research methodology used to be a narrative inquiry. Following a wide survey of PAEMST recipients, five volunteer participants were chosen for the study. Data were collected from each participant using a one-to-one interview and the written section of each participant's PAEMST application. A narrative was written for each participant describing the path they had followed to become a highly effective high school mathematics teacher. The narrative was sent to each participant, and a follow-up interview was conducted via telephone amending the narrative to reflect the participant's additions and deletions. From the five amended narratives, eight themes were identified: (a) influences; (b) education; (c) professional development; (d) NCTM standards; (e) 
teaching style: beginning, current, or end of a career; (f) obstacles; (g) personality traits and personal beliefs; and (h) student influence.

Several of the themes were supported by previous research. However, this research study discovered two new findings. First, the five participants had common characteristics and beliefs: (a) belief in their students, (b) persistence, (c) belief that professional development is vital for teacher growth, and (d) passion about mathematics and about conveying that passion to their students. The second research finding pertained to the influence that their own students had on all of the five participants. All the participants purposely sought out their students' thoughts about the classroom curriculum and about the instruction they received. The teachers considered their students part of the classroom learning community, and they honored and acted on their input.

Finally, in addition to describing the trajectory of five PAEMST winning teachers, this study offers recommendations for students studying to become high school mathematics teachers, teacher educators, and educational researchers. For these students, their teaching preparation courses need to be taught adhering to the four principles of learning: activity, reflection, collaboration and community. According to this research, the model of teacher preparation courses that emphasize the teaching of the above four principles using a traditional teacher-directed method does not prepare future mathematics teachers for the use of SBC teaching in their classrooms. Suggestions about further research are addressed. 


\section{Acknowledgements}

I like to thank my advisor, Dr. Ron Narode, who guided me toward a topic that was perfectly fitted to my prior teaching experiences and as he put it, "made for me to explore." His guidance through the dissertation process was informative and educationally challenging. I would like to thank my committee members, Dr. Jeanette Palmiter, Dr. Christine Chaille, and Dr. Samual Henry for professional advice and help. My doctoral cohort was extremely helpful, supplying both knowledge and encouragement. Of particular note, was the help of cohort members Kim Ilosvay, Karen Maxwell, Akiko Ota, Heather Bartos, and Marla Barber provided help in reading sections of my dissertation, and furnishing important insight on my writing. I want to also acknowledge Lucas Bernhardt for his invaluable, candid writing advice. Finally, I want to thank my first editor and wife, Carol. Her encouragement during the dissertation process maintained both my focus and sanity.

There's a whole other life waiting to be lived when...

One day we're brave enough

To talk with Conviction of the Heart.

-Kenny Loggins 
Table of Contents

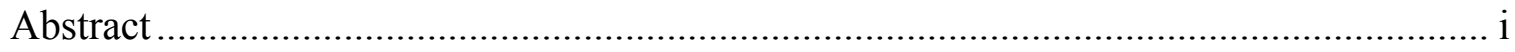

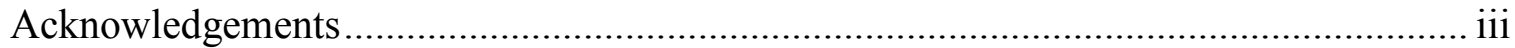

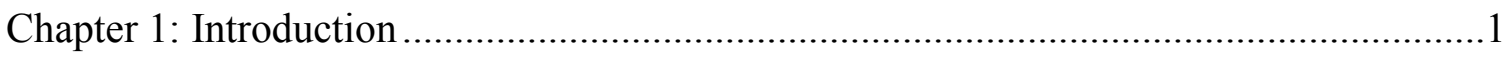

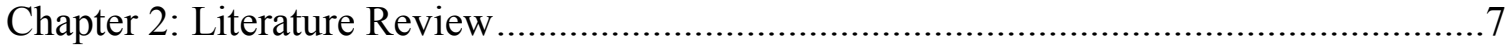

A Successful Mathematics Teacher ................................................................... 7

Successful SBC Mathematics Teacher. ...............................................................22

Constructivism: From a Learning Theory to a Pedagogy ..................................28

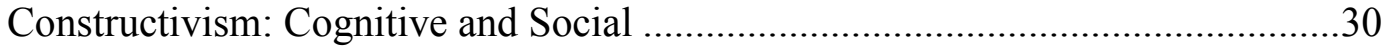

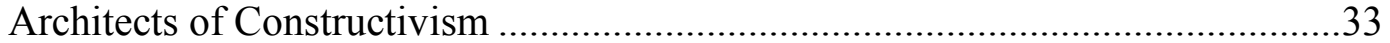

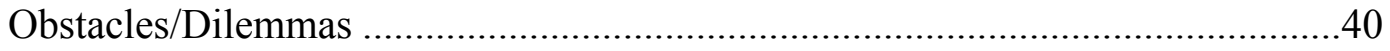

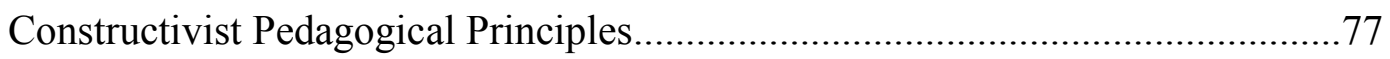

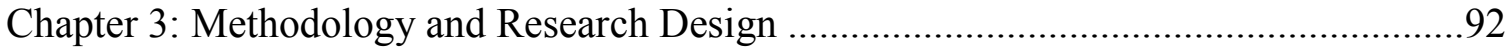

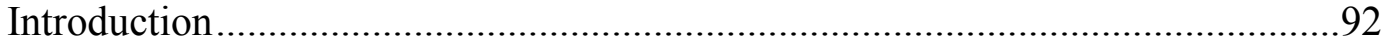

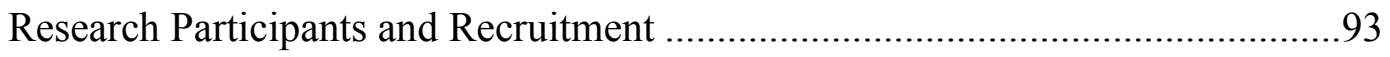

Research Design......................................................................................96

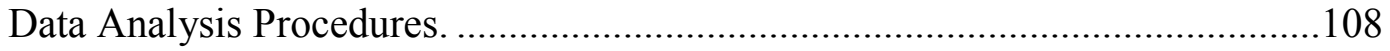

Ethical Issues: Confidentiality, Authenticity, and Reliability ...........................112

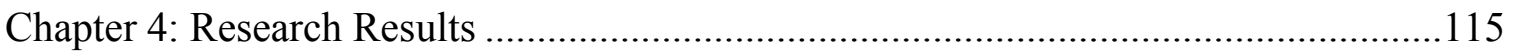

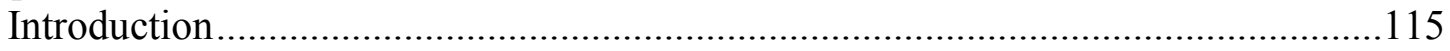

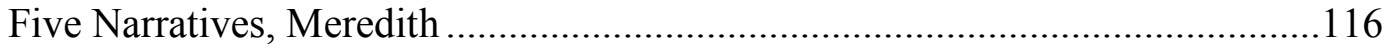

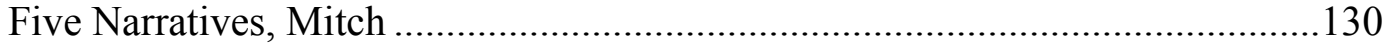

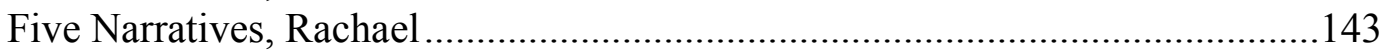

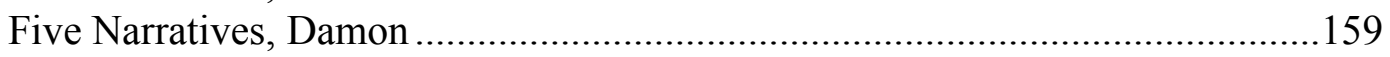

Five Narratives: Cole ............................................................................ 172

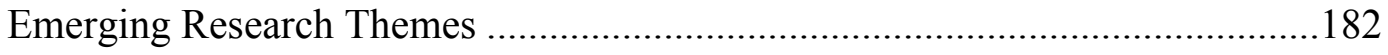

Conclusion: Addressing the Research Questions. ...........................................200

Chapter 5: Interpretations, Recommendations, Implications, Limitations, and

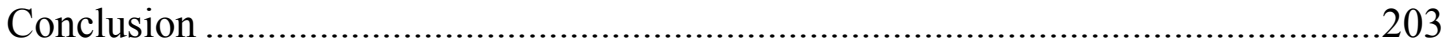

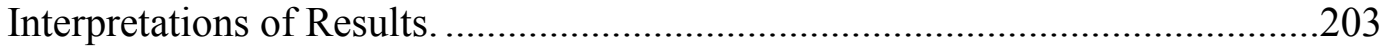

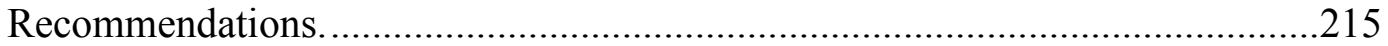

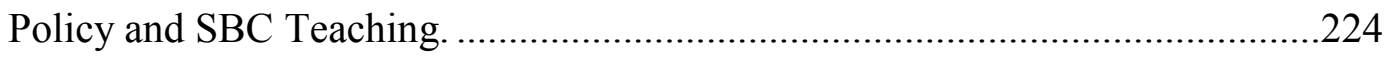

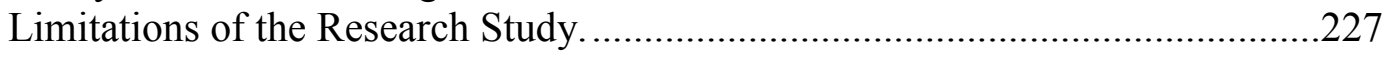

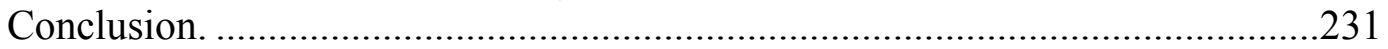

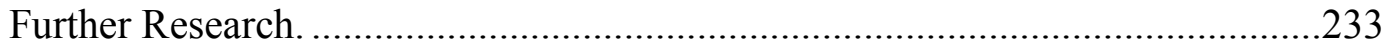


Appendices

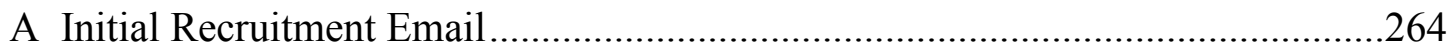

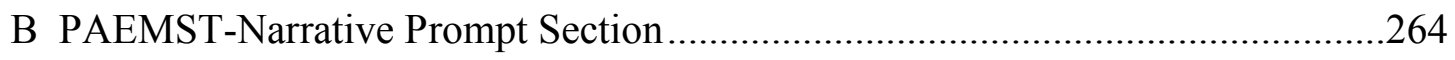

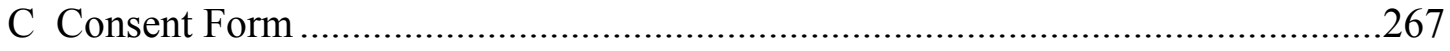

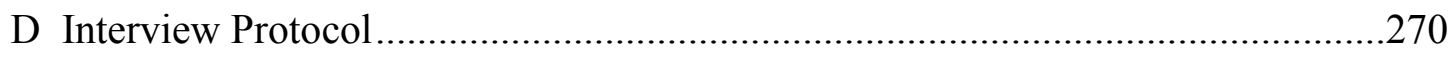

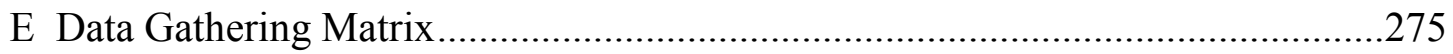




\section{CHAPTER 1}

\section{INTRODUCTION}

In 1989, the National Council of Teachers of Mathematics (NCTM) issued its publication, Curriculum and Evaluation: Standards for School Mathematics. The authors advocated a system of instruction referred as "standards-based teaching" which focused on the development of deep mathematical understanding and reasoning. They also supported lessening the instruction of mathematical procedures, while promoting mathematics curricula that is both mathematically rich and contextual (NCTM, 1989). Prior to this time, the majority of mathematics lessons in the United States' public and private schools involved extensive, teacher-directed explanation of new material followed by student seatwork on paper-and-pencil assignments with little or no discussion or exploration of concepts (National Center for Education Statistics, 2003; Stigler \& Hiebert, 2004). In an extensive ethnographic study to determine the reasons why this form of mathematical instruction has dominated in the United States, Gregg (1995) concluded that teacher competence in school mathematics instruction is viewed as providing students with skills and procedures, particular to a textbook, and assessing students' understanding via a written, objective test. The scores on these tests served as the measure of mathematical proficiency the students had achieved. Cobb, Wood, Yackel, and McNeal (1992) wrote that the above mathematical instruction and curriculum are viewed as the American school mathematics tradition (p. 597). The NCTM (1989) concept of school mathematics diverged from this predominant view of mathematics teaching. The main difference between the traditional and the standards- 
based, constructivism (SBC) educational positions may be understood as a disagreement over the concept of mathematical rigor.

The concept of mathematical rigor is conceived of differently by the traditional and SBC mathematics education communities (Gojak, 2013). For traditionalist mathematics educators, the swift and accurate demonstration of isolated mathematical skills and procedures on writing objective tests constitutes mathematical rigor in a classroom (Garelick, 2005; Klein, 2000, 2007). For these educators, the goal of mathematics teaching is the development of students' mastery of procedural knowledge-isolated mathematical facts and procedural skills (Gojak, 2013). For SBC mathematics educators, mathematical rigor is demonstrated through problem-solving that requires deep understanding of fewer but more powerful concepts that runs throughout mathematics, and the ability to communicate that understanding to others (Kilpatrick, Swafford, \& Findell, 2001; Schoenfeld, 1992, 1996). For example, the NCTM maintains the belief that representation, proportionality, function, and computation are the four potent concepts that run through all of mathematics (National Council of Teachers of Mathematics, 1989, 2000). For traditional mathematics teachers, teaching proportionality involves teaching the procedure for setting up and solving proportions. A score on a written, objective test that requires the solving of isolated proportion problems similar to the problems the students practiced represents the amount of mathematical rigor the students have obtained (P. Wilson, Cooney, \& Stinson, 2005). For SBC mathematics teachers, teaching proportionality involves mathematically rich tasks that allow the students to engage in and develop the concept that the comparison of two quantities in a 
ratio relationship characterizes a proportion. Furthermore, these mathematically rich tasks, foster the idea that proportional reasoning is used throughout mathematics to resolve problems. For these SBC teachers, assessment of mathematical rigor involves the students demonstrating and defending their thinking, not just computation (Fosnot, 1993).

Since the 1980s, a wealth of research has supported the claim that reformed mathematics instruction is successful in raising learning outcomes in a classroom setting (Ball, 1997; Ball \& McDiarmid, 1988; Matthews, 2000; National Research Council, 1989, 1990; Schoenfeld, 1992, 1996; Smith, 1996; Stigler, \& Hiebert, 2004).

Nonetheless, the controversy surrounding whether or not reformed mathematics instruction is truly rigorous has persisted, and the majority of the mathematical instruction in United States high schools is still based on the traditionalist paradigm of teaching (Cobb, Wood, Yackel, \& McNeal, 1992; Gregg, 1995; National Center of Education Statistics, 2003; Sirotnik, 1983; Stigler \& Hiebert, 2004). Kilpatrick (2009) estimated that only $10 \%$ of United States mathematics teachers are actively involved in SBC mathematics teaching, while a substantial majority, $90 \%$ of mathematics teachers, employs a traditionalist mathematics teaching paradigm in their classrooms.

The participants of this study are recognized, reform-minded mathematics teachers at the high school level who continue to develop and apply their concept of mathematical rigor in their classrooms despite the cultural and political obstacles created by the traditionalist mathematics educational community and the dramatic pedagogical changes required by the use of a reformist's teaching paradigm. The participants are past recipients of the Presidential Award for Excellence in Mathematics and Science Teaching 
(PAEMST) and members of the Council of Presidential Awardees in Mathematics (CPAM), and they were chosen for this study because they have demonstrated a commitment to SBC teaching. In a national study, Weiss and Raphael (1996) noted that 97\% of the 930 PAEMST mathematics and science teachers were aware of and used teaching strategies consistent with the recommended national standards from the NCTM and the National Science Teacher Association. Besides the 930 PAEMST recipients, the study also involved 2,605 non-PAEMST teachers, and inquired into the participants’ backgrounds, preparation, classroom practices, and professional activities. The fact that the number of United States' mathematics teachers using a traditional teaching paradigm $(90 \%)$ and the number of PAEMST recipients using an SBC teaching paradigm $(97 \%)$ is so askew implies that PAEMST, CPAM participants may have lacked support from their peers, and perhaps faced outright opposition, on their path to success. This dissertation identifies what their experiences were and what pedagogical, social, political, conceptual challenges they encountered in using an SBC teaching paradigm in their mathematics classroom, as well as how they overcame those challenges.

The purpose of this research study is to describe and analyze the self-reported experiences of exemplary high school mathematics teachers who have developed and used an SBC teaching paradigm in their classrooms. These teachers, as noted above, are past recipients of the PAEMST and members of the CPAM who were chosen for this study because they have demonstrated a commitment to SBC teaching. This research study looks at these teachers' self-described personal and professional transformations 
related to cultivating a teaching paradigm. In doing so, this study addresses the following research questions:

1. What are the paths SBC secondary mathematics teachers who received the PAEMST pursued to become highly effective?

2. What obstacles and challenges did they encounter and how were these obstacles overcome?

3. What sustained them on their journeys?

Like the study's participants, I am a past recipient of the PAEMST and a member of the CPAM. I applied for the PAEMST because the criteria for the award were precisely the decisive factors I had incorporated into my mathematics instruction.

I have drawn motivation for this study from my mathematics teaching experience as a PAEMST recipient in a high school where 14 out of 15 mathematics teachers used a traditionalist teaching paradigm. The interactions in my classroom with my students were excellent, and I felt that I was making a difference in my students' lives. However, the politics and traditional mathematics culture in my department were unsupportive of me as a teacher. I left the teaching profession to pursue my doctoral degree in hopes of finding and studying the experiences of individuals similar to myself.

Another contributing factor in my conducting this research study was the fact that during my last 15 years of teaching, I mentored reformist-minded mathematics student teachers. These teachers performed very well in my class, and when they graduated with their mathematics teaching degree, I believed they would go into the teaching field and begin to instruct using an SBC teaching paradigm. When many (8 out 10) of these student teachers secured a high school teaching position and were confronted with a traditional mathematics education community, they converted into teachers who used a traditionalist 
teaching pedagogy. I had thought that these student teachers were dedicated to an SBC paradigm of teaching, and their transition to using a traditionalist mathematics instruction disappointed me. However, these experiences motivated me to pursue the study of teachers who persist and excel in their SBC mathematical teaching practice.

Prior to the examination of the research questions, this paper surveys the research literature on what it means to be a successful mathematics high school teacher. The paper addresses the criteria for both a successful traditionalist and successful SBC mathematics teacher. 


\section{CHAPTER 2}

\section{LITERATURE REVIEW}

\section{A Successful Mathematics Teacher}

For decades, at every level of education the issue of what constitutes a successful mathematics teacher has permeated the literature (McEwan-Adkins, 2001). The topic of effective teaching is highly important because of the positive link between effective teaching and student learning (Sanders \& Rivers, 1996). Prior to the 1960s, successful mathematics teaching was defined as the effective dissemination of mathematical procedures and skills using a combination of lecturing and problem demonstration (Cobb, Wood, Yackel, \& McNeal, 1992; Gregg, 1995; Sirotnik, 1983). Hiebert et al. (2005) contended that United States mathematics teachers employ the above system of teaching because of a constellation of pressures to emphasize attention to lower-level mathematics skills.

Mathematician and educator P 1 ya (1962) challenged this accepted definition of successful mathematics teaching; he proposed that effective mathematics teaching involves teaching students to think. P 1 ya believed that the role of the teacher was not to impart information, but to develop students' abilities to use this received information. $\mathrm{He}$ emphasized that a successful mathematics teacher should follow the Ten Commandments of Teaching:

(a) be interested in your subject, (b) know your subject, (c) try to read the faces of your students, and see their expectations and difficulties by putting yourself in their place, (d) 
realize that the best way to learn anything is to discover it by yourself, (e) give your students not only information, but also know-how, mental attitudes, and the habit of habitual work, (f) let the students learn guessing; (g) let the students learn proving, (h) look out for such features of the problem at hand as may be useful in solving the problems to come - try to disclose the general pattern that lies behind the present concrete situation, (i) do not give away your whole secret at once-let the students guess before you tell it—let them find out by themselves as much as feasible; (j) suggest - do not force information down their throats (P 1 ya, 1962, p. 116). Schoenfeld (1987) asserted that P 1 ya's writings shifted the conversation in the mathematics education community about teaching. After P 1 ya, successful mathematics teaching increasingly involved putting the emphasis on problem-based inquiry instead of “instruction [focused on] mastery of basic skills: the facts, rules, formulas, and computational procedures" (Baroody, 1993, p. 3).

Rosenshine and Furst (as cited in P. Wilson et al., 2005, p. 85) reviewed educational process-product studies on teacher effectiveness and formulated 11 variables associated with successful teaching: (a) clarity, (b) variability, (c) enthusiasm, (d) taskoriented or business-like behaviors, (e) the opportunity to learn, (f) the use of student ideas and general indirectness, (g) the use of structuring comments, (h) types of questions, (i) probing, (j) criticism, and (k) the level of difficulty of instruction. Further, other mathematics education researchers and educators were attracted to clarity and variability characteristics because "if teaching could be judged clear and flexible then 
student learning could be improved" (p. 86). In other words, these characteristics were considered part of successful teaching because they promoted student learning.

Traina (1999), a noted historian, attempted to identify characteristics that distinguish successful teachers by examining the autobiographies of 125 prominent American men and women from the $19^{\text {th }}$ and $20^{\text {th }}$ centuries representing various social, economic, geographic, religious, and racial backgrounds. Traina examined each person's autobiography, specifically noting their thoughts on their educational experiences and what they had to say about the teachers they valued. He was looking for consistent patterns in descriptions of teaching in the autobiographies. He found three distinguishing characteristics in each person narrative that described valued teachers: "(a) a competence in the subject matter; (b) deeply caring about their students; and (c) a distinctive character" (p. 34). The following section of this paper will examine research on what it means to be a successful mathematics teacher using Traina's three distinguishing characteristics as guiding categories.

It should be noted that in researching the concept of a successful mathematics teacher terms such as good, organized, efficient, outstanding, superior, skillful, and effects have been used in place of the word "successful" (McEwan-Adkins, 2001). In the review of the literature informing Traina's three characteristics, analogous words to 'successful' will be used interchangeably to accommodate the ways various educators and researchers describe characteristics that make teachers highly effective.

\section{Competence in the Subject Matter}


In describing the characteristics of successful teachers, Traina (1999) emphasized knowledge of the subject matter and the ability to convey this knowledge to students. According to Triana, each autobiographer he studied, viewed the combination of these two characteristics as representing competence in the subject matter, which encouraged their engagement in the class.

Research has supported the idea that pedagogical content knowledge is a vital subset of content knowledge for teachers (Richardson, 2003). In a pivotal study of the knowledge teachers need in order to be effective in the classroom, Shulman (1987) asserted that a teacher must be well-informed in content knowledge and the specific pedagogy associated with a particular content. In the case of mathematics, Ball, Thames, and Phelps (2008) supported Shulman's findings, stating that for mathematics teachers to be effective, it is paramount that they cultivate a mastery of content knowledge and subject-specific, pedagogical knowledge. For example, besides having mastery knowledge of fractional skills and concepts and the different ways they are used in mathematics (i.e., ratios, part-to-whole, etc.), an effective mathematics teacher needs to be aware of teaching strategies and models that allow students to experience and understand the different uses of fractions.

\section{Deeply Caring About Their Students}

Highly successful teachers demonstrate the qualities of respect, caring, empathy, and fairness in their communications with students, which indicates their deep caring for their students (McEwan-Adkins, 2001). Dole (2003) maintained the teacher/student relationship is students' stronger adult bond other than their relationship with their 
parents, and that in order to make this relationship positive teachers must convey respect, caring, and fairness. The NCTM (2000) has maintained that one of the foremost methods of establishing such relationships is advancing the concept of equity in the mathematics classroom. To accomplish this, teachers need to have high expectations for their students (Brophy, 1982; Delpit, 1995, 2006; Jamar \& Pitts, 2005). Another significant component of creating equity in mathematics is the belief that all students are capable of constructing a noteworthy understanding of mathematics (NCTM, 1989, 2000). Bandura (1996) stated that helping students cultivate the belief that they are adept and successful at learning encourages student autonomy and self-regulated learning in a classroom. Furthermore, by emphasizing equity in the classroom, effective teachers model democratic characteristics such as empowering students to participate in problem-solving and conflict resolution (Bartell \& Meyer, 2008). They also provide opportunities for students to determine the course of their own learning and take purposeful actions to meet their goals (Wehmeyer, 2001). Bosworth (1995) observed more than 300 middle school classrooms and interviewed more than 100 middle school students from two different middle schools. Based on these observations and interviews, she identified two attributes that indicated to students that teachers care about them and their learning: helpfulness and friendliness. These teacher attributes, according to students, created a classroom atmosphere that was conducive to learning.

\section{A Distinctive Character}

In describing a vague but important characteristic of the successful teacher, Traina (1999) wrote that there seemed to be something of the "distinctive character" of a teacher 
that brought them success with their students. In a sense, it reflects the teacher's individuality and personality that is conveyed to students over time. He referred to this as the most "elusive" (p. 34) of the three characteristics he focused on in his research. However, the characteristic enhances the other two successful teacher attributes, and frequently makes the teacher memorable to his or her students. McEwan-Adkins (2001) referred to characteristics such as excitement, passion, energy, humor, appeal, innovation, and uniqueness as "style," and asserts these characteristics are frequently associated with highly effective teachers. Banner and Cannon (1997) stated that the distinctive characteristics exhibited by successful teachers are not the products of training or education, but are "ingredients of our own humanity" (p. 2). Research suggests that highly effective teachers, when instructing, demonstrate personality characteristics that suggest confidence in their content knowledge. They tend to convey that knowledge with energy and enthusiasm (Hamann, Baker, McAllister, \& Bauer, 2000; Madsen, 2003). Fairhurst and Fairhurst (1995) observed other distinctive characteristics of effective teachers, including imagination and the ability to change, which allows teachers to develop novel and stimulating classrooms. Martin (1997) found that effective teachers tend to be highly sensitive to the individual needs of their students and are concerned about both the students' and their own personal growth. Finally, research has shown that highly effective teachers embrace their own unique characteristics, and their students tend to react in a positive manner; they develop the ability to express themselves as authentic learners in the classroom (Fairhurst \& Fairhurst, 1995). 
McEwan-Adkins (2001) claimed that successful teachers, besides demonstrating deep pedagogical and content knowledge, need to cultivate personal characteristics that produce results, such as: (a) with-it-ness, (b) motivational expertise, (c) instructional effectiveness; and (d) curiosity and awareness. McEwan-Adkins asserted that these four characteristics are part of effective teachers' personalities and that they are "central and absolutely essential to students' learning" (p. 47).

With-it-ness. The term with-it-ness, coined by Kouin (1969), refers to the state of being aware of and using three critical components of the classroom: (a) classroom management and organization (b) engagement of students, and (c) effective use of time.

Classroom management and organization. McEwan-Adkins (2001) claimed that for successful teachers, the management and organizing of a classroom's environment, time, and discipline involves establishing a set of behaviors and activities that promote effective and efficient instruction. Glasgow and Hicks (2009) concurred with this assertion and advocated such teaching practices as: (a) making and posting a daily agenda, (b) utilizing workable strategies for preventing and managing classroom discipline problems, and (c) saving voice by engaging students in curricular conversations. Making and posting a daily agenda, according to Ausubel (2000), allows students to view how the teacher has organized the daily lesson, which provides an opportunity to develop a meaningful sense of the lesson. Zuckerman (2007), in her research on 68 secondary science teachers' effective strategies for preventing and managing classroom discipline problems, discovered that successful teachers employ variations of the following strategies: (a) changing the pace of the class or the activity in 
a lesson, (b) using the least distracting intervention by utilizing a sequence of nonverbal to verbal strategies, and (c) conferencing and conferring privately with a chronically disruptive student. Finally, one of the most valuable tools teachers can use for classroom management is controlling their voice. According to Siebert (1999), on the average, a teacher talks 6.3 hours a day, and most of that is to focus a class or to give out directions. Siebert recommended that when it comes to teachers using their voice "less is more." Using a quiet voice in the classroom also sets the tone in the classroom for respecting conversations and debates.

Engagement of students. In their study of high school mathematics teachers, P. Wilson et al. (2005) interviewed nine teachers, asking what the notion of good mathematics teaching meant to them. Eight of the nine teachers asserted that to be successful a teacher needed to develop and manage an environment where students are engaged. For these teachers, engagement involved student actions such as "writing, taking notes, manipulating materials, doing experiments, asking questions, listening, using technology such as computers and calculators, interacting in groups with fellow students, and demonstrating as well as explaining thinking" (P.Wilson et al., 2005, pp. 95-96). P 1 ya (1962) emphasized the concept of encouraging student engagement through having students work on mathematical problems they find "interesting and worthwhile" (as cited in Schoenfeld, 1987, p. 286). The NCTM (2000) has maintained that worthwhile mathematical tasks will both introduce important mathematical ideas to students and engage and challenge them intellectually. Well-chosen tasks can pique students' curiosity and draw them into mathematics, Furthermore, effective mathematics 
teachers frequently use these tasks to challenge students to extend their thinking and learning (NCTM, 1989, 1991, 2000; P. Wilson et al., 2005). Mathematically rich tasks allow teachers to draw upon students' prior knowledge/experiences and suppositions, which may be used to expand the mathematics curriculum (Brooks \& Brooks, 1999). This teacher-devised curriculum creates further student engagement because mathematics becomes more relevant and contextual to the students (Boaler, 1998). According to Heller and M. Gordon (1992), effective mathematics teachers increase student engagement in the classroom by using strategies that promote "students talking about their own ideas, listening to other students' ideas, and evaluating and substantiating opinions with sources, logical argument, and evidence" (p. 10) in order to build a community of learners. Brooks and Brooks (1999) stated that students' learning is enhanced when teachers take student concerns and observations into account in designing their mathematics curriculum.

Effective use of time. Research has shed light on the attributes of teachers that promote effective use of time. P. Wilson et al.'s (2005) research of nine high school mathematics teachers developing and using an SBC mathematics curriculum revealed that all the participants felt that preparation and flexibility were the keys to effective time management in their classroom. Preparation allowed the teachers to establish a classroom environment that encouraged students' engagement and motivation. However, the teachers believed that flexibility in both their pedagogical content and content knowledge allowed them to be attentive to their students' understanding of the mathematics. Wasley, Hampel, and Clark (1997), in a 3-year study of high school students, found that a 
correlation exists between students' interest and investment in their work at school and their teachers' repertoire of strategies for engaging them. In a study of effective schools, Teddlie, Kirby, and Stringfield (1989) found further notable classroom characteristics of teachers who were effective in their use of classroom time were classes: (a) start on time, (b) involves student-centered instruction, and (c) stress high academic expectations.

Motivational expertise. Successful mathematics teachers have developed highly effective teaching strategies that motivate students (Glasgow \& Hicks, 2009). Middleton and Spanias (1999) contended that one of the foremost goals in mathematics teaching is developing in students' intrinsic motivation that will enable them to "engage in academic tasks because they enjoy them" (p. 66). They further asserted that students who have demonstrated intrinsic motivation exhibit positive learning characteristics like creative methods of problem-solving and effective learning strategies, and show a willingness to select difficult academic tasks and persist in solving them without the inducement of external motivation. Research has identified teaching strategies that promote student development of intrinsic motivation (Middleton \& Spanias, 1999; Seegers \& Boekaerts, 1993). One such method is linking mathematics to students' lives outside of school, which makes mathematics, both contextual and relevant (NCTM, 1989, 1991; National Research Council, 1989). Effective mathematics teachers also adopt instructional strategies that are participation-based rather than transmission-based (Matteson, Swarthout, \& Zientek, 2011). According to the NCTM (1989, 2000), students who are actively engaged in mathematically rich tasks increase their mathematical understanding more than students who are given mathematics via lecture and demonstration. Research 
has shown that non-white students' intrinsic motivation toward mathematics is increased when the mathematics concentrates on the students' social lives and cultures (Matteson et al., 2011). Finally, students' motivation improves when their mathematics teachers communicate both high expectations and a belief that all their students are capable of learning mathematics (Boaler, 1998; McEwan-Adkins, 2001; NCTM, 1989, 2000).

Instructional effectiveness. The NCTM (2000) asserted that effective mathematics teaching requires a significant commitment to the development of student understanding of mathematics. Often, teachers who make that commitment, experience a need to change their traditional, teacher-driven approach to teaching mathematics to a problem-based inquiry approach (J. A. Thomas \& Monroe, 2006; D. Y. White, 2003; Wood, Cobb, \& Yackel, 1991). Romberg (1992) stated that effective teaching advances the notion that mathematics is not a static, bounded collection of facts and procedures to be absorbed, but is a dynamic process that includes "gathering, discovering and creating knowledge in the course of any activity having a purpose" (p. 61). In a self-study of his transformation from using traditional teacher- and textbook-driven methods of teaching mathematics to using a reformist, problem-based inquiry paradigm, J. A. Thomas and Monroe (2006) described the changes in Thomas's thoughts on instructional effectiveness. Prior to the study, Thomas noted that there was little student discourse about mathematics in his classroom. Students sat quietly at their desks, working on problems from their mathematics textbooks and Thomas's interactions with the students were limited to praising them and working one-on-one with individual students who were struggling with the assigned problems. Seeking ways to make mathematics more 
meaningful and interesting, Thomas began to use mathematically rich tasks to engage his students. However, he realized that to maintain students' engagement in the tasks, he needed to increase both his ability to conduct classroom discourse and to ask questions that promote student thinking and learning.

Conducting class discourse. The NCTM (1991), in their publication, Professional Standards for Teaching Mathematics, stressed that to affect student learning, it is essential for effective teachers to encourage students to participate in mathematical discourse in the classroom (Cobb, Boufi, McClain, \& Whitenack, 1997; Kazemi \& Stipek, 2001; Nathan \& Knuth, 2003; Walshaw \& Anthony, 2008). The authors went on to state that teachers need to focus on "orchestrating the oral and written discourse in ways that contribute to students' understanding of mathematics" (NCTM, 1991, p. 35). Organizing whole class discussions that promote student thinking is a challenge for all mathematics teachers (Ball, 1993: Lampert, 1990). Stein, Engle, Smith, and Hughes (2008) addressed this issue in their research, and they documented five practices that make teachers' work more purposeful, and that enable them to cultivate a richer mathematical environment and discourse in the classroom: (a) anticipating student responses to mathematically rich tasks, (b) monitoring students' responses to the tasks during the exploration phase, (c) purposely selecting student work to share in whole group discussions, (d) purposely scaffolding the students' work to be discussed, and (e) helping the class make mathematical connections between different students' work to develop powerful mathematical ideas. Furthermore, they contended that effective classroom discourse must be accountable to the discipline of mathematics without 
undermining the students' contributions to the discussion. Teachers must strive to employ students' ideas as "launching points" (Stein et al., 2008, p. 328) to shape the classroom discourse so that, over time, mathematical ideas surface, contradictions are exposed, and students' understanding is developed and strengthened. Stein et al. noted that successful mathematics teachers use classroom discourse to meld students' understanding of mathematics with the processes that mathematicians use in doing mathematics. Anderson (2007) stated that successful teachers realize "learning mathematics involves the development of each student's identity as a member of the mathematics classroom community" (p. 7), and effective classroom discourse fosters this.

The use of effective questioning to increase students' learning. J. A. Thomas and Monroe (2006) asserted that the "art" by asking "good" questions was paramount in conducting group and entire classroom discourse, which in turn increased students' mathematical understanding. Stein et al. (2008) concurred with this observation arguing that once a worthwhile mathematical task is introduced and the students become initially engaged with it, effective teachers need to guide their endeavor by focusing the students' efforts toward finishing the tasks. Good questioning that allows students to verbally expand and defend their mathematical work accomplishes this undertaking. Research has examined different questioning strategies that have increased student understanding and engagement (Stein et al., 2008). For example, teachers can ask students to compare their different strategies for resolving a mathematical task and note the differences and similarities (Hodge \& Cobb, 2003). Following class discussion that involves students' ideas, a teacher could prompt students to reexamine their own thinking and evaluate and 
revise that thinking (Brendehur \& Frykholm, 2000; Engle \& Conant, 2002). These questioning methods enable students to connect their mathematical thinking with that of their peers, which helps make classroom and small group discussions more coherent (Stein et al., 2008).

Curiosity and awareness. McEwan-Adkins (2001) asserted that highly effective teachers possess intellectual characteristics that demonstrate their knowledge, curiosity, and awareness about their subject. She referred to these characteristics as "book learning, street smarts, and a mental life" (p. 104). In the next section, the research concerning these three characteristics will be examined.

Knowledge: Book learning. As noted earlier, possessing content knowledge of mathematics is paramount to being a successful mathematics teacher (NCTM, 1991). In Everyone Counts, a study for the National Research Council (1989), the authors stated, "Effective teachers are those who can stimulate students to learn mathematics, and there is compelling evidence that students learn mathematics well only when they construct their own mathematical understanding” (p. 59). According to Smith (1996), teaching for the development of students' deep understanding puts intensive demands on teachers' content knowledge. Successful teachers are those who continually increase their knowledge in the areas of content and pedagogical knowledge (Ball 1990a, 1990b, Leitzel, 1991).

Curiosity: Street smarts. McEwan-Adkins (2001) defined the concept of "Curiosity: street smarts" as knowledge of students, the school, and the community in which the teacher is teaching. Effective teachers use this knowledge to create a positive 
instructional setting in their classroom (Delpit, 1995, 2006). Getting to know their students' motivations, culture, and prior experiences allows successful teachers to use that knowledge in creating relevant and engaging curriculum (Delpit, 2006; Dewey, 1916; Stigler \& Hiebert, 2004). The NCTM (2000) asserted that educational equity is important for the education of all students, but that "equity does not mean that every student should receive the same instruction" (p. 11). Instead, effective mathematics teachers develop and incorporate appropriate opportunities and accommodations for each student based on his or her prior experiences. Nasir, Hand, and Taylor (2008) argued that all knowledge is cultural, which is to say associated with the cultural and social worlds we inhabit. Knowledge is not neutral in terms of power, as some types of knowledge are aligned with communities with power, and other types of knowledge are aligned with people without power (Delpit, 1995, Freire, 1974, 1982). For Nasir et al. (2008), culture shows up in a mathematics classroom on three analytical planes: "(a) the way that language mediates knowledge, (b) features of math classrooms as contexts that support or constrain different forms of knowledge, and (c) the way that radicalized identities and expectations play out in mathematics class" (p. 197). Successful high school mathematics teachers construct their instruction in such a way that it is thoroughly contextualized and relevant to the real world (NCTM, 2000). To promote instruction that addresses the different cultures in their mathematics classrooms, effective teachers give their students opportunities to define the subject matter in a way that is meaningful to them. In doing so, teachers are given authority to the students to develop and evaluate mathematical methods. This teaching strategy supports students' understanding and holds students 
responsible for each other's mathematical thinking and questioning (Boaler, 1998; Boaler \& Greeno, 2000; Chazan \& Ball, 1999). Nasir et al. (2008), in researching literature on mathematics teaching and students' cultural knowledge, concluded that mathematics holds a privileged position in our society as a worthy activity for its smartest citizens. For that reason, effective teachers need to dispel the attitude that mathematics is out of reach of the "common" man and is removed from and inaccessible to an individual's everyday experience.

\section{Successful SBC Mathematics Teacher}

As noted earlier, the successful SBC mathematics teachers emphasize a teaching pedagogy based on the belief that all students are capable of developing a deep understanding of mathematics (NCTM, 1989, 2000; Prawat, 1992). These teachers embrace teaching as a process that encourages analysis, reflective thinking, collaboration, and problem-solving, and they realize they must cultivate teaching strategies that advance the acquisition of such skills in their classrooms (P. Wilson et al., 2005; Windschitl, 1999; Wood, 2002). Many SBC teachers acknowledge that their students enter their classrooms with valuable skills, knowledge, and experiences that can be expanded upon. This belief of SBC mathematics teachers departs from the traditional mathematics teachers' beliefs about the learning; teachers have turned to the psychology of constructivism when constructing their teaching pedagogy (Brooks \& Brooks, 1999; Fennema \& Nelson, 1997; Hiebert, 1997; Walshaw \& Anthony, 2008; Wood, 2002). Researchers maintain that mathematics teachers who employ SBC teaching pedagogy 
demonstrate characteristics associated with successful teaching (Fennema \& Nelson, 1997; Prawat, 1992; Windschitl, 1999, 2002).

\section{SBC Teachers: Competence in Subject Matter}

From his research, Triana (1999) concluded that successful teachers demonstrate a convincing grasp of both content and pedagogical knowledge. Ball, Lubienski, and Mewborn (2001) contended that a highly effective SBC teacher needs to have an excellent grasp of mathematics in order to understand students' explanations, suppositions, and demonstrations of their knowledge of mathematics. Furthermore, highly effective SBC mathematics teachers cultivate pedagogical skills that are different from those used in traditional mathematics classrooms, creating and maintaining a classroom environment that is student-centered, engaging, cooperative, and focused on problem-solving (Schifter, 2005; Smith, 1996; J. A. Thomas \& Monroe, 2006). In such an environment, teachers encourage students to "demonstrate and explain ideas, interpret texts, predict phenomena, and construct arguments based on evidence" (Windschitl, 1999, p. 144). The goal of cultivating such an environment is the development of students' deep mathematical understanding and their ability to demonstrate and use this acquired understanding (NCTM, 1989, 2000; Prawat, 1992, Stigler \& Hiebert, 2004).

The establishment of SBC mathematics classrooms requires teachers to expand their management and organization of a classroom (Windschitl, 1999; Zuckerman, 2007). In classrooms where students are constructing their understanding, SBC teachers nurture valuable instructional skills related to conducting classroom discussions (Stein et al., 2008) and questioning (Fosnot, 1996; Spillane \& Zeuli, 1999). According to Engle and 
Conant (2002), these instructional skills, foster productive student engagement and collaboration in the classroom, which promotes the emergence of a community of learners. In such an environment, students become passionately engaged; they use the information in scholarly ways, develop arguments defending their thinking, and generate questions regarding the assigned tasks/projects (Sherin, Mendez, \& Louis, 2004). The classroom transforms into an effective learning atmosphere where students make sense of mathematics (Elmore, Peterson, \& McCarthey, 1996).

As noted earlier, highly effective teachers have been found to work on enlarging the intrinsic motivation of students. Standards-based mathematics teachers who use SBC pedagogy create student motivation by: (a) using students' prior knowledge and experiences to create mathematical understanding and, (b) using of students' suppositions to develop relevant curriculum (Ball, 1997; Brooks \& Brooks, 1999). Successful SBC mathematics teachers encourage and guide students to use their prior experiences and knowledge when working on mathematical tasks/projects (NCTM, 2000; National Research Council, 1990). Schifter (2005) and Schoenfeld (1992) contended that using students' prior knowledge and experiences encourages mathematical sense making, which, in turn, develops students' self-confidence in solving mathematical problems. Dewey (1916) maintained that successful teachers routinely utilize the common experiences of their students' lives as starting points for drawing the students into more sophisticated forms of knowledge that are particular to a given subject (i.e., mathematics). When students note that their mathematical efforts are being used to define 
the curriculum of the classroom, they develop a sense of control over their own education, which increases their motivation (Brooks \& Brooks, 1999; Prawat, 1992).

\section{SBC Teacher: Deeply Caring for the Students}

Traina (1999) noted that the one characteristic of a successful teacher that appeared in all the autobiographies he researched was the deep caring these teachers exhibited toward students. Bosworth (1995) found in her research of middle school students that students defined caring as "doing something for someone when they cannot do it themselves" (p. 687). She concluded that having a helpful attitude was a major characteristic of successful teachers. As noted earlier, the NCTM (2000) and National Research Council (2001) asserted that SBC mathematics teachers convey caring for their students by acting on their belief that all students are capable of developing mathematical understanding. They accomplish this by designing a classroom environment that "helps students to search rather than fellow" (Brooks \& Brooks, 1999, p. 102). These teachers encourage and accept each student's autonomy and initiative, and, in doing so, address equity in the classroom (NCTM, 1989, 2000). SBC mathematics teachers strive to create a community of learners in their classroom where students and teachers help each other (Sherin et al., 2004). Noddings (2001) contended that successful SBC mathematics teachers establish a caring relationship with their students by listening intently to their students' ideas and receiving their experiences and thoughts with empathy. In doing so, these teachers help their students to realize and expand their mathematics capabilities. Furthermore, for SBC teachers caring indicates an effort on the teachers' part to create 
and participate in social interactions that are responsive to the needs of their students (Hackenberg, 2010).

Banner and Cannon (1997) argued that teaching is a characteristic of vision and spirit requiring fullness of heart and complete engagement. They observed that effective teachers acknowledge that teaching is a complicated endeavor, but have the "conviction that teaching — helping students see the world more openly, fully, and deeply—is among life's noblest and most responsible activities" (p. ix). Noddings (2001) contended that to develop caring relationships with their students, highly effective teachers attend to being educators first and teachers of particular subjects second (i.e., mathematics).

\section{SBC Teacher: Distinctive Character}

Triana (1999) noted that teachers' "distinctive character" (p. 34) facilitates a caring relationship with their students. In research on to note successful teachers of at-risk students, Peterson, Bennet, and Sherman (1991) found that these teachers exhibited several common, distinctive characteristics: (a) created a classroom where their students belong, (b) showed interest in the identities of individual students, (c) were sensitive to students' problems and needs, and (d) conveyed their high expectations to the students. SBC mathematics teachers demonstrate similar personality characteristics. As noted earlier, SBC teachers strive to create an engaging classroom environment where students become part of a community of learners (Heller \& M. Gordon, 1992). In developing such an environment, SBC mathematics teachers continually seek individual students' points of view by using mathematically rich tasks and questioning techniques (Brooks \& Brooks, 1999). A distinctive characteristic of SBC mathematics teachers is 
their ability to use students' mathematical suppositions to adjust classroom curriculum (M. M. Gordon, 2008; Stigler \& Hiebert, 2004). Goos (2004) referred to a mathematics classroom environment where discussion and collaboration are the norm, where students are expected to demonstrate and defend their mathematical ideas, and where conjectures are valued as "communities of mathematical inquiry" (p. 259). Van Oers (2001) contended that in such classrooms, students are conscious of the fact that their teachers are responsive to their needs and efforts, and they are appreciative of teachers' promotion of a mathematical environment that allows them to create their own conceptual understanding. In their research, Lee, Cawthon, and Dawson (2013) found that efficacious, SBC teachers demonstrated high expectations for their students and were successful in promoting ways to meet those expectations. They went on to argue that these high expectations conveyed to students the teachers' caring for them and their education.

Research has shown that effective mathematics teachers need to realize that to affect their students' understanding of mathematics, ability to use mathematics to solve problems, and confidence in doing mathematics they must understand and be committed to their students as learners of mathematics (NCTM, 2000). According to Richardson (2003), the successful use of constructivist pedagogy accomplishes this, and demonstrates the characteristics of successful teaching. In other words, the effective SBC teacher of mathematics is successful teaching.

In the remainder of the Literature Review, research on the use of constructivism in mathematics classrooms will be presented. The rest of the chapter is divided into the 
following topics: (a) the adaptation of constructivism from a learning theory to a teaching pedagogy, (b) cognitive and social constructivism, (c) the architects (developers) of constructivism as it is used in standards-based mathematics classrooms; (d) the obstacles reformists encounter in developing and using constructivism in their classrooms, and (e) the principles of constructivism used in mathematics classrooms.

The literature on both the attributes of highly effective mathematics teachers, and the development and use of constructivism in mathematics classroom will provide a knowledge base for conducting research on the study's research questions: (a) What are the SBC high school mathematics teachers pursued to become highly effective mathematics teachers?, (b) What obstacles and challenges did they encounter and how were these obstacles overcome?, and (c) What sustained them on their journeys?

\section{Constructivism: From a Learning Theory to a Pedagogy}

For the SBC mathematics educators, the concept of mathematical rigor contributes to the creation of a classroom environment where students construct their own mathematical understanding (NCTM, 1989, 2000). This concept of students' construction of mathematical meaning has led SBC mathematical educators to look at the psychology of constructivism as the basis for developing an SBC teaching pedagogy (Phillips, 1995; Simon, 1995; P. Wilson et al., 2005; Windschitl, 1999). Even though standards-based mathematics educators commonly employ the theory of constructivism in constructing a classroom learning environment, it is important for this paper to address the issue that originally the theory of constructivism, unlike behaviorism, was not an educational pedagogy, but rather a theory of learning that, after being translated into teaching 
strategies, eventually formed constructivist pedagogy (Applefield, Huber, \& Moallem, 2000; Confrey, 1990). This pedagogy reflects the SBC mathematics educators' conviction that all students are able to construct a deep understanding of mathematics (Ball, 1996; Brooks \& Brooks, 1999).

Initially, constructivism was a cognitive learning theory rather than a teaching pedagogy (Davis \& Sumara, 2002; Windschitl, 2002). As such, the application of constructivism in the mathematics classroom has been at times problematic because there are no prescribed theoretical teaching methods (Davis \& Sumara, 2002). However, over the last three decades, mathematics educators have developed a pedagogy based on the constructivist learning theories, where the goal of mathematic teachers' pedagogical approaches and strategies is the construction of deep mathematical understanding in or between students (Brooks \& Brooks, 1999; Schoenfeld, 1992). Consequently, the constructivist pedagogy is less a model than a description of instructional strategies, techniques, and methods that facilitate students' deep understanding of mathematical concepts and procedures (Windschitl, 2002).

Since the 1980s, cognitive researchers and mathematics educators have developed effective pedagogies based on constructivism (Stigler \& Hiebert, 2004). For example, Harvard University’s Active Learning Practice for Schools developed a program, Teaching for Understanding that purposely placed students in unfamiliar situations and had them resolve each situation. One of the program's chief tenets is informed by the ideas drawn from Piaget's experiments that involved placing articles in front of learners, seeing what they would do, and asking them about their thinking as they worked through 
the process of negotiating the challenges the article presented (Powell \& Kalina, 2009). Another program, Improving Student Achievement in Mathematics had its origins in William Brownell's work in the 1940s on the effects of valuing meaning and understanding in mathematics. Based on the practice of having students study mathematics taken from real life problems, the program emphasizes students' development of the contextual meaning of the mathematics they are studying. The program is structured around research that supports the idea that students who develop an early conceptual understanding later perform better than those who do not develop this understanding when demonstrating procedural knowledge (Grouws \& Cebulla, 2000). These two programs are illustrations of how constructivism has been adapted from a learning theory to a teaching pedagogy. In this context, constructivism is really a misnomer, because there are not one, but many theories of constructivism and each theory utilizes different concepts regarding how individuals develop an understanding of reality (Davis \& Sumara, 2002). In the present study, both cognitive and social constructivism will be discussed because of the heavy reliance of both types of constructivism by SBC mathematics educators in developing their constructivist pedagogy in their classrooms.

\section{Constructivism: Cognitive and Social}

Various groups of theorists conceptualize constructivist learning differences, and the conceptualizations differ primarily in whether they emphasize the individual cognitive process or the social construction of knowledge (Phillips, 1995).

Constructivism that describes individual cognitive processes holds to a system of 
explanations of how individual learners create the intellectual structure of their worlds, while constructivism that emphasizes the social construction of knowledge, maintain that constructed knowledge has both an individual and a social component (Windschitl, 2002). B. G. Wilson (1996) described the key difference between the two constructivist conceptualizations:

Whereas social constructivists see learning as increasing one's ability to participate with others in meaningful activity, cognitive constructivists focus on how individuals create more sophisticated mental representations and problemsolving abilities by using tools, information resources, and input from other individuals. (p. 6)

Both ways of conceptualizing constructivism have the same general interest in how individuals learn and construct knowledge, but differ markedly with respect to the mechanisms that accomplish this (Phillips, 1995). In spite of the differing conceptions of constructivism, reform mathematics teachers, with the help of educational and cognitive researchers, have continued to develop practical, successful classroom applications for both cognitive and social constructivist learning theories over the last three decades (Fosnot, 1993; M. Gordon, 2009b). These mathematics teachers faced the profound challenge of acquiring new skills for applying constructivism as the basis of instruction, and reorienting the culture of their classrooms consistent with constructivism (Brooks \& Brooks, 1999; Windschitl, 2002). However, compelling educational research has shown, "Students learn mathematics well only when they construct their own mathematical understanding” (National Research Council, 1990, p. 58). Mathematics teachers who overcome obstacles to the use of constructivism and endeavor to implement it in their 
classrooms can be seen as positively affecting the development of mathematical understanding in their students (Ball, 1996; Brooks \& Brooks, 1999).

The proliferation of both valid and dubious research on constructivism has caused confusion in the field of education (Davis \& Sumara, 2002). The many versions of constructivism, which overlap in important ways, but nonetheless exhibit major differences, have caused significant misunderstandings among educators (Phillips, 1995). The range of noted authors writing about constructivism spans a broad philosophical and theoretical spectrum. In his article, The Good, the Bad, and the Ugly: The Many Faces of Constructivism, Phillips (1995) listed constructivist theorists/writers as various as Ernst von Glasersfeld, Immanuel Kant, Thomas Kuhn, Jean Piaget, John Dewey, Lev Vygotsky, and Jerome Bruner. He contended that these individuals represent a small list drawn from of a much larger, but nonetheless non-exhaustive list, all of which suggests the range, complexity, and symbolic force of constructivist ideas. Phillips pointed out that the many theories of constructivism have common elements, but also have significant differences, such as whether the individual's concept of reality is constructed either cognitively or socially. M. M. Gordon (2009a) noted the wealth of research on the application of constructivism in education, and maintained that the way of understanding and assessing knowledge in the classroom dramatically shifts based on whether researchers use the theories of Piaget, Vygotsky, or Freire. Fogarty (1999) concurred with M. M. Gordon's assessment and added John Dewey to the list. She wrote:

Just as a traditional architect might borrow the fundamental elements and signature styling from a master architect, such as Frank Lloyd Wright, educators borrow from master craft people. They borrow from master cognitive psychologists and neurobiologists who have helped shape structures for the 
intellect; they are strongly influenced by the foundational works of the proponents of a constructivist theory of learning. (p. 76)

The following section presents a brief synthesis of each influential architect's theory of constructivism and the contribution of each theory to mathematics education.

\section{Architects of Constructivism}

\section{Architects of Constructivism: John Dewey, Experience and Social Action}

Dewey's contribution to the constructivist mathematics classroom originated in his belief that learners' knowledge about their environment develops through acting upon the world and through the world acting upon them. Kivinen and Ristela (2003), describing Dewey's idea, wrote, "We do things and have things done to us; we act and we react, and we can learn from all kinds of experience" (p. 365). Dewey (1916) expressed the same idea concisely in his now famous quote: "Learning is doing" (p. 192). At the University of Chicago, where he served as the head of Department of Philosophy, Dewey established The Laboratory School. The school was designed to integrate learning with experience, including the use of long-term projects based on students' experiences and prior knowledge as the foundation of the school's curriculum. While the students worked on the projects, Dewey and fellow teachers circulated around the classrooms and interacted with the students. From these interactions, Dewey and the fellow teachers drew out topics of interest from the students, and, once identified, the teachers incorporated these topics into the curriculum with the help of the students (Hytten, 2000; Tanner, 1997). During this entire process, teachers took on the role of facilitator, encouraging, questioning, and helping the students. This model promotes the idea that students are in control and that they can work toward becoming independent learners (Glassman, 2001). 
In summary, the process of learning, for Dewey, was at least as important as what was learned, and in classrooms designed around Dewey's educational philosophy, the teachers are, in today's vernacular, the guide on the side, and the curriculum of the classroom becomes a collaboration between the students and the teacher (M. Gordon, 2009a; Hytten, 2000).

Dewey is considered one of the chief forerunners of social constructivism; the students' experiences, as well as prior learning, and knowing, are an "affair of doing" (Fogarty, 1999, p. 76) in which the learners are continuously active in developing their own learning with the help of the teacher. Prawat (1995), commenting on Dewey's approach to education, contended that Dewey had developed "a pragmatic instrumental approach involving a 'triangular relationship' among the individual, the community, and the world mediated by socially constructed ideas" (p. 14). Indicators of Dewey's contributions to the philosophy of constructivism in today's constructivist mathematics classroom are the prevalence of collaborative learning groups, student-generated projects based on students' experiences and prior knowledge, and teachers' use of contextual mathematical materials.

\section{Architects of Constructivism: Jean Piaget, Discovery Learning}

The paradigm labeled discovery learning was actually initially coined by Bruner (1961). However, the process of discovery learning, which has become a current constructivist paradigm of mathematics and science education, has been associated with Piaget's cognitive theory of constructivism (Zimmerman, 1982). The process involves learners actively constructing their own knowledge based on their view of their current 
reality, prior experiences, and current knowledge (Noddings, 1990). Piaget (1970) considered himself a genetic epistemologist; he studied how humans come to know what they know over time. In his theory of constructivism, Piaget maintained that learners do not internalize knowledge from the outside in, but construct knowledge from the inside out by interacting with their environment (Piaget, 1965, 1970; Piaget \& Wells, 1973). In spite of his lifelong epistemological research, Piaget steadfastly refused to consider himself an educationist. However, he drew on his research in genetic psychology and epistemology to develop suggestions for education, which educators and educational researchers have used to develop constructivist teaching strategies (Piaget, 1970). In mathematics classrooms, Piaget's influence appears in such student-centered activities as the exploration of mathematical tasks with multiple entry points, reflective journal writing, and communication among students and with the teacher about their thinking, observations, and possible problem solutions.

\section{Architects of Constructivism: Lev Vygotsky, Culture and Language}

Vygotsky's (Vygotsky \& Cole, 1978) theory of social constructivism has had a noticeable effect on current constructivist teaching practices. The use of scaffolding and cooperative learning groups in mathematical classrooms is a direct offshoot of his social constructivist theories (Dangel, Guyton, \& McIntyre, 2004; Fogarty, 1999; M. Gordon, 2009a). When using social constructivist pedagogy in a classroom, the teacher is creating educational experiences that highlight problematic aspects of the students' experiences and prior knowledge, and then guiding students in the construction of appropriate knowledge and skills that will enable them to cope more meaningfully with both their 
prior experiences and knowledge (Gregory, 2002). This is commensurate with Vygotsky's assertion that an adult provides the guidance for this construction using the students' cultural tools of language and experiences. Vygotsky's concept of the Zone of Proximal Development (ZPD) has had the profound impact of steering many teachers away from their traditional role as purveyors of mathematical truths (M. Gordon, 2009b). Vygotsky (Vygotsky \& Cole, 1978) defined this concept as "the distance between the actual developmental level as determined by independent problem-solving and the level of potential development as determined through problem-solving under adult guidance or in collaboration with more capable peers" (p. 86). Kincheloe (1991), in writing about Vygotsky and ZPD, stated,

Since mental activity, he has maintained, takes place in a social and cultural context, thought will operate differently in diverse historical situations. Cognition thus is shaped by the interactions among social actors; the contexts in which they act and the form their activities assume. (p. 9)

Vygotsky's ZPD has had the noteworthy effect on current constructivist mathematics teaching practices of inspiring constructivist mathematics teachers to take on the role of the facilitator who guides students' observations, conversations, and problem-solving with the goal of discovering socially constructed truths.

\section{Architects of Constructivism: Paulo Freire, Values, Knowledge, and Transformation}

Paulo Freire (1974) maintained that it was crucial that we promote education for all to transform society and allow all students to succeed. For this to transpire in the classroom, he advocated for using students' societal and cultural experiences as the basis of instruction in the classroom. Freire (1974) insisted that knowledge is not static, that 
there is no dichotomy between objectivity and subjectivity or between reflection and action, and that knowledge is not neutral. Furthermore, knowledge is continually created and re-created as people reflect and act on the world, and, in doing so, transform them. Knowledge does not exist apart from human consciousness; it is produced by collectively searching for meaning and trying to make sense of the world. Knowledge, therefore, is not fixed permanently in the abstract properties attributed to objects, but is a process in which acquiring existing knowledge and producing new knowledge exist in the same cycle of knowledge acquisition and knowledge creation (Freire, 1982). He asserted that individuals must be considered in terms of the world they live in, and that their thinking is shaped by the cultures and communities they live in. As such, people's knowledge, consciousness, and experiences are inescapably social (Freire \& Macedo, 1987). Individuals think/reflect by themselves, but they alter their thinking when they share it with others.

A teaching pedagogy embracing Freire's learning theories needs to incorporate collaborative problem-solving based on students' culture, experiences, and prior knowledge. Freire (1982) argued that his pedagogy challenged the notion that teachers deposit ideas into passive students, which he referred as the "banking" method of education. He felt it was imperative that students have both time for reflection and time to share their thinking with other students and the teachers, as both the teacher and students benefit from reflective thinking and collaboration. They develop joint responsibility in the process of learning and growing in the classroom. The traditional roles of teacher and 
student are reversed in Freire's pedagogy; the students become the teacher and the teacher becomes the student (Freire, 1982).

Gottesman (2010) claimed that although John Dewey is the most recognized scholar in the field of education, Paulo Freire should share a similarly prominent position. Both theorists believed that student reflection and action in relation to the world outside the classroom is essential to learning and transforming the world. As such, a constructivist mathematics classroom based on Freire's reflection and dialogue between the teacher and students would include a mathematics curriculum would be based on the ideas developed by the teacher and students collaborating together. According to Freire (1982), a shared mathematics curriculum provides a connection between students' lives and mathematics. For example, students might examine a local police department's records of traffic violations in their local area during a particular month, and while doing so, compare 16 to 21 year olds' driving violations to driving violations of drivers' in different age groups. After making this comparison, the students might discuss the concept of automobile insurance, and, for example, what is a 'fair' insurance policy and cost based on the local area statistics? Using such activities, students would have a chance to engage in mathematics that provides a way to voice, interpret, and act upon their concerns. Freire (1982) wrote,

Our task is not to teach students to think - they can already think; but, to exchange our ways of thinking with each other and look together for better ways of thinking with each other and look together for better ways of approaching the decodification of an object. (p. 323)

The phrase "decodification of an object" means students are able to construct meaning and understanding of the studied "object" (Freire, 1982). In the case of mathematics 
constructivist mathematics classroom, mathematics would be demystified and becomes a useful tool for empowering students to take charge of their lives and influence society (Shor, 1987).

\section{Architects of Constructivism: Pedagogy and Pragmatism}

The previous sections presented brief summaries of Dewey, Piaget, Vygotsky and Freire's contributions to constructivism, and examples of how mathematics educators have employed each "architect's" theories and created constructivist teaching strategies for the classroom. There are important differences between each theorist. For example, distinctions between Piaget's subject-centered constructivism, where individuals cognitively create their own understanding of reality, and the social constructivism of Vygotsky where individuals with the help of other individuals construct their understanding of reality using their culture and language, are noted earlier in this paper. Another example of distinction is Freire's theory of critical constructivism, which develops the consciousness or critical thinking skills of the students and Dewey's form of social constructivism (Gottesman, 2010). For Dewey (1916), learners need to work toward the common goals of the society, and students must learn to refer their own use of abilities and talents to that of others. In doing so, students develop the ideals of democratic society. Freire agrees that working toward democratic ideals in a classroom is important, but views this as insufficient, because doing so would create a society that is stable, and stability implies that there is oppression (Gottesman, 2010).

This distinction can be illustrated by the example of a mathematics classroom where curriculum is developed around "student-led projects." For Dewey, the student-led 
project is finished with the completion of all the teacher/student criteria for the project, but for Freire, the student-led project acts as a catalyst that creates more questions about topics that emerge during the project (Gottesman, 2010). Despite these differences between these architects of constructivism, "These four theorists share a conception of constructivism that is essentially pragmatic, one that is deeply concerned with changing current educational practice to foster active learning and genuine understanding" (M. Gordon, 2009b, pp. 55-56). Their development of operational constructivist theories speaks directly to pragmatic concerns of mathematics teachers by giving them directions on how to create constructivist teaching strategies and criteria for critiquing the effective use of these developed constructivist approaches.

However, even when equipped with pragmatic constructivist theories, mathematics teachers who attempt to institute a constructivist teaching and learning environment face many obstacles. The following section of this paper explores the literature and research that address these obstacles.

\section{Obstacles/Dilemmas}

\section{Introduction}

Mathematics teachers attempting to change their teaching by adopting a constructivism (SBC) philosophy confront obstacles ranging from resistance in the classroom in terms of students expressing their dislike for the teacher's instructional strategies to outside resistance from parents and administrators unfamiliar with the emphasis on the mathematical understanding rather than mathematical skill proficiency (Phillips, 1995; Simon, 1995). In using constructivism in their classrooms, teachers 
implement a unique set of teaching strategies that promote a student-centered classroom, a classroom where the student's prior knowledge and experiences become the daily "building blocks" of the teacher's lesson (Brooks \& Brooks, 1999). However, the use of constructivism entails far more than a set of teaching strategies, as it implies a different relationship between teacher, students, and the outside world than that of the traditionalist paradigm. This relationship comes with new expectations about the classroom environment and operation (Windschitl, 1999). SBC mathematics teachers must attend to the complex concerns and beliefs of the educational community, which are comprised of students, teachers, administrators, parents, and local educational supporters (NCTM, 2000). Additionally, the SBC mathematics teachers must contend with the above struggles with shareholders frequently in a traditionalist educational environment that discourages changes (Brooks \& Brooks, 1999). Kilpatrick (2009) estimated that only $10 \%$ of United State mathematics teachers are actively involved in curriculum reform and SBC teaching due to impediments caused by the traditional mathematics community's beliefs, misunderstandings, and concerns about changing mathematical curricula and instruction. Research has shown that beginning mathematics teacher who comes to their new job with training in implementing SBC pedagogy in their classrooms struggle in their attempts to apply the pedagogy in their classrooms. In a 3-year longitudinal study, Simmons et al. (1999) observed that $80 \%$ of 58 beginning high school mathematics teachers who began teaching using a constructivist, student-centered approach reverted to a traditional teaching pedagogy by their third year of teaching. Mathematics teachers attempting to create an SBC classroom environment are taking risks, and these teachers 
must have the courage to stand by their convictions if they intend to apply SBC approaches in their teaching (Fosnot, 1993; Windschitl, 2002).

In studying obstacles to SBC teaching in schools, which he referred to as “dilemmas,” Windschitl (2002) identified four general categories: (a) conceptual, (b) pedagogical, (c) cultural, and (d) political. Research on the use of SBC pedagogy in mathematics classrooms that fail to address the above four categories of obstacles frequently compromises mathematics teachers' attempts in implementing constructivism in their classrooms (Appleton \& Asoko, 1996; Ball, 1993; Cohen \& Ball, 1990, Marlowe \& Page, 2005).

Davis and Sumara (2002) noted that since the 1990s, the classroom use of constructivism has increased and since then the amount of research on the subject of constructivism in education has increased exponentially. In their research using the ERIC database, they noted that the frequent use of the words constructivism and constructivist increased exponentially over the preceding 30 years. The average annual number of articles about constructivist education written annually in the 1970s was in the single digits. In the $1980 \mathrm{~s}$, the number of articles written annually reached double digits. In the 1990s, the number increased to triple digits, and by the year 2000, the number of articles had passed 1,000 annually (p. 409). As noted earlier in this paper, SBC teaching practices have demonstrated significant success in promoting student learning (Fang \& Ashley, 2004; M. M. Gordon, 2008; Marlowe \& Page, 2005). Windschitl (2002) attributed the rise in the publication on constructivism to both the increase in the application of SBC ideas in the classroom and the use of reliable quantitative and qualitative research 
techniques for evaluating its effectiveness. Using this large base of research, the following section examines each of Windschitl's four categories of obstacles/dilemmas.

\section{Conceptual Obstacles}

There are many different forms of constructivism, and each of these forms share a concern with human beings creating an understanding of reality (Phillips, 1995). Davis and Sumara (2002) maintained that not all these constructivist theories apply to the domain of education. They argued that theories in one academic discipline do not easily transfer to another discipline. As noted previously, constructivist theories, unlike behaviorist theories, are not sources of practical advice for teachers. Most constructivist theories are more descriptive rather than prescriptive, leaving them open to misinterpretation, while behaviorist theories, "speak more directly to practical concerns of educators" (Davis \& Sumara, 2002, p. 417). Some mathematics teachers' misinterpretations of constructivism have steered them toward two kinds of conceptual obstacles: (a) applicability, the misunderstanding of the different theories of constructivism (Matthews, 2000), and (b) usage, the misapplication of constructivism (Cobb, Yackel, \& Wood, 1992).

Frequently teachers who attempt to use constructivism are not familiar with the epistemological and ontological components of constructivism (Ball, 1993, 1996). Both qualitative and quantitative research asserts that teachers may be skilled at creating and facilitating learning experiences for their students and assessing understanding, but still lack a clear understanding of why these experiences are so vital (M. Gordon, 2009a, Wrenn \& Wrenn, 2009). The degree to which teachers understand constructivism 
determines how skillfully it is used in their mathematics classroom (Windschitl, 2002). Without a deep understanding of constructivism, teachers frequently misuse constructivist teaching strategies (Hyslop-Margison \& Strobel, 2007). For example, teachers may prevent their students from exploring a mathematical task by telling them their expressed thinking is incorrect (Ball, 1996). Without opportunities to work through their thinking and apply their prior knowledge to a mathematical task, students are denied a chance to develop new understanding of the mathematics involved in the tasks (Lampert, 1990). By giving the "correct" solution to the students, the teachers have conveyed that they are the sole mathematical authority in the classroom (M. Gordon, 2009a). This misapplication of constructivism stemmed from the teacher's misunderstanding the basic tenet of constructivism that the individual constructs the meaning of their own reality, in this case, the meaning of the mathematics in the tasks (Beck, Czerniak, \& Lumpe, 2000; M. Gordon, 2009a). The extent of teachers' misunderstandings and misapplications determines the degree which the use of constructivism succeeds or fails in their classrooms (Beck et al., 2000; Windschitl, 2002).

For teachers accustomed to a teacher-directed, the behaviorist paradigm of teaching, it is particularly difficult to change to a constructivist, student-centered approach (Cobb, Wood, \& Yackel, 1990, Schifter, 2005). Smith (1996) observed that constructivist teaching challenges the fundamental traditionalist assumption that the teacher is the direct cause of student learning, and when traditionalist teachers attempt to use constructivism in their mathematics classrooms, they frequently design a lesson by sequencing classroom events in an order similar to that of a traditionalist lesson. 
Furthermore, Smith contended that traditionalist teachers frequently adhere to this agenda, even when activities call for a change in the direction of the teachers' instructions. For example, a classroom may begin with an experiment to determine a possible formula for the volume of a circular cone by comparing its volume to the volume of cylinder both having congruent circular bases. Students make paper models of both the cone and cylinder, and fill each model with rice. The students develop ideas about how to compare the volumes of rice held by each of the models. From their measurements, they derive formulas for both the cone and cylinder. Some of the students come up with incorrect formulas, but instead of having them defend their thinking, the teacher remedies the students' misconception by giving them the correct formulas. The traditionalist teacher is acting on the behaviorist teaching belief of reinforcing correct answers and discouraging incorrect answers, which assumes the likelihood that, given a similar mathematical problem, students will produce the correct answer (Beck et al., 2000; Doyle, 1988). By using this traditionalist teaching strategy, teachers are controlling the education of their students, and not providing opportunities for them to reflect on their solutions and create their own understanding of the problems (Beck et al., 2000, Smith, 1996).

Like the above example, misunderstandings of the meaning of constructivism are the product of teachers' familiarity with traditionalist mathematics teaching strategies both as teachers and as students (M. Gordon, 2009a; Smith, 1996; Windschitl, 1999). It is hard for mathematics teachers to ignore their former teachings and to change their beliefs and actions in the classroom, and when traditionalist teachers try using constructivism in 
their classroom, they often do so using traditionalist beliefs as a 'filter' to view their classroom actions (Smith, 1996).

When teachers who have fully adopted constructivist theories and curriculum work with their students, they move around their classrooms helping students to talk about their thinking (Brooks \& Brooks, 1999). When students describe their thinking, the teachers do not cut off the discussion by saying, "good job." Instead, constructivist teachers continue to 'press the learning' by directing students to think more deeply about or to reflect on the ramifications of their solutions (Brooks \& Brooks, 1999; Doyle, 1988). Teachers who are still using the traditionalist-teaching mode will tell their students when their answer is correct, and when it is incorrect, will go about correcting the students' thinking (Cobb, Wood, Yackel, \& McNeal, 2009; Gregg, 1995). These types of reactions stop student thinking, and indicate to the students that the teacher is the source of mathematical knowledge in the classroom (Beck et al., 2000; Smith, 1996). Though these teachers may feel that they are conducting a student-centered, constructivist classroom, they are reverting to a traditionalist, teacher-centered mathematics instruction by giving answers and denying their students opportunities to create their own understandings (Huberman, 1995). Tobin (1993) encountered such a situation in his case study of a high school mathematics teacher. The teacher claimed that he maintained a constructivist environment, but observations of the teacher conducting class indicated that he was actually continuing to use teacher-centered routines such as asking convergent questions and searching for students who could provide the correct answers to his questions. 
Yackel and Cobb (1996) discovered that teachers who misunderstood the interconnections of constructivist techniques used only particular parts of SBC teaching strategies, and that undermined its effective usage. Huberman (1995) called this process of using particular techniques, but not all of the methods of constructivism teaching, “tinkering." Noddings (1990) described such use of constructivism as leading to or remitting in,

Acts of [that] are more arbitrary, only loosely connecting new information with existing ideas; those constructions are fragile, transient, and applicable only within a narrow range of contexts, and they often sustain themselves only through brute force of memorization. (p. 12)

An example of tinkering, or weak constructivism, is when teachers set up mathematical tasks that offer only limited ways for the students to begin (Hyslop-Margison \& Strobel, 2007; Phillips, 1995). Teachers then go around the room, giving hints to students who are having trouble engaging in the tasks. With each additional hint, the teachers take more control from the students, and the students realize that if they continue to struggle the teachers will give them all the needed information to complete the tasks. Instead of guiding students by asking probing questions, referring to students' prior knowledge or experiences, or having students talk about why they cannot begin the tasks, the teacher eases the students' burdens by giving hints, and, in doing so, establishes the fact that the teacher is the mathematical authority in the classroom (Huberman, 1995). In a classroom where constructivist teaching is the norm, students engaging in mathematical tasks acquire knowledge that is meaningful by redefining their prior knowledge and experiences and accommodating it with the newly discovered knowledge (Schoenfeld, 1992; Stigler \& Hiebert, 2004). Constructivist theorists refer to this type constructivist 
learning as strong, because the learners connect new information with existing ideas to form meaningful knowledge (Hyslop-Margison \& Strobel, 2007; Windschitl, 2002).

Ball (1990b) observed an example of tinkering in a research case study involving an elementary teacher attempting to engage her students using methods consistent with the tenets of constructivism. The teacher professed that she was using constructivist teaching strategies, but under close examination was found to be using low-level strategies that emphasized memorization of skills and procedures. Instead of allowing her students to engage in mathematics through discovery, the teacher fell back to the traditional, behaviorist instructional paradigm with its instructional goal of the transmission of knowledge to students. Instead of seeing constructivism as cultural change that means examining their own beliefs and practices, many teachers view the use of constructivism as one pedagogical tool that may be appropriate for certain purposes in their instruction (Cobb, 1988).

In summary, many mathematics teachers profess to embrace constructivism in their teaching, but make the error of not understanding how constructivist fundamentals dictate wholly new teaching strategies (Applefield et al., 2000; Phillips, 1995). Creating a constructivist culture in a mathematics classroom is much more than adopting "a set of teaching techniques; it is a coherent pattern of expectations that underlie new relationships between students, teachers, and the world of ideas" (Windschitl, 1999, p. 752). For this transformation to be successful teachers must go beyond knowing about constructivism; they must learn to think as a constructivist (Noddings, 1990). For example, SBC mathematics teachers tend to view all students expressed thinking as an 
opportunity to help the students develop further understanding of mathematics. For these teachers, students' incorrect and correct answers to mathematical tasks are not the end of students' engagement in the tasks, but a chance to reflect on their thinking and engage further with mathematics. Teachers using constructivism in their mathematics classroom are not "taken aback" by incorrect answers; they become intrigued by students' thinking. These teachers want their students to explain and defend their answers, so they can see their thinking (Fosnot, 1993; Brooks \& Brooks, 1999). In a traditional mathematics classroom, correct answers to problems are both the end of the problem-solving process for students and an indicator of that student's limit of knowledge about the mathematics procedure or skill represented in the problems. In constructivist classrooms, incorrect and correct answers to mathematical tasks serve as starting points for teachers in developing insight into their students' mathematical understanding (Brooks \& Brooks, 1999; NCTM, 1991; Stein, Grover, \& Henningsen 1996). While in a traditionalist mathematics classroom the teachers' thinking is that an answer is the end of the learning process, but in a constructivist mathematics classroom the teachers' thinking is that the answer is the beginning of the learning process (Fosnot, 1993).

\section{Pedagogical Obstacles}

Constructivist mathematics teaching requires a major alteration in teachers' customary expectations of instruction, toward embracing a new and completely different set of instructional strategies. Constructivist teaching is "much more complex and unpredictable than traditional teacher-directed instruction” (M. Gordon, 2009b, p. 41). Instead of dispensing mathematical facts and procedures to students, the basis for 
instruction is the development of students' meaningful understanding of mathematical concepts and skills. Mathematics classrooms, once based on a traditional didactic relationship where teachers "tell" and the students "listen and replicate," becomes places where the teacher-student relationship is dynamic, complex, and unpredictable (Cohen, 1987; Pedersen \& Liu, 2003).

Recent research has chronicled the difficulty teachers' experience in making this conversion to constructivist classrooms (Cavanagh \& Prescott, 2010; Chiu \& Whitebread, 2011; Educational Resources Information Center, 1997; Gregg, 1995). The Salish I Research Project researchers observed new teachers in ten different educational programs across America during the first three years of their teaching. The researchers found, "Most [new teachers] reverted to much more teacher-directed instruction and textdominated content” (Educational Resources Information Center, 1997, p. 35). In another study of student teachers, Cavanagh and Prescott (2010) found that, despite two years of intensive individual reflection and group collaboration, three beginning high school mathematics teachers had a difficult time using constructivist pedagogy in their classrooms. Research looking at Taiwanese teachers implementing a new constructivist mathematics curriculum revealed that the teachers were dissatisfied with the curriculum because they did not understand how the new material emphasized concepts and led to skill building (Chiu \& Whitebread, 2011). Gregg (1995) conducted a case study of a secondary teacher who tried to implement constructivism in her classroom while the remainder of her mathematics department $(n=4)$ continued teaching using traditional teacher-directed pedagogy. Gregg found that tensions caused by her deviation from the 
school's mathematics tradition forced the teacher to convert back to the traditional mathematics teaching. These examples suggest that many teachers cannot overcome the obstacles they encounter when they attempt to adopt the use of constructivism in their classroom, and they frequently revert to the traditional mathematics instructional strategies (Windschitl, 1999).

Teachers' knowledge of subject matter is one of the most important influences on student learning in the classroom (Ball, 1993, 1996; Ball et al., 2001). While there is no definitive agreement about what critical knowledge teachers require, many educational researchers agree about three broad components of teacher knowledge put forth in Shulman's research (Ball et al., 2001; Lampert, 1990; McEwan-Adkins, 2001) Shulman (1987) identified three essential forms of knowledge teachers that is essential to be effective: (a) mathematical knowledge and its presentation to students; (b) knowledge of students' behaviors and thinking; and (c) knowledge of classroom practice. Research has shown that standards-based mathematics teachers using the constructivist teaching paradigm in their need to possess all three of these forms of knowledge; if teachers do not, research has shown that they revert to traditional mathematics instruction (Gregg, 1995; Hiebert, Gallimore, \& Stigler, 2002). Shulman (1987) also maintained that teachers must commit to continually increase their knowledge in the above three areas when seeking to change to a reformist, constructivist classroom. The following sections of this paper look further into pedagogical obstacles to using constructivism in the classroom through the lens of each of these three kinds of teacher knowledge. 
Mathematical knowledge and its presentation to students. The basis of a constructivist mathematics classroom is active inquiry and problem-solving that involves conceptually rich mathematical activities. Such activities demand that teachers have a well-developed mathematics to support instruction. Kilpatrick et al. (2001) defined mathematical knowledge as,

Knowledge of mathematical facts, concepts, procedures, and the relationships among them; knowledge of the ways that mathematical ideas can be represented; and knowledge of mathematics as a discipline - in particular, how mathematical knowledge is produced, the nature of discourse in mathematics, and the norms and standards of evidence that guide argument and proof. (p. 371)

Constructivist teachers' mathematical knowledge needs to be both deep and broad enough to help them appreciate and understand the variety of ways students express their thinking and solutions (Ball, 1993, 1996). Teachers' mathematical knowledge needs to be deep to be effective in inquiry-oriented classroom, more so than for their traditionalist teacher counterparts (Shulman, 1987). In a constructivist mathematics classroom, teachers must be able to understand concepts and accurately perform procedures. However, to do so, these teachers require a strong foundation of conceptual knowledge of mathematical concepts and procedures (Ball, 1993, 1996; Kilpatrick et al., 2001). This type of knowledge allows teachers to unpack students' written and oral thinking. Without such knowledge, teachers tend to control the classroom in a teacher-directed manner, instead of conducting student-teacher conversations that allow students a chance to develop their own understandings (Carlsen, 1992).

Research has indicated that United States mathematics teachers do not have a high degree of mathematical concept knowledge (Ball et al., 2001; Frykholm, 1999; Hill \& 
Ball, 2004). Mathematics teachers seeking to initiate SBC pedagogy in their classroom are often at a loss regarding knowing what and how to teach because they are unfamiliar with the content knowledge required to shift to a classroom that promotes problemsolving, explanations, and understanding (Ball, 1990a, 1996; Ball \& McDiarmid, 1988; Simon, 1993; Simon \& Schifter, 1991). Elmore et al. (1996) found that elementary teachers, who lacked content knowledge, were unable to match their teaching to reform teaching goals advocated by their schools. Student teachers' lack of a rich understanding of mathematics often prevents them from adopting the very SBC practices that they experienced as learners (Ball, 1990b). Those attempting to implement mathematics education reform have encountered difficulties caused by the lack of a teacher's content knowledge.

For mathematics teachers to be effective they need to be proficient in two forms of mathematical content knowledge: procedural knowledge and principal knowledge. Procedural knowledge consists of "knowing computational procedures and mainly involves following predetermined steps to compute correct steps" (Spillane \& Zeuli, 1999, p. 4). As noted earlier, procedural knowledge has dominated the United States K12 curricula. Sherin (2002) claimed that teachers view the implementation of reform mathematics curricula through the lens of their current practices and mathematical procedural knowledge, but these teachers lack principle knowledge — that is, knowledge that involves key ideas and concepts that can be used to construct procedures for solving mathematical problems (Lampert, 1986). Without thorough grounding in principle knowledge teachers frequently fail in their attempts to introduce mathematical reforms in 
their classrooms (Ball 1993, 1996; Windschitl, 2002). When new curricula contain mathematical principle knowledge that is difficult for a teacher, this curricula material is frequently altered or ignored. As a result, teachers do not implement their reform curricula as intended (Cohen, 1990; Putnam, 1992; Spillane \& Zeuli, 1999).

Knowledge of students' behaviors and thinking. Teachers' ability to uncover and adapt to students' prior knowledge, experiences, and points of view are both vital and necessary in constructivist education. According to Confrey (1990), constructivism is,

Essentially a theory about the limits of human knowledge, a belief that all knowledge is necessarily a product of our own cognitive acts . . . We construct our understanding through our experiences, and the character of our experience are influenced profoundly by our cognitive lens. (p. 108)

Mastery of the accurate interpretation of student knowledge is essential for effective SBC teaching (Brook \& Brook, 1999; Fosnot, 1993; M. Gordon, 2009b). As noted earlier, SBC mathematics educators in the 1990s sought to overcome limitations of traditional mathematics instruction by introducing standards-based reforms that emphasized student development of deep understanding of mathematical concepts and skills (McCaffrey et al., 2001). Their efforts shaped constructivist principles and its concept of an active learner. To promote students' active participation, SBC teachers must continually engage their students. Assessment of the students' opinions, ideas, and attitudes about the subject matter is critical for teachers, because it helps teachers make mathematics both contextual and meaningful (Confrey, 1990). This is not the case for the traditional mathematics teachers (Cobb, Yackel, \& Wood, 1992; Colvin, 1999).

Assessment of students' understanding of mathematical concepts in a traditional, teacher-directed mathematics classroom is primarily the responsibility of the teacher, 
requiring minimal input from students (Driscoll, Confrey, \& Martz, 1987). Research of United States' K-12 students revealed that many students in traditionalist classrooms had severe misconceptions across all mathematical topics and achievement levels, and the use of objective written assessments often failed to identify or alleviate these misconceptions for students. The research also showed that misconceptions in mathematics are persistent despite increased direct instruction (Benander \& Clement, 1985; Vinner, 1990).

The use of constructivist approaches in a mathematics classroom demands that teachers pay attention to students' prior mathematical knowledge and current thinking, their common conceptions and misconceptions, and the likely sources of those ideas (Brooks \& Brooks, 1999; Fosnot, 1993; Schifter, 2005; Windschitl, 1999, 2002). Communication, both written and oral forms, plays a crucial role in revealing and determining students' thinking. Communication is a very complex process, and in discussing this process as it applies to teaching, Confrey (1990) wrote,

When teaching concepts, as a form of communication, the teacher must form an adequate model of the students' ways of viewing an idea and the teacher then must assist the students in restructuring those views to be more adequate from the students' and from the teacher's perspective. (p. 110)

Research has shown that teachers' knowledge of their students' mathematical thinking affects how they teach and how their students achieve (Ball, 1997; Goos, 1995; Rees \& And, 1992). Knowledge of students includes both knowledge of particular, current students and knowledge of student learning in general. The ability to listen to students is a requisite skill for SBC mathematics teachers who seek to benefit all students in their classrooms (Kilpatrick et al., 2001). Authorizing the students to share their perspectives in class enhances the educational experiences for both the teacher and fellow students; 
both can see a student's perspective on a problem and learn from it. By listening to students, the mathematics becomes more accessible to students (Dahl, 1995). When students listen to, they feel they are taken seriously as knowledgeable participants in classroom conversations (Cook-Sather \& Shultz, 2001). Students feel empowered and they are motivated to participate in the classroom (Shultz \& Cook-Sather, 2001). McEwan-Adkins (2001) asserted that highly effective teachers are good detectives who are constantly searching for meaning in students' behaviors, communications, and responses. SBC teachers develop listening skills as part their observation skills, which allow them to construct knowledge about the students (Brooks \& Brooks, 1999). They then use the information to "structure learning tasks, raise expectations and gain the trust and respect of their students" (McEwan-Adkins, 2001, p. 112). Covey and Gulledge (1994) asserted that a high effective SBC teacher becomes a student of their students; they search for understanding prior to their endeavor to understand.

Instructional skills, such as questioning in order to probe students' thoughts, conjectures, and aids in establishing an SBC classroom culture (Brooks \& Brooks, 1999; Fosnot, 1993). For example, in an SBC mathematics classroom, students' observations can lead to meaningful, developmental curricular tangents. That is, student thinking frequently helps SBC teachers determine the direction of their instruction and which future mathematics should be addressed (Windschitl, 2002). Effective questioning serves a number of other purposes in an SBC classroom besides eliciting student thinking. Because effectively questioning by a teacher conveys to students that the teacher genuinely cares about their learning, students become more engaged in the mathematics 
(Walshaw \& Anthony, 2008). The authors of Professional Standards for Teaching Mathematics argued, "The teacher of mathematics should orchestrate discourse by... listening carefully to students ... [and] asking students to clarify and justify their ideas" (NCTM, 1991, p. 35). The process of promoting students' development of powerful and effective mathematical constructions is a daunting task. It requires that teachers develop an image/model of their students' thinking and understanding, and a plan for how to further develop that constructed knowledge or how to continue to "press the learning" (Confrey, 1990). This ability to judge student constructions is difficult to develop and use in a mathematics classroom; the prior mathematical experiences of both mathematics teachers and their students often hinder the development of this vital, constructivist teaching strategy (Smith, 1996). Writing about mathematics teachers attempting to use constructivism in their classrooms, Russell (1993) argued that both the teachers and students can obstruct the process of ascertaining students' thinking, because both teachers and students have personal histories shaped by continuous exposure to traditional teacher-centered instruction that is based upon the acquisition of procedural knowledge through drill-and-practice rather than the acquisition of mathematical understanding.

The dominance of traditional mathematics curriculum in United States schools has had the effect of not only limiting teachers' abilities to discern students' knowledge, but has obstructed the use of SBC instruction. Teachers faced with covering the lengthy traditional curriculum often sacrifice the time it takes to develop their students' understanding of principle knowledge in favor of covering procedural knowledge, which entails using direct instruction instead of using an SBC teaching pedagogy. Smith (1996) 
described teachers' difficult position regarding this issue: "Despite wide acceptance of the reform among mathematics educators and policymakers, teachers can feel pressure from many sources to compromise the reform principles and return to telling" (p. 396). The following section will explore the research on the instructional knowledge mathematics teachers must master in order to implement constructivist practices in their classrooms.

Knowledge of classroom practice. In attempting to use inquiry-based, studentcentered instruction guided by the tenets of constructivism, many mathematics teachers have experienced difficulties caused by both a lack of knowledge of and barriers to adopting of effective SBC classroom practices (Ball, 1993; Leinhardt, \& Steele, 2005; Schoenfeld, 1999; Sherin, 2002). Kilpatrick et al. (2001) provided a description of what understanding constructivist classroom practices entails:

Knowing classroom practices means knowing what is to be taught and how to plan, conduct, and assess effective lessons on that mathematical content. It includes knowledge of the resources at one's disposal for helping students reach those goals. It also includes skills in organizing one's class to create a community of learners and in managing classroom discourse and learning activities so that everyone is engaged in substantive mathematical work. (p. 379)

In order to successfully introduce constructivism in their classrooms, mathematics teachers must undergo a major transformation in their thinking about teaching and learning, as well as learn how constructivism's tenets translate into classroom teaching strategies. Gregg (1995) observed that in attempting to apply constructivist teaching methods, mathematics teachers experience many tensions transitioning from a traditional teacher-directed classroom, with its emphasis on memorizing rules and formal procedures and theories. In addition to going through major philosophical, epistemological, and 
ontological changes, teachers attempting to successfully to use SBC teaching strategies in their classroom often discovered that they must increase their knowledge of classroom instructional and assessment practices. Cohen (1987) asserted that teachers who elect to use constructivist pedagogy in their classroom must work harder than their traditionalist peers, and focus on constructivist teaching strategies that are radically different from the traditional pedagogy of lecturing, assigning homework, and giving written objective tests.

Constructivism frequently looks "attractive" to teachers because of its use of discovery learning methods, but deep-rooted problems arise when teachers attempt to use it in their mathematics classrooms (Cobb et al., 1990). The significant gap between the traditional mathematical and the SBC paradigms have required mathematics teachers attempting to utilize constructivism to construct their own knowledge and develop a classroom environment that "break (s) radically from the traditional model in which the teachers themselves are schooled" (Windschitl, 2002, p. 138). Their lack of knowledge about constructivist teaching strategies has forced many teachers to continuously seek improvement in their teaching. Using student thinking to help determine both the future design the classroom mathematics curriculum and the environment of the classroom is an example of a constructivist teaching strategy that requires of the teacher continuous improvement (Ball, 1996; Marlowe, \& Page, 2005; Windschitl, 2002).

Using student thinking that leads to key instructional decisions is the first of several major challenges teachers encounter in creating constructivist mathematical lessons (Lampert, 1990; Spillane \& Zeuli, 1999). Research indicates that SBC mathematics teachers who possessed a deep understanding of their students' knowledge 
and experiences were able to design, mathematical rich tasks that have many entry points that allow all students to engage in problem-solving (Brooks \& Brooks, 1999). These mathematics teachers then supported student learning by making observations of, and engaging in, discourse with individual students, groups of students, or staff and administration. Frequently, traditional mathematics teachers seek out a single correct answer to each one of their questions, but SBC mathematics teachers formed an elaborate set of strategies that support their students' frequent diverse problem solutions (Windschitl, 2002). Guiding these instructional conversations is challenging, not to mention time and energy consuming; the emphasis of these conversations is not to elicit a correct answer, but to probe and challenge students' thinking (Lampert, 1990; NCTM, 1989, 1991, 2000; Schifter \& Fosnot, 1993; Simon, 1986).

Many mathematics teachers have never witnessed constructivist conversations and, therefore, develop their own skills as they participate in instructional conversations (Cobb et al., 1990; Cohen, 1990). During these conversations, SBC teachers are assessing their students' knowledge. These conversations may involve larger groups, small groups, or individual students, and have the potential to serve as invaluable assessment methods that are as rich, complex, and interpretive as the learning activities themselves. However, as valuable as it is, developing and maintaining the aptitude for this form of conversation is difficult for most teachers. In a study of 25 elementary mathematics teachers conducting one-on-one or small group instruction conversations, Spillane and Zeuli (1999) found that the teachers frequently undermined the conversation by leading the students toward a correct answer. Carlsen (1992), in his research on high school science 
teachers, observed that the majority of the teachers' classroom conversations discouraged student participation. Classroom discussions dominated by teachers reinforce the notion that the teachers are the authority in the classroom and their answers are the correct ones (Smith, 1996).

In addition to fostering student learning, conversations in a constructivist classroom frequently generate assessment possibilities such as student journal writing, clinical interviews, individual and group presentations, observations, physical models, and research reports (Black \& Wiliam, 1998). Frequently referred to as authentic assessments, SBC mathematics teachers frequently replaced the traditional objective paper-and-pencil, single-answer tests with these assessments because they give a better picture how the answer was generated by students (Ball, 1996; NCTM, 1995; Windschitl, 2002). The development of authentic assessments commonly requires a commitment by SBC mathematics teachers to constant professional growth. However, according to Smith (1996), for the vast majority of United States mathematics teachers, their beliefs about mathematics allow them to dismiss this form of assessment. Many mathematics teachers in training react similarly to authentic assessments. Frykholm (1999) reported that many student teachers dismiss the use of authentic assessments when confronted by the traditional mathematics school culture.

Another important component of building knowledge of constructivist classroom practice is securing sources of feedback that allow teachers a chance to learn and become more effective (Lewis \& Tsuchida, 1999; Lewis, Perry, Friedkin, \& Roth, 2012). Lack of feedback on their classroom practices is an obstacle many SBC teachers face, and the 
process of continuing constructivist education in their classrooms becomes more cumbersome as a result (National Research Council, 2001). For example, to obtain feedback on their constructivist practices, mathematics teachers often turn to fellow teachers, becoming members of such groups as Lesson Study and Critical Friends Protocol (Desimone, Smith, Baker, \& Ueno, 2005; Hiebert et al., 2002; Lewis \& Tsuchida, 1999; Lewis, Perry, \& Murata, 2006; Wachob, 2011). These groups “provide opportunities for teachers to discuss with one another how the ideas they encounter influence their practice and how their practice influences what they are learning" (Kilpatrick et al., 2001, p. 389). Such groups become integral to SBC mathematics teachers' professional growth. Attending conferences, workshops, and classes also help teachers learn new strategies that support their continued professional growth (Ball \& McDiarmid, 1988).

Keeping up with current research is a formidable task for constructivist mathematics teachers, who — once they have started down the path of constructivist teaching — often find themselves overwhelmed, and retreat to the use of traditional mathematics instructional strategies Windschitl, 2002). Even with the help of excellent collaboration groups and other resources for professional development, constructivist mathematics teachers frequently encounter a wider culture of the educational community that can be unsupportive and at times combative, which may force teachers to return to traditional mathematics pedagogy (Smith, 1996: Spillane \& Zeuli, 1999; Windschitl, 1999). 


\section{Cultural Obstacles}

Mathematics teachers who wish to implement constructivism in their classroom often encounter deep-rooted cultural obstacles. These mathematics teachers, according to Spillane and Zeuli (1999), work within an American education culture is generally resistant to reform, and especially resistant to constructivism. Researchers have documented that procedural knowledge, not principle knowledge, has dominated the United States' K-12 curriculum for generations (Spillane \& Zeuli, 1999). For the vast majority of Americans, the mathematics instruction they experienced was teacher-based and lecture-delivered, with problem demonstrations that emphasized only fact and procedure acquisition. As Barbeau (as cited in Spillane \& Zeuli, 1999) noted, "For most Americans, mathematics is an established body of rules and procedures and doing mathematics involves chiefly, if not exclusively, manipulating numbers" (p. 4). Researchers have found that these images of mathematics instruction and learning are ingrained in the American schooling culture. Oakes, Quartz, Ryan, \& Lipton (2000), studying middle schools undergoing mathematical curricular and pedagogical reform, found that most teachers, administrators, and parents expected a mathematics classroom to be quiet and orderly, with students seated and not talking. These same groups of individuals defined student engagement in a mathematics classroom as attentiveness without speaking, gesturing, collaborating, or moving about. In a study of more than 1,000 United States classrooms, Goodlad (1984) found that each class demonstrated a sameness consisting of the repetitive procedures of lecturing, questioning, monitoring, and testing. This prevalent American educational culture has exerted pressure on 
mathematics teachers to adopt the traditional view of their work and of student learning (Cobb et al., 1992; Manouchehri \& Goodman, 1998; Suurtamm \& Graves, 2007).

Operating in a traditional American educational culture, SBC mathematics teachers experience challenges from students, colleagues, administrators, and parents, who question their classroom practices because they do not resemble the more familiar practices of traditionalist teachers (Windschitl, 2002). Handal and Herrington (2003) found that most students and school administrators are not acquainted with constructivist teaching strategies. Students more familiar with traditional mathematics teaching strategies and their emphasis on procedural knowledge and their one-correct answer philosophy resisted the constructivist approaches because of their unfamiliar emphasis on will students justify both their mathematical thinking and problem solutions. The researchers also observed that administrators, unaccustomed and disapproving of to the classroom activities and their appearance of disorder, did not provide adequate support in the form of either professional training or resource materials.

In addition, SBC mathematics teachers frequently meet opposition from colleagues (Smith, 1996). Manouchehri and Goodman (1998) studied 66 middle school teachers (grades 6 to 8) using a reform, standards-based curriculum that emphasized student-centered pedagogy. They observed, "In schools where the teachers were surrounded by colleagues and peers who were skeptical about the standards-based curricula as well as about the practicality of the classroom practice materials, the teachers were less inclined to use the programs" (p. 34). Research suggests that the United States educational culture, with its framework of norms, expectations, and values, is both highly 
structured and unaccommodating to constructivist teaching and learning practice (M.

Gordon, 2009a). In other words, for teachers to create and sustain a constructivist culture in their mathematics classroom, they must confront an entrenched educational culture that is highly unsupportive of their efforts. To do so, mathematics teachers must have both courage and a strong belief system regarding how students learn mathematics (Windschitl, 2002). Foremost among the challenges they face are the antagonistic beliefs and practices of their colleagues.

Inconsistent use of reform mathematics and constructivism is a direct result of the beliefs and practices of the majority of teachers in the United States (Smith, 1996). Mathematics teachers' belief systems reflect their personal theories about the nature of knowledge, which, in turn, influence their decisions concerning curriculum and teaching approaches (Handal \& Herrington, 2003). While some teachers have embraced standardsbased reform and the use of constructivist teaching methods, others have only enacted marginal changes. One reason for this reluctance is that many teachers' view of constructivism is based on their traditional beliefs about mathematics, teaching, and learning (American Educational Research Association, 1990; Cohen \& Ball, 1990; Spillane \& Zeuli, 1999). For mathematics teachers to convert the culture in their classroom from a traditional teacher-directed classroom to a constructivist classroom, they often must overcome their own personal history as a learner. Many teachers may find it difficult to create patterns of beliefs and practices consistent with constructivism because they themselves are products of the traditional mathematics education. Mathematics teachers, drawing on their experiences in learning, are predisposed to 
teaching mathematics by telling, and when these teachers, state facts and demonstrate procedures to their students using clear and accurate telling, they experience a strong sense of teaching efficacy (Smith, 1996).

Educational research indicates that teachers' sense of efficacy is an important causal influence on their practice and their students' learning (Smith, 1996). Goertz, Floden, and O'Day (1996) defined teachers' sense of efficacy as "their belief in their ability to have a positive effect on student learning" (p. 142). Mathematics teachers who built their sense of efficacy on telling mathematics conduct classroom lectures on controllable mathematical content, often a lesson from a textbook. These lectures are well designed and orderly, offering students clear prescriptions for what they must do with the content to demonstrate their learning. Using the same lecture when faced with the same mathematical topics allows teachers to create a sense of efficacy based on telling. SBC teaching strategies remove the traditional mathematics instruction by telling, which eliminates a familiar teaching pedagogy with which teachers have extensive experience both as a student and a teacher? Rejecting the certainty afforded by repeated, reproducible pedagogy creates tensions for SBC teachers (Ball, 1993; Cobb, Yackel, \& Wood, 1992). Educated with the traditional methods, teachers who have attempted to use constructivism in their classroom must look at changing their practice dramatically and find new sources for their sense of efficacy (Smith, 1996). In their 2-year study on 66 middle school teachers adopting mathematical reforms and the use of constructivism, Manouchehri and Goodman (1998) found that by the fifth month of the study only 20 out of the 66 teachers were regularly using the reformed curriculum material and teaching 
pedagogy. Frykholm (1999) conducted a 3-year study on 66 beginning high school mathematics teachers who had all received extensive practice in standards-based instruction in their pre-service education. He observed that during the participants' third year of teaching, of 208 class periods 185 were completely teacher-centered with lecturing as the basis of instruction. Only $23(11 \%)$ of the class periods were entirely consistent with constructivist instruction pedagogy. In follow-up interviews with the study's participants, many teachers acknowledged that they had experienced SBC instruction as college students, but that it was easier to revert to teacher-centered instruction when they started teaching. The participants said that they received more support for this approach to teaching from both their teaching colleagues and administration. Some of the participating teachers recounted confrontations with administrators who were concerned that the students would not pass the state's standardized mathematics performance test. These teachers felt pressured to "teach to the test," and felt that they must defer to these political concerns.

The day-to-day operations of schools and classrooms function within a framework of norms, expectations, and values. When the concept of culture is applied to schools and classrooms, then questions arise (Windschitl, 2002). What practices are employed in a classroom? What beliefs and values are these practices base on? What are the relationships between teachers and students? How are these practices, beliefs, values, and relationships maintained? For the vast majority of mathematics classrooms in the United States a teacher-centered culture holds sway (Cobb, Wood, Yackel, \& McNeal, 1992; Gregg, 1995; National Center for Education Statistics, 2003; Sirotnik, 1983; Stigler \& 
Hiebert, 2004). As noted earlier, this culture has been predominant throughout the United States, and for mathematics teachers, who wish to adopt constructivist pedagogy in their classrooms, not addressing the deeply-rooted cultural barriers could doom their efforts at reforming their teaching.

\section{Political Obstacles}

The use of constructivism by mathematics teachers frequently puts them politically at odds with their colleagues, administrators, students, and parents.

Constructivist teaching, according to Mirel (2003), frequently generates controversy and dramatic conflicts that make successful instruction difficult, if not impossible. SBC instruction requires fundamental changes in the way education is practiced, and these changes require teachers to learn to teach in ways they are unaccustomed to. Changing to SBC teaching is a risky endeavor for most teachers; such change forces mathematics teachers and their administrators to redesign their jobs by focusing on the continuous improvement of instruction in the classroom, and this process has many political implications (Elmore, National Academy of Sciences, \& National Research Council, 1997). Windschitl (2002) defined the term political within the context of education as "the aspects of education that are linked with the exercise, preservation, or redistribution of power among students, teachers, administrators, parents, school board members, and other participants in the educational enterprise" (p. 154).

When mathematics teachers attempt to use constructivism in their classroom, the first political obstacle they confront is the traditional mathematics curriculum (Windshitl, 2002). As noted earlier, the traditional mathematics curriculum differs from the SBC 
mathematics curriculum, which is comprised of many rich mathematical tasks that emphasize the big ideas that run throughout mathematics, and allow students multiple entry points to assign tasks (Brooks \& Brooks, 1999). These teachers-designed tasks involve individual and group-problem-solving and allow teachers to ascertain their students' knowledge about the mathematical concepts and skills embedded in each task. SBC teachers' instructional strategies frequently alarm administrators (Haney, Lumpe, \& Czerniak, 2003). Administrators are accustomed to seeing traditional mathematics curriculum and instruction, and many possess the deeply held conviction that the learning of mathematics is the acquisition of skills and concepts. This conviction puts administrators at odds with teachers using teacher-designed mathematical tasks (Rogers, 1999). States' Departments of Education determine the mathematics curricula and the assessments of their effectiveness, while the implementation and assessments are normally left to the administration in local school districts (Brooks \& Brooks, 1999). Politically conservative educators resist passing the authority to create curricula to teachers because they fear both teachers' autonomy and the teaching of critical thinking skills to students (Elliot \& MacLennan, 1994). In the state of Texas, for example, the State's Republican Party recently added a provision to their political platform that supports knowledge-based education and proposed a ban on programs that promote critical thinking skills, challenge students' fixed beliefs, and undermine parental authority (Heitin, 2012). Policymakers have sought to control curriculum and standardize teaching rather than educate and empower administrators and teachers to make sophisticated decisions about their own curricula (Rogers, 1999). 
The fact that schools' cultures are often comprised of embedded, traditional teacher-centered practices causes political difficulties for mathematics teachers endeavoring to teach using constructivism (Windschitl, 2002). Cuban (1990, 1993) observed that since the $1800 \mathrm{~s}$, educationists have endeavored to change the traditional teacher-centered practices to student-centered practices. In every attempt, the traditional teacher-centered practices prevailed, which makes them seem impervious to attempts at significant and sustained reforms. He noted that school and classroom structures and the culture of teaching turn both new and veteran teachers into supporters of traditional mathematics instruction, who in turn erect political obstacles to SBC teaching. Gregg (1995), concurring with Cuban, asserted,

It seems almost impossible that a teacher in school mathematics tradition would question or reflect on the take-as-shared beliefs and practices of this tradition as a result of students' poor test performance. There are taken-as-shared explanations that have been constructed to make sense of such a phenomenon. From an outsider's perspective, it appears that these "too hard" and "bad question" explanations inhibit teachers and students from questioning other taken-as-shared beliefs about teaching and learning. (p. 463)

Experienced mathematics teachers use their taken-as-shared beliefs about effective teaching to interpret the SBC mathematics and incorporate only those elements consistent with their views and beliefs. Discussing the findings of Cohen (1990) and Putnam (1992) on this topic, Sherin (2002) wrote,

Although in some cases, teachers to adapt new materials successfully, in other cases, teachers transform these materials to be used with their familiar instructional routines. As a result, teachers who use reform-based curricula do not always appear to be implementing reform in the ways intended. (p. 122)

Even when teachers attempt to use SBC mathematics teaching in their classroom, many teachers - confronted by shifts away from a pedagogy emphasizing learning rules and 
procedures toward one focusing on understanding, explanation, and problem-solvingfind the change problematic, and are often at a loss to know what and how to teach (Ball, 1990a; Borko et al., 1992; Eisenhart, 1993; Putnam, 1992; Simon, 1993; Simon \& Schifter, 1991).

A source of political contention for SBC mathematics teachers is their students. Handal and Herrington (2003) observed that students, with personal histories of traditional, teacher-centered teaching, are resistant to the unfamiliar approaches of SBC teaching. For these students, mathematics is a set of rules, skills, and procedures that need memorizing, and there is only one correct procedure and answer for each mathematics problem. Frequently, students' resistance to standard-based mathematics curricula takes the form of expressions of discomfort with the new curricula (Cooney, 1988). Students frequently express this discomfort to their parents. In the case of Escondido, a suburb in San Diego County in the 1990s, students' discomfort with their SBC mathematics curriculum caused their parents to feel dissatisfied, fear that their children would not do well on college entrance examinations. These parents went to the local school board and protested the use of SBC mathematics curriculum in the district's high schools. Despite evidence that students using the SBC mathematics curriculum did well on college entrance examinations, the Escondido school board mandated the SBC curriculum be dropped and replaced by a traditional mathematics curriculum (Colvin, 1999).

School systems and their administrators often discourage innovation and change, and promote classrooms that are both stable and seemingly harmonious (Sullivan, 1989). As noted previously, administrators do not understand the activity that is involved in SBC 
mathematics classrooms, they are more accustomed to orderly classrooms where students are seated quietly at their desks, practicing exercises from their textbooks. Ball (1997) pointed out that many administrators are not happy with what they perceive as a lack of coverage and pacing, and are concerned that their students will not do well on knowledge-based state achievement tests.

The majority of parents experienced mathematics education consisting of traditional, teacher-directed instruction, and they expect the same for their children (Kohn, 1998). Discussing the pressure from students and parents on SBC mathematics teachers, Windschitl (2002) wrote,

Teachers not only felt pressure from the standards movement, but often felt they must attune their instruction to expectations for students and parents....parents, as educational stakeholders, often see constructivist approaches as dangerously experimental and are skeptical about the use of such pedagogy with their children. (p. 155)

In particular, parents of high-achieving students are concerned that innovative methods and curricula will negatively affect their children's standardized test scores and, consequently, their admission to prestigious universities (Kohn, 1998). Kohn emphasized that test scores were more important to these parents than the development of higherorder thinking and problem-solving skills. Even though the vast majority of parents suffered through their mathematics education, they still insisted that their children go through the same traditional mathematics education. As a result, teachers frequently feared parents' and administrators' perception of curriculum innovation, and felt they must defend the innovations they were attempting even before they themselves felt convinced of their value or self-confident (Ball, 1997). 
During the 1990s, parents in such states as California, Indiana, Texas, New York, and Massachusetts expressed dissatisfaction with standards-based curricula and SBC teaching in their local school district. They formed political groups that managed to change their respective state mathematics standards in order to de-emphasize problemsolving and understanding of standards and to emphasize proficiency in mathematical procedures and skills (Strotsky, 2007). These political shifts were part of a larger controversy dubbed “The Math Wars” by prominent mathematics educators such as Van de Walle (1999) and Klein (2000). Although the controversy began in the early 1990s and centered on mathematics curricula and strategies employed in instruction, the tone of the controversy became even more oppositional toward SBC mathematics teaching with the increase of high-stakes standardized testing at the state level, which was a response to the public's call for better accountability of the education of the United States' public school students (Theobald \& Mills, 1995).

This increased emphasis on standardized testing in the United States is frequently coupled with a concept of accountability that links students' test scores to the effectiveness of the teaching process (Theobald \& Mills, 1995). The system of utilizing standardized testing to enforce school/teacher accountability is frequently referred to as the standards movement because it links both testing and accountability to a state's mathematics standards. Smerdon, Burkam, and Lee (1999) argued that SBC mathematics teachers must deal with the standards movement that has come to dominate the current educational agenda and influence teachers' choices of instructional strategies, school district's mathematics curriculum, types of classroom assessments, student promotion, 
school policies, and other aspects of school life. The passage of the 2001 federal law labeled, No Child Left Behind, increased the pressure on mathematics teachers to use a traditional mathematical curriculum (Meier \& Wood, 2004).

With the passage of No Child Left Behind, United States' public schools were given a mandate to increase all their students' test scores or risk being designated a "failing school" and put on probation (Meier \& Wood, 2004). Without improvement in student test scores, schools faced the possibility of losing federal monies. Under the threat of costing their school funding and resources, teachers 'teach to the test' and they feel obligated to 'cover the material' using direct instruction, with an emphasis on basic mathematics skill acquisition (Darling-Hammond, 1997; Elmore, 2002; M. Gordon, 2009a). Such a policy, according to Darling-Hammond (1997), discourages teachers from spending time on professional training and from reflecting on their own practices and the ways these practices affected student learning. In a study of high school teachers in Mississippi and Tennessee, Volger and Burton (2010) found that more than $90 \%$ of the teachers surveyed $(n=1550)$ were preoccupied with their students passing their respective state tests. The authors also found that the teachers altered their instructional practices to maximize test scores and coverage of each state's mathematics standards. While many of the teachers practiced a combination of standard-based and traditional instruction, they expressed dissatisfaction over the fact that the tests caused them to resort to direct instruction. These teachers felt they were sacrificing their students' chance to understand mathematical concepts and skills because the state test questions emphasize procedural knowledge over deeper understanding. 
Even where states' standardized tests emphasized mathematical understanding over procedural knowledge, many teachers elected to use traditional mathematics instruction. In a study of New Jersey fourth grade teachers' mathematical instructional strategies and state testing, Schorr, Firestone, and Monfils (2003) found that although the state tests were based on national reform standards, the vast majority of teachers did not change their traditional instructional strategies in favor of SBC methods. The researchers attributed their obstinacy to two factors: (a) lack of confidence in the application of SBC methods caused by a lack of pedagogical and mathematical knowledge, and (b) the familiarity of the traditional teaching pedagogy. In Kentucky schools, Jones and Whitford (1997) found that the majority of the teachers in their study taught to the state test continuously during the school year. The state test was primarily performance-based, with emphasis on the understanding and usage of mathematical concepts. However, the state linked the results with an accountability, reward/punishment system that forced the "teachers focus on whatever is thought to raise test scores rather than on instruction aimed at addressing individual student needs" (p. 277). Regarding states' Education Departments and mathematical reforms, Brooks and Brooks (1999) observed,

State education departments could and should support good educational practice. But too often do they do not ... Rather than set standards for professional practice and the development of local capacity to enhance student learning, many state education departments have placed even greater weight on the same managerial equation that has failed repeatedly in the past: State Standards $=$ State Tests; State Test Results $=$ Student Achievement; Student Achievement $=$ Rewards and Punishment. (p. 19) 
Confronted with state standardized tests and accountability, even mathematics teachers attempting to implement constructivism in their classroom frequently teach to the test, and these practices train students to engage in rote learning of the test materials.

The political obstacles created by colleagues, students, parents, and administrators, combined with the current educational environment of high-stake testing and accountability, discourage many mathematics teachers from reforming their classrooms. Added to these political obstacles are the aforementioned conceptual, pedagogical, and social obstacles that dissuade mathematics teachers from using constructivism in their classrooms. Battista (1999) observed that traditionalist mathematics educators, when dismissing mathematical reforms, frequently cite isolated examples of alleged failures of such reforms. However, these same educators ignore the countless failures of the last century of the traditional teaching mathematics paradigm and curriculum. Battista (1999) argued that the American system of mathematics education does not serve the American students. Backing up this claim, he cited the National Research Council's statement that " $60 \%$ of college mathematics enrollments are in classes ordinarily taught in high school" (Committee on the Mathematical Sciences in the Year 2000, National Research Council, \& National Research Council, 1989, p. 51). Mullis, Dossey, Owen and Phillips (1993) observed from the data of the 1990 and 1992 NAEP assessments, that American 12-grade students were on 13\% to $16 \%$ proficient in mathematics. In yet another study, the National Research Council (1989) found that " $75 \%$ of Americans stop studying mathematics before they complete career or job prerequisites" (pp. 1-2). The authors of the report asserted that the United States has a 
"pandemic of mathematics miseducation ... [and] ... misconceptions about mathematics and mathematics learning are so deeply ingrained in our society that most people can't truly comprehend the improvements, so they fear and resist them" (p. 426).

Some high school mathematics teachers persist in using a constructivist approach in their classrooms despite the obstacles described above. Students' development of sense making and reasoning serves as a guiding principle for these SBC mathematics teachers. The quirky, often paradoxical nature of learning intrigues them; in paying attention to students' mathematical constructions, these teachers realize that they must change the 'business as usual' approach into a dramatically different classroom culture (Windschitl, 2002). They seek to reverse the current teacher-directed, telling instructional paradigm to an instructional paradigm, based on students creating or constructing their own knowledge of mathematics. These teachers conceive of the process of student-constructed knowledge as nonlinear and complex (Fosnot, 1993). SBC mathematics teachers set about creating a classroom where teachers look for students' understandings of concepts, and then "press the learning" of the students by formulating opportunities for students to refine or revise these understandings by posing contradictions, presenting new information, asking questions, encouraging research, and/ or engaging students in inquiries designed to challenge current concepts. (Brooks \& Brooks, 1999)

The methods described above accord with a set of predominant principles that, together, define constructivist pedagogy. In the next part of this paper, the research on constructivist principles that are used for creating constructivist classroom is examined.

\section{Constructivist Pedagogical Principles}




\section{Introduction}

As noted earlier, the conception of learning mathematics in a constructivist classroom and a traditionalist classroom differs dramatically, and these differences dictate diverse roles for both teachers and students. Additionally, teachers' and students' understanding of what constitutes effective participation in the mathematics classroom community (classroom norms) is altogether different in these two contexts (Simon, 1995). Wood et al. (1991) observed that the negotiation of constructivist classroom norms frequently took time, because students entered a mathematics class experienced in traditional mathematics instruction. For example, the authors noted that students coming from a traditional mathematics background assumed that they were to figure out what response the teachers wanted for questions instead of expressing their own thinking. Generally, constructivist teachers seek to capitalize on classroom activities by framing them in a way that will allow the teachers to discuss their expectations with their students. For instance, when students offered their solutions and justifications for tasks, instead of reacting to the solution as correct or not correct, teachers took the opportunity to stress the classroom norm that every student's thinking is instrumental to the operation of the constructivist mathematics classroom by asking questions such as, "Did anyone see the solution differently?" The negotiation and renegotiation of classroom norms was commonly required to create a classroom environment that achieved vital student outcomes: engagement in mathematically rich tasks and communication about mathematics (Wood, Cobb \& Yackel, 1991). Compared to traditional mathematics classrooms, where students sit passively at their desks and receive knowledge, students in 
constructivist mathematics classrooms are actively involved in developing their own understanding. In such a classroom, teachers encourage students to talk to each other, and individual students and groups of students feel comfortable voicing their opinions in discussions involving the teacher, small groups of students, and the whole class (Sfard, Forman, \& Kieran, 2001).

Establish a classroom environment. The process for establishing and negotiating classroom norms is instrumental in creating an effective, successful constructivist classroom environment. According to Walshaw and Anthony (2008), generating a thriving constructivist classroom involved engaging all students in dialogue, and this dialogue was dependent on a shared understanding of the importance of dialogue and the sharing of mathematical ideas. To achieve this, SBC teachers ensure that participation in all types of classroom discussions is both safe and inclusive for all students. This safe and inclusive classroom environment allows teachers to establish classroom criteria for fashioning a mathematical community.

Establish classroom criteria for a mathematical community. A constructivist mathematical community operates with a set of classroom norms purposely created by teachers using the products of teacher-student collaborations. The first step in setting up effective teacher-student collaboration in a constructivist classroom environment is honoring all student contributions, which is an inclusive pedagogical strategy. To effectively engage all students in dialogue, SBC teachers need to establish a shared understanding of the importance of dialogue and the sharing of mathematical ideas (Walshaw \& Anthony, 2008). There is abundant research documenting the observation 
that effective SBC mathematical pedagogical practices demand students' mathematical talk (Goos, 1995, 2004; Hiebert, 1997; Lampert \& Blunk, 1998; Wood, Williams \& McNeal, 2006). In spite of this, many students struggle to explain their mathematical ideas and they resist sharing their thinking with others in constructivist classrooms (Anthony \& Walshaw, 2008). SBC mathematics teachers explicitly create discourse principles (e.g., pacing and criteria for communication) that allow students to develop the appreciation for mathematical dialogue, which in turn that promotes mathematical reasoning that is transparent and available to all students for reflection (Wood, 2002). A pedagogical practice that does not attempt to synthesize the students' individual contributions tends to constrain the development of mathematical thinking (Mercer, 1995).

\section{Principle: Posing problems of Emerging Relevance to Students}

As noted previously, SBC mathematics educators believe the learning of mathematics is demonstrated by the students' development of deep understanding of both principle and procedural mathematical knowledge using their prior knowledge and experiences. To promote this developmental process in the classroom, SBC teachers offer rich mathematical tasks. Simon (1995) contended that teachers' decisions regarding rich mathematical tasks form the basis of their development of constructivist pedagogy. Rich mathematical activities give rise to opportunities for students to reexamine and reorganize their prior mathematical knowledge and experiences, and thus allow them to develop an increasingly sophisticated conceptual understanding. These rich mathematical tasks have the potential to engage all students in the mathematics classroom in 
mathematical conjectures that lead to productive thinking (Kilpatrick, 1987). The use of rich mathematical tasks plays an important role for SBC mathematics teachers' instruction (Smith, 1996).

SBC mathematics teachers rely on several essential norms when creating or designing rich mathematical tasks. Drawing on students' prior knowledge and experiences is an essential norm that allows students multiple points of entry that lead to engagement (Cobb, Wood, \& Yackel, 1990). Another advantage for mathematically rich tasks is that students consider them authentic. Tasks need to be viewed by students as activities that will increase their knowledge, and students need to feel that the mathematics is personally meaningful (Balacheff, 1990; Herbst, 2003; Lampert, 1990; Schoenfeld, 1992). Similarly, Ball (1993) stated that SBC mathematics teachers use both epistemological and functional perspectives in designing rich mathematical tasks. By utilizing rich mathematical tasks, SBC teachers convey to their students that the study of mathematics is more than the manipulation of numbers to compute a correct answer. Instead, students develop a view that engaging in mathematics is about making and testing mathematical conjectures, explaining and defending one's thinking, and participating in a community of learners.

\section{Principle: Structuring Learning Around Primary Concepts-The Quest for Essence}

SBC mathematics teachers strive to create a classroom environment that engages students and honors their individual styles, temperaments, and predilections, and structuring curriculum around big ideas allows for this. Perrone and Harvard University 
(1996) referred to big ideas as generative topics, which he defines as, "Those ideas, themes, and issues that provide the depth and variety of perspectives that help students develop significant understandings" (p. 12). SBC mathematics teachers view big ideas, not as a list of topics, but as the dynamic interconnections between mathematical and non-mathematical topics (Ritchhart, 1999). For example, instead of teaching the mathematical topic of place value as a set of ordered names to be related to as a series of columns, SBC teachers may broaden the subject by treating place value as a scheme for organizing and recording quantities.

The NCTM $(1989,2000)$ identified four major ideas that mathematics education should include: representation, proportionality, function, and computation.

Representation is defined as both representation of process and product. In other words, representation is the act of capturing a mathematical concept or related in some form and the form itself. The comparison of two quantities in a ratio relationship characterizes proportion, and proportionality reasoning is used throughout mathematics to resolve problems. A function defines a special relationship between two values. Functions have different representations such as tables, graphs, diagrams, symbolic expressions, and verbal expressions. In their discussion of computation, NCTM referred to the fluency of calculating throughout all of mathematics with pencil and paper and other calculating devices such as calculators and computers. Each of these four mathematical concepts run throughout all of mathematics and in the classroom mathematics students are continuing to use them to develop deep mathematical understanding. 
Big ideas help teachers re-conceptualize what they are teaching and view their curriculum with a fresh perspective, facilitated by making connections both to real-life situations and to other mathematical topics (Ritchhart, 1999). Incorporating newly developed perspectives in the classroom allows teachers to develop their own connections between mathematical concepts and skills. Kazemi and Franke (2004) studied ten elementary mathematics teachers collaborating on curriculum from student work on big idea activities. These collaborations guided them in determining the substance and direction of classroom discussions. In the process, these teachers attended to students' thinking and used it to change their lesson plans to incorporate the mathematics that emerged from their students' work. In general, the incorporation of big ideas into a mathematics classroom not only allows teachers to grow using their students' thinking, but also to bridge students' initial understandings with a mathematical understanding supported by the world at large (Walshaw \& Anthony, 2008).

The classroom role of SBC mathematics teachers is greatly affected by the use of mathematical tasks based on mathematical big ideas. During the students' investigations, teachers promote both mathematical and non-mathematical contextual ideas that prompt students to develop their own personal meanings (Balacheff, 1990; Herbst, 2003). When SBC teachers employ big mathematical ideas in classrooms, students make connections, which supports the acquisition of mathematical concepts and skills that build students' mathematical powers. In the process, SBC teachers may also acculturate students into the mathematics community through sharing with their students the conventions and meanings associated with mathematical discourse, representation, and forms of 
argumentation (Wood, 2002; Yackel \& Cobb, 1996). The use of big ideas in mathematics classrooms enables SBC $t$ teachers to successfully foster the language of mathematics among their students, and create constructivist classroom environments where students' learning goes beyond the narrow context of the original mathematical tasks; students shift from "being practitioners in becoming theoreticians" (Balacheff, 1990, p. 262). The knowledge newly constructed in the classroom is shared social knowledge within the broader community of mathematical learners.

\section{Principle: Inclusive and Demanding Constructive Pedagogy}

Effective constructivist pedagogy is both inclusive and demanding; it necessitates careful attention to students' explanations of their thinking. Effective teachers attempt to explore their students' thoughts, noticing and listening conscientiously to what students have to say (Kazemi \& Franke, 2004; Cobb, Yackel, \& Wood, 1992). In a case study of a seventh grade mathematics teacher, Manouchehri and Enderson (1999) provided evidence that the teacher's careful attention to students' explanations of their thinking allowed her to develop students' talk and interactions. The teacher accomplished this by providing responsive rather than direct support, monitoring student engagement and problem-solving with careful questioning and purposeful interventions. Cobb et al. (1997) maintained that knowing when to intervene in students' discussions is an essential skill for effective SBC mathematics teachers, and this intervention skill is dependent on the teachers' content knowledge.

According to Watson (2001), without adequate content knowledge, teachers often intervened and instructed their students, using a teaching strategy called "path 
smoothing" (p. 462). This strategy deliberately constrains conversations about a problem by reducing students' approach to a sequence of small, smooth steps that are easily traversed. Teachers who undervalue students' thinking by emphasizing procedural rules devalue the process of searching for solutions, the very process that leads to developing reasoning and thinking skills (Yackel \& Cobb, 1996). In constructivist classrooms, supportive problem-solving environments are created for students when teachers stimulate argumentation rather than deliver a smooth path to easy problems.

Furthermore, researchers have discovered that engaging in argumentation positively affects learning in constructivist mathematics classrooms (Goos, 2004; D. Y. White, 2003). O'Conner and Michaels (1996) observed that argumentation opportunities were particularly important when students took specific positions and defended them against the claims of others. Teaching argumentation techniques in a constructivist mathematics classroom are a highly complex activity, requiring teachers to employ scaffolding in their practices (Anghileri, 2006). SBC mathematics teachers must develop skills in modeling the desired reasoning and argumentation strategies, and in helping students' more capable peers provide similar modeling. Other skills that need to be developed are: (a) making contextual connections (Kazemi \& Franke, 2004), (b) providing appropriate time for exploring ideas and making connections (Ball, 1997), (c) encouraging student self-monitoring (Pape, Ball, \& Yetkin, 2003), and (d) consistently pressing for explanation, meaning, and understanding (Fraivillig, Murphy, \& Fuson, 1999). For successful argumentation to occur in a constructivist mathematics classroom, teachers must first establish norms for mathematically acceptable, diverse, sophisticated, 
efficient, or elegant explanation (Yackel \& Cobb, 1996). To press for understanding, teachers must urge students to elaborate on their thinking, encourage students to make their reasoning explicit, and then follow up with deeper exploration.

Successful SBC teachers develop a classroom environment where students work toward a consensus of classroom members' constructed mathematical knowledge, developing fresh mathematical interpretations (Woods, Cobb, \& Yackel, 1992; Yackel \& Cobb, 1996). These newly developed interpretations frequently lead to other mathematical realizations. Effective SBC teachers use these realizations to further explore mathematics.

\section{Principle: Adapting Curriculum to Address Students' Suppositions}

Students come to class with mathematical preconceptions, and these forms a critical part of the context in which SBC teaching unfolds. Curricula that make constructivism's cognitive, social, and emotional demands accessibility for students in relationship to their mathematical preconceptions have been proven to enhance learning (Brooks \& Brooks, 1999). SBC teachers need to improvise in response to students' unanticipated actions; teachers enact curricular decisions made in relation to students' thinking and suppositions. Known as the improvisational work of teaching by some researchers, this activity is grounded in the student-teacher relationship (Borko \& Livingston, 1989; Heaton 2000; Remillard, 1999). Ball (1993) stressed that SBC mathematics teachers must have "bifocal perspective-perceiving the mathematics through the mind of the learner while perceiving the mind of the learner through the 
mathematics" (p. 159). Simon (1995), emphasizing the symbiotic relationship between SBC teacher's content knowledge and students' mathematical suppositions, wrote, Constructivist teaching examines the role of different aspects of teachers' knowledge, and explores the ongoing and the inherent challenge to integrate the teacher's goals and direction for learning with the trajectory of students' mathematical thinking and learning. (p. 121)

Teachers have derived from big ideas mathematically rich tasks in order to help students generate new mathematical topics through interaction. These topics emerged from the classroom context, and allowed both the students and teachers to explore and "exploit a world of deep, rich, and powerful mathematics that has both focus and coherence" (Ritchhart, 1999, p. 467).

Studies have concluded that teaching is effective when it bridges students' intuitive understanding, as derived from prior knowledge and experiences, with mathematical understandings approved by the world at large (Walshaw \& Anthony, 2008). A study of 10 elementary mathematics teachers collaborating on using student work to guide them in choosing the substance and direction of classroom discussions, found that these teachers developed the ability to change their "instructional trajectories in the mathematics that emerged because of the group's attention to details of student thinking" (Kazemi \& Franke, 2004, p. 213). In her research on both elementary and middle school mathematics teachers, Lampert (1990) discovered how vital it was for mathematics teachers to choose rich mathematical tasks that produce student mathematical conjectures and hypotheses, which in turn introduces new mathematical topics to the classroom. She wrote, 
When we were switching to a new topic, the problem we started with was chosen for its potential to expose a wide range of students' thinking about a bit of mathematics, to make explicit and public what they could do and how then understand. Later problems were chosen based on an assessment of the results of the first and subsequent discussions of a topic, moving the agenda along into new but related mathematical territory. The most important criterion in picking a problem was that it is the sort of problem that would have the capacity to engage all of the students in the class in making and testing mathematical hypotheses. (p. 39)

Such rich mathematical tasks affect the content of a lesson. Instead of looking for one correct answer, students create arguments that support or reject solution strategies. Generating a strategy and justifying it with an argument reveals what students know about mathematics. However, to evaluate student suppositions about mathematically rich tasks, teachers must have an expert knowledge of mathematics that allows them to guide the classroom so that it encompasses students' solutions (Ball, 1996, 1997; Ball et al., 2001). This discourse, in turn, produces opportunities for teachers to develop accurate assessments of students' mathematical knowledge.

\section{Principle: Assessing Student Learning in the Context of Teaching}

Assessment has always been an integral part of any mathematics program. Determining the extent of individual students' or groups of students' knowledge is essential. In creating conceptual understanding for mathematics students, one of the major goals of SBC mathematical teaching is developing students' capacity for integrating, applying, and communicating their mathematical understandings. Such student acquired ability is referred to as mathematical power (Webb, Coxford, \& National Council of Teachers of Mathematics, 1993). The assessment of mathematical power requires methods and standards altogether different from the traditional summative 
assessment paradigm now commonly associated with mathematics instruction. Instead of assessing students according to their ability to quickly produce correct answers for mathematical problems on a written objective test, the assessment of mathematical power requires that the teacher pays attention to the students' willingness to use, apply, and communicate the mathematics they are studying (NCTM, 1989, 2000). Defining assessment in such a manner has allowed SBC mathematics teachers to use alternative formative assessment strategies such as scoring rubrics, journal writing, classroom observations, class dialogues, and student demonstration to help ascertain students' mathematical knowledge and understanding on a continuous basis (Ward, et al., 2010). Such assessments are referred to as formative because teachers adapt their teaching to meet their students' needs based on these students' ideas and responses. Black and Wiliam (1998), in reviewing 250 research studies on the use of formative assessments in classrooms, concluded such assessments are essential components of the classroom work and that their development can raise standards of student achievement.

In a constructivist classroom, formative assessment plays a much more active role in shaping the curriculum than summative assessment plays in a traditionalist classroom. Students' ability to communicate their process for deriving solutions points to a significant depth of understanding, because having a solution to a problem implies being able to justify that solution. Furthermore, since contextual learning is an essential component of a constructivist classroom, assessing students' ability to link a solution to other topics and possible solutions to other problems must be a high priority for an SBC mathematics teacher (Ward et al., 2010). 
The Constructivist teachers' use of formative assessment strategies enhances students learning in several important ways. First, the rich mathematical tasks used to assess students convey an important message to these students regarding what forms of mathematical knowledge and which methods of demonstrating that knowledge are valued. Secondly, feedback from the formative assessments empowers students in becoming more independent learners. Students, attending to rich mathematical tasks and dialoging with fellow students and teachers, realize that solving complex tasks involves far more than coming up with one correct answer. Thus, students "develop both a disposition and capacity to engage in self-assessment and reflection" (NCTM, 2000, p. 23). SBC mathematics teachers view assessment as an integral part of mathematics instruction; it contributes significantly to all students' mathematics learning. Brooks and Brooks (1999) contended that assessment in constructivist classrooms is used to develop the link between students' learning and teachers' instructional strategies. Assessment viewed in such a manner is an indispensable tool for transforming the class into a community of learners.

\section{Principles Conclusion}

At the high school level, many traditional mathematics educators contend that SBC teaching strategies are fundamentally flawed because they emphasize problemsolving at the expense of mathematical content (Smith, 1996). According to this perspective, the use of constructivism in mathematics classrooms lacks rigor because it fails to emphasize the acquisition of content knowledge. By contrast, SBC mathematics educators argue that SBC strategies encourage students to develop mathematical 
understandings viewed as superior to those produced through the traditional memorization of isolated mathematical skills and concepts. Proponents of the SBC mathematics-teaching paradigm maintains that in high school mathematics SBC classrooms, students are continuously developing meaning and mathematical concepts, explaining and defending their mathematical thinking, and, thereby, experiencing and practicing academic rigor. The expectations in SBC mathematics classrooms are that students demonstrate their created contextual knowledge by developing links between newly acquired mathematical understanding and new problems they experience both inside and outside the classroom.

In summary, this chapter has examined constructivism and its use in high school mathematics classrooms. It discussed the obstacles teachers confront when implementing constructivism in their classroom, and presented five guiding principles used when teaching mathematics within a constructivist paradigm. Using this information as a lens, my research investigates three questions:

1. What are the paths SBC secondary mathematics teachers who received the PAEMST pursued to become highly effective?

2. What obstacles and challenges did they encounter and how were these obstacles overcome?

3. What sustained them on their journeys?

In the next chapter, I introduce the research participants, as well as describe the research methodologies and design I used to address these questions. 


\section{CHAPTER 3}

\section{METHODOLOGY AND RESEARCH DESIGN}

\section{Introduction}

The title of this dissertation, The Journey to Becoming a Constructivist, Presidential Award for Excellence in Mathematics and Science Teaching, Secondary Mathematics Teacher, was selected because it represents the essence of this research study, which is the examination of highly effective teaching in a high school mathematics classroom that utilizes an SBC teaching paradigm. In the Literature Review, research on the characteristics of a successful teacher was presented, along with those characteristics of the SBC instructional paradigm. Research was also presented on five constructivist principles successfully incorporated into the SBC teaching paradigm: (a) posing problems

of emerging relevance to students; (b) structuring learning around primary concepts - the quest for essence; (c) using an inclusive and demanding constructive pedagogy; (d) adapting curriculum to address students' suppositions; and (e) assessing student learning in the context of teaching. Furthermore, the research was examined on the conceptual, pedagogical, societal, and political obstacles frequently encountered by mathematics teachers at the high school level utilizing SBC pedagogy. This cumulative research provided a basis for examining the study's research questions:

1. What are the paths SBC secondary mathematics teachers who received the PAEMST pursued to become highly effective?

2. What obstacles and challenges did they encounter and how were these obstacles met? 
3. What sustained them on their journeys?

This chapter provides a description of and the rationale for each data gathering instrument used, as well as a description of the research design and applications of the data gathering instruments used to investigate the above research questions. The chapter is divided into four sections: (a) research participants and recruitment, (b) research design: methodology, data gathering instruments, and data analysis process, and (c) ethical issues: confidentiality, authenticity, and reliability.

\section{Research Participants and Recruitment}

\section{Rationale for Using PAEMST Recipients for the Research}

According to Creswell (2008), homogeneous sampling is purposeful and involves researchers sampling individuals based on membership in a subgroup that has similar or

defining characteristics. In this study, the research participants are effective, high school mathematics teachers and have received a prestigious national award for their teaching acumen, the National Science Foundation's (NSF) PAEMST.

Use of SBC pedagogy, teaching in the classroom. In becoming PAEMST recipient, the research participants have shown that they are excellent teachers. Furthermore, according to research, these participants were using an SBC pedagogy in their classroom. Weiss and Raphael (1996) conducted a national study of 930 PAEMST recipients and 2,605 non-recipient teachers inquiring into their backgrounds, preparation, classroom practices, and professional activities. The researchers noted that $97 \%$ of the PAEMST mathematics and science teachers were aware of and used teaching strategies consistent with the recommended national standards from the NCTM and the National Science Teacher Association. Furthermore, all of the mathematics teachers in this study 
were cognizant of the NCTM standards, advocating the use of SBC teaching strategies in the classroom.

In summary, my rationale for using a purposeful sample of recipients of this highly-prestigious award is threefold: (a) they had been recognized for their high quality of teaching; (b) they had exhibited awareness and usage of SBC mathematics teaching; and (c) they were accessible for this study.

\section{Recruitment of Research Participants}

I used the CPAM listserv to recruit volunteers for the research. I had access to this listserv because I am a past PAEMST recipient and a member of CPAM. I initially sent out an invitation email using the CPAM listserv (see Appendix A for initial email). The initial email was comprised of two parts: (a) an invitation to participate email, and (b) an attachment explaining the requirements for participation in the research study. In the invitation part of the email I included: (a) a short description of myself, (b) the goal of the research study, (c) the three research questions, and (d) a short description on why the CPAM members were recruited. The email attachment included the following: (a) a request for a copy of either the Evidence of Learning section (PAEMST recipient prior to 2004) or Narrative Prompt section (PAEMST recipient, 2004 to the present) of their PAEMST application, (b) a request for demographic information, including the volunteer's name and gender, current high school teaching position, the numbers of years teaching mathematics, and the name of their high school, and the city, state it is located in, (c) assurances of confidentially, (d) mine and Dr. Narode's contact information, and 
(e) the process for each CPAM member to indicate their interest in becoming a research participant.

After 2 weeks, I received four replies from CPAM members volunteering to become participants in the research. Two of the volunteers, were not high school mathematics teachers; they were middle school mathematics teachers who taught algebra. I emailed both individuals, thanking them for their interest, and stating that I was only seeking high school teachers. Receiving just two of the five needed volunteers, I elected to create an additional listserv.

CPAM has created a database of all their members that includes the members' school address and a contact email address, and I had access to this database because of my membership. With the CPAM information, I created a listserv consisting of 780 secondary mathematics teachers' email addresses, representing all 50 states. I sent out the email to each of the 780 listserv teachers individually, and I received three replies indicating they wanted to be involved in my research.

In my initial proposal, I indicated that I would coordinate with my advisor, Dr. Ron Narode, and select five research participants based on the following criteria;

- They had taught mathematics for at least ten years and at least five years at the high school level.

- They were articulate as demonstrated by his or her Evidence of Learning or Narrative Prompt section of the PAEMST application depending on the year of the award.

- They may be characterized as an SBC mathematics teacher.

- They had taught a number of mathematics classes in high school, ranging from Pre-Algebra to Calculus. 
Analyzing both the sent PAEMST required information, and the demographic information of the five volunteers, it was determined by Dr. Narode and I that all five qualified for the research study. Instead of going through a list of 15 or so volunteers and determine five research participants as initially visualized in the original research proposal, Dr Narode and I decided to use the five volunteered participants and, in doing so, the recruitment process became one based on "first come basis."

\section{Research Design}

In this section I discuss my research design. I discuss the: (a) research methodology, (b) data collection processes employed, and (c) data analyzing process I utilized.

\section{Methodology}

Qualitative research. Qualitative research methodologies developed because they were suited for research problems in which the researcher knows little information from the literature about a phenomenon being studied, and more must be learned from participants before qualitative methods can be employed (Creswell, 2008). Lincoln and Guba (1985) asserted that qualitative research approaches, called naturalistic inquiry, concentrate on the participant's point of view and the setting or context (e.g., the classroom), highlighting the participant's personally-held views on educational issues. Quantitative researchers focus on specific, narrow questions: collecting quantifiable data, analyzing that data using statistics, and conducting their inquiry in an unbiased, objective manner. Qualitative researchers, in contrast, ask broad questions, collect data from participants frequently consisting of participants' own words, and describe and analyze 
these words to reveal themes and patterns (Creswell, 2008). As a distinct form of qualitative research methodology developed in the field of education in 1990, narrative inquiry concentrates on the study of a single individual's story (Connelly \& Clandinin, 1990).

Narrative inquiry. H. White (1980) observed that narrative inquiry views life holistically, and though it has its roots in the field of literary criticism, where narrative work originated, it can also trace its lineage to oral history, drama, psychology, folklore, and film philosophy. Narrative inquiry has been used as a research methodology in such fields as anthropology, sociology, and criminology. Of note, Polkinghorne (1988) explored the use of narrative inquiry in the field of psychology, developing an alternative way of looking at the concept of self; instead of viewing the self as identified with the type of conceptual structure used to understand substances or representatives, the concept of self can be better understood through a narrative. For Polkinghorne (1991), viewing the self as a narrative or story, instead of as a substance, reveals the temporal and developmental aspect of human existence. Drawing from Polkinghorne's narrative research methodology and Coles' (1989) literary concepts of narrative, Connelly and Clandinin (1988) first employed narrative inquiry in the field of educational research, basing their definition of narrative inquiry on Dewey's notion that life is an education. For Connelly and Clandinin (1988), narrative inquiry is a research methodology that brings "theoretical ideas about the nature of human life as lived to bear on educational experience as lived" (p. 3). Concurring with this description, Rosiek and Atkinson (2007) argued that narratives build on the literature that examines the lived experience of 
teaching, and that experiential narratives (i.e., narrative inquiry) are ontological — they "describe the qualities of teaching as they are lived by teachers" (p. 513). In defining narrative inquiry, Connelly and Clandinin (1990) wrote that humans live storied lives, and narrative inquiry is a methodology that captures an individual's experience of a story in relationship to a phenomenon. Narrative inquiry involves working with research participants' consciously told stories, recognizing that these are founded on deeper stories of which the participants are often unaware. Participants construct stories that support their interpretation of themselves, excluding experiences and events that undermine the identities they currently profess. Bell (2003) asserted that all participants' structured stories provide a window into their beliefs and experiences. However, narrative inquiry is more than telling stories; it involves many complex factors that must be attended to before any research using the methodology will be adequate (Clandinin, Pushor, \& Orr, 2007).

Connelly and Clandinin (1990) contended that to undertake narrative inquiry research study, researchers must pay attention to three commonplaces: temporality, sociality, and place. They maintained that these commonplaces provide the framework for understanding individuals' narratives. Temporality refers to the idea that in narrative inquiry people, places, and events change through time. The commonplace element of sociality deals with existential circumstances, such as environment, surrounding factors, forces, and people that shape personal conditions such as feelings, hopes, and desires. The third commonplace, place, refers to the specific physical environments such as classrooms, schools, workshops or conferences, where the narrative occurred. 
Researchers must be attentive to the ways these three commonplace elements change throughout the study. Clandinin, Pushor, \& Orr, (2007) wrote that narrative inquirers need to think of their inquiry phenomenon, topic, and participants as occurring in a "multi-dimensioned, ever changing life space," because "to plan a narrative inquiry, is to plan to be self-consciously aware of everything happening within that life space" (p. 481).

I chose narrative inquiry for this study's methodology because its characteristics allowed the participants to define themselves in their own narrative. Hearing participants tell the stories of their journey toward SBC teaching allowed me to better understand their perspectives on the learning of mathematics, the obstacles they encountered, and what principles they used when applying SBC pedagogy in their classrooms. Telling stories is a natural part of life, and the participants had stories that they were willing to tell (McEwan \& Egan, 1995, 1997). Another important aspect of narrative inquiry is the collaboration between me and the participants. This collaboration allowed me to connect with the participants, who have stories similar to my own. Creswell (2008) describing the reasons for using narrative inquiry, wrote, "Narrative research captures an everyday, normal form of data that is familiar to individuals" (p. 512). This "normal form of data" provided a rich source of information that addressed my research questions.

Narrative inquiry, research steps. There are many forms of narrative inquiry. However, Creswell (2008) has maintained that a narrative study follows seven major steps, regardless of the form of narrative research it employs:

- Step 1. Identify the phenomenon to explore that addresses an educational problem 
- Step 2. Purposely select an individual from whom you can learn about the phenomenon

- Step 3. Collect the story from the individual

- Step 4. Restory or retell the individual's story

- Step 5. Collaborate with the participant—-storyteller

- Step 6. Write a story about the participant's experiences

- Step 7. Validate the accuracy of the report. (pp. 523-525)

The following is a description of the steps in relation to my research study.

Step 1. Identify the phenomenon to explore that addresses an educational

problem.

In the Introduction section of this paper, Step 1 was addressed. The phenomenon of this research study was defined as the development and use of SBC pedagogy of PAEMST, mathematics teachers at the high school level.

Step 2. Purposely select an individual from whom you can learn about the

phenomenon.

In the Research Participant and Recruitment section of chapter 3, step 2 was addressed. High school mathematics teachers were defined as participants for the research study. These teachers instructed using an SBC teaching pedagogy, have received the PAEMST, and members of CPAM. The chosen participants are award-winning individuals with whom I collaborated with and learned from regarding their use of SBC teaching pedagogy in their high school mathematics classroom.

Step 3. Collect the narrative from the individual. In this study, collecting the stories of the participants' experiences using SBC teaching in their mathematics 
classroom involved two data gathering instruments: one-on-one interviews and the Narrative Prompt (2004 to the current PAEMST recipient) or Evidence of Learning (prior to 2004 PAEMST recipient) section of the PAEMST application. The description and rationale for each source is covered in the Data Gathering Instrument section of this chapter located below. In the remainder of this section, the research design as it pertains to the use of each of these data gathering sources is addressed.

In the above Participation and Recruitment section, I addressed part one of the research design: the recruitment of the study's participants and the process for obtaining both the participants' PAEMST narrative prompt section of their application and their demographic information.

The second part of the research design was the face-to-face, one-on-one narrative interview is described in the Data Gathering Instruments section of this chapter located below. My goal in using this type of interview was to have the participants tell their stories about their development and use of SBC pedagogy in their high school mathematics classroom. Schram (2006) observed that these stories are "a natural, obvious, and authentic window into how people construct meaning in their lives" (p. 105). According to this perspective, the participants' stories bring the researcher closer to the complete picture in the setting where the stories occur-their classroom in their school (Glesne, 2011).

As a narrative inquiry researcher, one of my main concerns was to develop a comfortable and confidential atmosphere that led to collaboration between the participants and me. To ensure this, I coordinated with the participants in choosing a time 
and a place to share their stories. Furthermore, these familiar environments (e.g., a classroom) provided stimuli that helped the participants to remember parts of their stories they might have forgotten if the interviews occurred in less-familiar or less private places (Creswell, 2008). Prior to and during the interviews I attended to the concept of availability, which refers to the notion that the participant should not feel rushed; they should feel that they have adequate time to tell their narrative.

Prior to the interview, I addressed procedures that might have otherwise interrupted the interview sessions. I gave the participants a copy of the interview consent form, and I asked them to read the document and sign it if they agree with it. A copy of this consent letter is in Appendix $\mathrm{C}$ of this paper. I made the participants aware of the fact that the interviews were taped using both a digital recorder and a digital pen/recorder. Furthermore, I made sure the recording devices were running properly prior to the interview. Additionally, I assured the participants that they were able to convey their narratives with few interruptions by me, except for occasional clarification questions.

Once the interview started, I followed an interview protocol. Creswell (2008) described the interview protocol as a form designed by the researcher that includes instructions for the process of the interview, the questions the researcher will ask, and a space for taking notes. A copy of the interview protocol that I used appears in Appendix D.

During the interview process, I used individualized probes to promote further development of interviewees' answers. Creswell (2008) defined probes as the "subquestions under each question the researcher asks to elicit more information" 
(p. 299). The creation of a nonthreatening atmosphere and the use of probing questions allowed me to delve into the complexity of the participants' stories, while at the same time maintaining the flexibility that permitted the participants to tell their entire story. As a result, I had the opportunity to understand the participants' attitudes and beliefs about the use of SBC pedagogy in a high school mathematics classroom. The individualization of the interview probes was accomplished by using participants' responses from their PAEMST narrative prompt document.

Once we had finished the interviews, I thanked the participants for their cooperation in this part of my research project and double checked their current contact information. I also explained the process of retelling their narrative and the part they would play in developing the final written narrative. This process is clarified below in the Step 4 and Step 5 sections.

Step 4. Restory or retell the individual's narrative. Retelling the participants' narratives involved using the raw data from the Narrative Prompt or Evidence of Learning section of the PAEMST application and the notes from and recordings of the one-on-one interview. I arranged this data according to the commonplaces of temporality, sociality, and place as noted earlier in the Narrative Inquiry section of this paper.

Concentrating on the development and use of SBC teaching strategies in the participants' classrooms, I wrote the participants' narratives focusing on the setting, characters, actions, problems, and resolutions as they relate to the research questions (Creswell, 2008). In particular, I elected to write each participant's narrative using a chronological order. Once their narratives were written, I sent them to the participants via email. The 
participants were encouraged to review their narrative for validity, possible errors, and omissions. A scheduled phone call or Face Time session followed for further input and collaboration with the participants.

Step 5. Collaborate with the participant-storyteller. During this step, the participants and I collaborated via phone or Face Time on augmenting the initial narrative. The goal of this collaboration was to edit the initially written narrative so that it presents a more accurate picture of participants' understandings and experiences.

Furthermore, each participant was encouraged to write a reflective response to the written narrative that will be included in the final dissertation.

Step 6. Write a narrative about the participant's experiences. During this step, I rewrote the participants' initial narratives using the information acquire from the telephone/Face Time collaborations. In rewriting these narratives, I concentrated on themes that developed surrounding the participants' use of SBC pedagogy in teaching mathematics at the high school level (Creswell, 2008). The Literature Review section contributed to this section by acting as a lens to aid understanding of the meaning of the participants' original narrative and their subsequent rewritten narratives.

Step 7. Validate the accuracy of the report. Validating the accuracy of participants' narratives occurred during the collaboration step with the participants, and the subsequent step of rewriting of each participants' narratives. In rewriting the narratives, I drew from participants' one-to-one interviews, the participants' PAEMST document, and the additional data supplied to me by each participant during collaboration step. 
Writing both the initial narrative and narrative after the collaboration step, I was cognizant of several disadvantages of Narrative Inquiry methodology. One of the disadvantages that I confronted was the focusing only the individual rather than focusing on the social context of narrative (Marshall \& Rossman, 1995). For example, in the Literature Review, it was noted that SBC teachers frequently seek out further education and collaboration with fellow teaching colleagues and professional educators. These social collaborations came up in all of the participants' narratives and, mindful of the above limitation, I explored them in hopes of informing the understanding of the influence they had on each of the participants' development and use of an SBC paradigm in their classrooms.

Crites (1986) warned that the researcher must be aware of "the illusion of causality," which is the inference that an interviewee's narrative sequencing possesses correct cause-and-effect connections. During the entire study, I was well aware of the possible lack of such connections and attempted not read causality into the data analysis where it did not exist. Furthermore, the combination of the two data gathering process discussed below, helped me deal with this limitation.

\section{Data Gathering Instruments}

The two data gathering processes used in this study - face-to-face, one-on-one narrative interviews and personal documents in the form of a particular section of the participants' Presidential application document-were purposely chosen for the examination of the research phenomenon, SBC mathematics teaching at the high school level. The following is a description of the two data gathering process. 


\section{Narrative prompt or evidence of learning documents: Description and}

rational. Both personal and professional documents are excellent sources of data in narrative inquiry (Connelly \& Clandinin, 1990). Bogdan and Biklen (2006) suggested that personal documents should be written as first-person narratives and that they should describe the research participants' individual actions and experiences. Such documents provide an unobtrusive method for the researcher to obtain a rich source of information about the participants' values and beliefs in a particular setting (e.g., participants' classrooms). According to Glesne (1999), documents serve the important function of supplying information that raises questions. Such questions prove beneficial to me because they both supported and challenged interview data. Another positive aspect of the use of documents in qualitative research is the fact that they were readily available for analysis.

Each participant's written PAEMST document (Narrative Prompt or Evidence of Learning) described their chosen unit of instruction and addressed the following:

- Mastery of mathematics or science content appropriate for the graduate level taught.

- Use of instructional methods and strategies that are appropriate for the students in the class and that support student learning.

- Effective use of student assessments to evaluate, monitors, and improve student learning.

- Reflective practice and lifelong learning to improve teaching and student learning.

- Leadership in education outside the classroom. 
I utilized the data from these documents as a source for the development of themes for the research study, and as a source for developing possible questions for the other data gathering process, narrative one-to-one interviews

Narrative interview: Description and rationale. Interviews play a significant part in the narrative inquiry methodology. The use of narrative inquiry in studying teacher education captures the richness and indeterminacy faced by teachers and the complexity of our understandings of what teaching is (Carter, 1993). Through narrative inquiry, the narrative becomes a central focus for conducting educational research (Carter, 1993; Scholes, 1980). Using narratives, research subjects impose order and coherence on experiences and work out the meaning of incidents and events in the real world. The interviews provide a format in which experiences, actions, and events can be discussed in an attempt to make them understandable, shareable, and unforgettable.

In qualitative research, the interview is defined as a process where researchers ask one or more participants general, open-ended questions and record their answers (Creswell, 2008). Open-ended questions were used in the interview process because they allowed the participants to voice their experiences unhindered by the perspectives of the researcher or past research findings. Connelly and Clandinin (1990) asserted that the main source of data collection in narrative inquiry is the unstructured interview. They wrote, "Interviews are conducted between researcher and participant, transcripts are made, the meetings are made available for further discussion, and they become part of the ongoing narrative record" (p. 5). Using one-on-one, face-to-face, open-ended interviews accomplished two fundamental objectives in the narrative inquiry process. The interviews 
permitted the participants to tell their first-person narrative addressing the research questions, while also allowing the development of a collaborative relationship with me. In conducting the one-to-one interviews, I initially deferred to above interview description and began each interview with open-ended questions. I followed the interview questioning technique of letting the participant talk, but my questions become less openended as the interview continued. When the participant related a narrative, I would key into the participant's narrative and have the participant elaborate and expand on their statements. I also began the collaborative process during the interview by prefixing a question with the personal teaching situation. For example, when introducing the obstacle of administrator's lack of knowledge of SBC mathematics teaching methods, I would say, "In my teaching career, I never had an administrator who was a mathematics teacher, and I found myself frequently educating them about SBC teaching-what was your experience with administrators and your teaching?" Such questions helped develop an interview atmosphere that was casual and supportive. I felt the participants opened up further knowing that I had experienced what they had gone through. This collaboration atmosphere continued on later on in the narrative inquiry process during the telephone/Face Time collaboration.

\section{Data Analysis Procedures}

\section{Identifying Themes}

During the data analysis process, I referred to two sources in helping in the process of identifying themes that were common to all five narratives. The two sources were: (a) Miles and Huberman (1994), An Expanded Sourcebook: Qualitative Data 
Analysis, and (b) Creswell (2008), Educational Research: Planning, Conducting, and Evaluating Quantitative and Qualitative Research (Third Edition). In both sources, the first step of data analysis was to read through the data sources at least three times. Employing the narrative inquiry steps listed above, I was able to read each participant's narrative and PAEMST document five times. The identification of research themes was aided by the chronological format I elected to use in the writing of each narrative. The format allowed me to easily compare the narratives to each other. I also used the following three research questions to guide me in coding investigation.

1. What are the paths SBC secondary mathematics teachers who received the PAEMST pursued to become highly effective?

2. What obstacles and challenges did they encounter and how were these obstacles met?

3. What sustained them on their journeys?

For example, when considering the research question one, I observed that each participant had traveled a similar path in their development and use of SBC pedagogy in their teaching. Each participant began their teaching career using a traditional teacherdirected pedagogy and over a period of time they transformed their teaching practice and began to use an SBC teaching methods in their classrooms. From these observations I was able to create the themes, "Teaching, Beginning" and "Teaching, End of Career or Current." Using this observation, I began to explore the data looking for catalysts that promoted each participant's teaching transformation, and I came up with the following themes (a) Influences: Family, Mentors, Teachers/Professors, and Educational Organizations, (b) Education: Precollege, Undergraduate, and Graduate, (c) National Council of Teachers of Mathematics Standards, and (d) Professional Development. 
Continuing my data analysis, I next considered the research question number two, and I noticed that each participant had confronted obstacles in developing and using SBC pedagogy. I created the theme, "Obstacles" to address my observation. Finally, in considering the research question number three, I noticed that participants had created ways of overcoming the obstacles that were encountered by using two sources: their personality characteristics and the influence of their students. These two sources became themes: (a) Personality Characteristics, and Students' Influence.

Based on my readings of Miles and Huberman (1994), I decided to arrange my data in a matrix. I agreed with Miles and Huberman that exhibiting data in a matrix allowed me to concentrate on my research question and to analyze the data for information that addresses the questions and ignore information that is not relevant to the questions. The matrix I created, allowed me to focus and organize my information coherently. I created matrix using the five participants' names as the labels of the matrix' rows and the themes as labels of the matrix' columns. Once the structure of the matrix had been created, I went through each participant's written narrative looking for data that supported each theme. Appendix E is the Data Gathering Matrix that represents the final outcome of my data analysis. In chapter 5 of this paper, I created possible recommendations that the supported by this research data.

Description of data gathering matrix. The Data Gathering Matrix was designed using information from Miles and Huberman (1994) book, An Expanded Sourcebook: Qualitative Data Analysis ( $2^{\text {nd }}$ Ed.). The matrix was set-up with the rows of the matrix representing the research participants and the columns of the matrix representing the 
identified themes. Data from each participant's narrative that pertained to a particular theme was placed in the position box that represented that participant and theme. For example, when researching Meredith's narrative for data that addressed the theme of Influence-Family the following was written in the matrix box that represented, Meredith, Influence-Family, "Father ingrained the idea that 'a problem was an opportunity"' (see Appendix E). I gathered data for each participant that was pertinent to each of the studies' identified themes.

\section{Rewriting Narratives and Data Comparison}

In narrative research, the researcher completes two writings; there is a personal narrative of the participant, and the jointly shared and constructed research narrative. In this study, the first narrative is the narrative of the participants' efforts to develop and apply SBC paradigm in their high school mathematics classrooms, written in their own words as it appeared in their PAEMST personal statement. The participant's voice dominates in this narrative, while in the constructive research narrative, the researcher's voice is central. The researcher, collaborating with the participant, writes the second narrative addressing the study's research. The rewriting of the participant narrative allows for the elaboration of both narratives.

Following the narrative inquiry methodology steps described earlier in this paper, each participant's narrative will be rewritten, emphasizing the themes developed in the coding process. While writing the narrative of each participant's development and use of an SBC pedagogy in their mathematics classroom, I was able to observe similarities and differences between the participants' narratives. 


\section{Ethical Issues: Confidentiality, Authenticity, and Reliability}

As noted earlier in this paper, the qualitative research methodology of narrative inquiry in this research study entailed examining participants' narratives as they relate to a phenomenon of developing and using SBC teaching in a mathematics high school classroom. While telling their narratives, participants were asked to disclose details of their life experiences concerning this transformation. During this narrative inquiry, research study, a great degree of mutual trust was created between me and the participants through collaboration during the initial one-to-one interviews, and the follow-up phone or Face Time sessions. From these collaborations ethical issues did not arise. These ethical entanglements were avoided because during the process, I continue to insist the narratives represent the participant's story. My job in the research was to represent their educational experience in terms of using and developing SBC teaching as accurately as possible. To do so, I constantly assured the participants that this was their story, and they had the right to add or delete anything in their narrative that was not accurate or valid to their experiences. By doing so, I followed Creswell's recommendations for ethical research: (a) "the rights of participants, (b) honoring the research sites that [the researcher] visits, and (c) reporting research fully and honestly" (Creswell, 2008, p. 11).

\section{Authenticity}

Attending to the authenticity of the reported findings or this study, then I rewrote the participants' narratives using the noted commonplaces of temporality, sociality, and place. Besides giving the written narrative a framework, using these commonplaces 
allows the reader to connect with the narrative by employing familiar terms (e.g., classroom), thus supplying 'authenticity' to the narratives.

Rights of the participants. Although this research presented minimal risk to the participants, utmost care will be taken to protect their rights. The study involved the examination of the participants' development and use of SBC teaching paradigm in their high school mathematics classroom. Data for the study will be gathered from three sources: (a) one-on-one, face-to-face, open-ended interviews, (b) participants' written responses in their Narrative Prompt or Evidence of Learning section of their PAEMST application, and (c) participants' demographic information. The data gathered is confidential; only myself, my adviser, Dr. Ron Narode, and the participants will view it. The study's final report, pseudonyms were used for each participant, their school, school district, and state. The identity of each participant was kept private; only myself, my adviser and Dr. Ron Narode know the identity of the research study's participants. The data that was gathered and hard copies of any correspondence between me and the applicants during the research study will be kept for three years after the publication of my dissertation in a locked cabinet. At the end of this time period, all information and collected data will be destroyed.

Honoring the research sites. As noted earlier in this paper, I the site for the oneon-one, opened-ended interview was determined by the participant in collaboration with me. During the discussion of a possible interview site, I stressed to the participants that their confidentiality and comfort was of the utmost importance to me, and that choosing a place where both of these concerns are addressed ensured that the interview will be both 
relaxed and secured. Prior to the interview, I informed the participants that I would be taping the interview with two devices, a digital recorder and digital note pen, and that I had tested both these devices prior to the interview.

Reporting research fully and honestly. Narrative Inquiry, as noted earlier in this paper, involves collaboration between the researcher and the study's participants. In this study, I wrote a narrative based on the data gathered from the participants' Narrative Prompt or Evidence of Learning section of their PAEMST application and notes and recordings from a one-on-one, open-ended interview. This narrative was submitted to the participants for editing and additions. Participants were asked to submit, if they care to, a reflective paper responding to the initial narrative. Collaboration is regarding these edits, additions, and reflections occurred during a telephone call or a Face Time session between the participant and me. Using the acquired new information, I rewrote a more valid narrative, integrating the participant's edits and additions. The participant's written reflection will be included in the dissertation. This approach to narrative inquiry methodology assured that the research is both a full and honest appraisal of the participants' development and use and develop an SBC teaching pedagogy in their high school mathematics classroom. 
CHAPTER 4

\section{RESEARCH RESULTS}

\section{Introduction}

In this chapter, the participants' narratives will be presented along with research findings. According to Creswell (2008), teachers live storied lives and it is important to provide personal accounts about their classrooms, their schools, the educational issues they face, and the settings in which they have worked. The narratives in this research were created using the seven step narrative inquiry process outlined in chapter 3 , and they represent the participants' life experiences in terms of becoming noted, highly effective mathematics teachers who employed an SBC pedagogy in their classroom. The narratives also represent the primary outcome of the narrative inquiry, research process, and as a researcher, I felt it was important to honor these narratives by incorporating them in chapter 4. Additionally, their inclusion gives the reader a basis for understanding the themes that emerged during the data analysis process described in chapter 3.

A description of the data analysis process was included in chapter 3 . The following three research questions were used as guidelines:

1. What are the paths SBC secondary mathematics teachers who received the PAEMST pursued to become highly effective?

2. What obstacles and challenges did they encounter and how were these obstacles overcome?

3. What sustained them on their journeys? 
From the narrative, themes were derived, which are discussed in this chapter. The chapter follows the following outline: (a) the five individuals' narratives, (b) themes and patterns that emerged, and (c) a conclusion addressing the three research questions.

\section{Five Narratives, Meredith}

\section{Meredith's Narrative: Mentorship}

Grant (1998) wrote that the majority of educators view the first year of teaching as especially challenging, and asserted that they have turned to mentorship. Research has produced mixed results regarding the effectiveness of mentorship. For example, the National Center for Research on Teaching and Learning (1992) at Michigan State University found that the benefits of mentorship for newly-hired teachers were a "myth" (p. 4). On the other hand, Feiman-Nemser (1992) provided several case studies revealing positive effects of mentorship. She contended that mentorship is highly effective, particularly if the mentor teacher encourages the beginning teacher to take advantage of the available professional learning community, including university classes, conferences, and in-school collaborative groups. In Meredith's case, a mentor encouraged her to become involved with local, state, and national mathematics education associations. Her mentor's advice had a significant positive impact on Meredith's teaching career.

\section{Meredith's Narrative: Family Influences}

Meredith was born and raised in a community in a high desert region of the Western United States. She was the fourth child of eight. When asked what influence her family had on her choice of profession, she spoke of her father being a teacher for three years before becoming a physical therapist. However, he did not promote the teaching 
profession to Meredith. Meredith did recall that her father had a direct influence on her teaching. He tended to view any problem as an opportunity, and this belief shaped Meredith efforts in dealing with discipline of her students during her teaching career. She viewed problems with students as opportunities to relate to them. There were other experiences throughout her childhood that possibly "planted the seed" for a teaching career. For example, Meredith recalled teaching her four younger siblings the song "Jingle Bells" prior to Christmas on the stair steps in her home. She also remembered helping her mother teach students at a local Catholic elementary school, and later, students in middle and high school.

\section{Meredith's Narrative: Precollege Education}

Meredith performed well throughout her precollege education, receiving A grades in all of her mathematics classes during her junior and senior years. She singled out both a junior high and a senior high teacher who encouraged her in mathematics by providing “extra credit and enrichment projects." Nevertheless, in her precollege education, all her math teachers, including the two mentioned above, used a teacher-directed pedagogy. Meredith said that she came out of her precollege education with a view that she was "good at math," but immediately clarified that this meant she was good at replicating mathematical "procedures."

\section{Meredith's Narrative: University Undergraduate Mathematics Education}

When Meredith entered college in the late 1970s, her career goal was to become a social worker. She felt that she would be good at this because she enjoyed working with people. However, she was counseled to stay away from social service fields because they 
were not "good fields to get jobs." Her college advisor asked if there were other fields that had she had considered. She replied, "I am good at math." At that point, Meredith embarked on a career in mathematics education. Initially, Meredith experienced little difficulty in the pursuit of her career goal. Her personal methods of learning mathematics were adequate for earning A grades in her first year of college calculus courses. However, her grades fell in the ensuing years of her undergraduate studies, when Meredith began to struggle with higher-level mathematics classes. Her learning style of reproducing procedures offered little help with developing an understanding of the subjects covered in these "abstract mathematics" courses.

Meredith found her undergraduate education classes and mathematics methods classes both discouraging and of little use. Her student teaching experience in middle school was also neither illuminating nor helpful. According to Meredith, she would "sit in the back of the classroom watching [her cooperating] teacher sitting next to an overhead projector going over the math, while the students made remarks and paid little attention to him." The experience might have been detrimental if not for a mathematics teacher named John who was teaching next door. He took her under his wing and helped her with her student teaching experience.

\section{Meredith's Narrative: Influential Mentor Teacher and Upward Bound Experience}

John would eventually become an influential lifelong mentor and advocate for Meredith, and in 1983 he helped her secure a mathematics teaching position in the same middle school where she had done her student teaching. Around this time, Meredith 
accepted a separate summer teaching position that would have a profound impact on her future teaching.

In the summer of 1983, prior to starting at her new teaching position, Meredith experienced a life-changing episode when she was hired to teach mathematics to Upward Bound students. Upward Bound is a program funded by the United States Department of Education designed to improve first generation immigrant students' academic and study skills in high school. The program's instructors strive to develop their students' educational and career plans, and to help students access and succeed in higher education (“Upward Bound Program,” 2012). The program Meredith became involved in included many nonnative speakers who were transported to the local rural community from a nearby urban area, and with whom Meredith lived in a local college dorm. Instead of viewing this situation as discouraging, Meredith found it a "fabulous learning experience." She felt that this teaching experience taught her how to manage a classroom populated by students with diverse abilities, and to attend to each student's individual mathematical needs. She truly enjoyed this experience, and was looking forward to starting her "real" teaching the following school year.

\section{Meredith's Narrative: First Teaching Experience}

In the fall of 1983, Meredith began teaching mathematics in a middle school in a rural community located near a large urban area. Meredith's remembrances of her first year involved "teaching straight from the textbook." For her, teaching entailed lecturing and demonstrating the algorithmic "processes" of adding, subtracting, multiplying, and dividing fractions and decimals. Meredith used this teacher-directed practice her entire 
first year of teaching. If it was not for her mentor, John, helping, she felt that she would have continued using this teaching method.

\section{Meredith's Narrative: Eye-Opening Experiences and Professional Development}

In the fall of 1984, John convinced her to attend a regional mathematics

conference sponsored by the state mathematics teacher association. At the conference, Meredith attended workshops and presentations that "opened [her] eyes" to different methods and materials for teaching mathematics, including the use of hands-on manipulatives and visual models. Meredith felt that attending this conference "changed her life," and she began seeking out further materials similar to those she had seen during the conference. During the following years with John's help, she began to develop and implement a teaching pedagogy that enhanced her students' understanding of the mathematics covered in the classroom. She developed a highly collaborative relationship with John, who had created a pre-algebra curriculum that she used. The emphasis in the pre-algebra class was on developing estimation skills along with procedural knowledge of pre-algebra topics. Meredith was appreciative of both the pre-algebra curriculum and the opportunity to collaborate.

The following year, she made further progress toward her goal of facilitating students' mathematical understanding when she and John attended a 2-week workshop sponsored by the NSF and a local university. The workshop included an introduction to an NSF-funded middle school curriculum titled Visual Mathematics. The instructional staff included the local authors of the program, mathematics professors from two of the state's largest public universities, and nationally recognized authors such as Al Bennett 
from the University of Vermont (Fraction Bars and Decimal Squares) and Glenda Lappen from Michigan State University (Connected Mathematics Project). Meredith participated in activities from several NSF-funded curricula that emphasized the development of a deep understanding of arithmetic and mathematics using visual and hands-on models. She felt that she increased her understanding of the ways individuals construct meanings for mathematical procedures and concepts. She was persuaded to use the Visual Mathematics curriculum the following year in her classes, and both Meredith and John taught Pre-algebra classes incorporating the Visual Mathematics curriculum. The newly-designed curriculum emphasizes the development of students' understanding of mathematical concepts and procedures, as well as their estimation/number sense.

Meredith continued engaging in professional development during the ensuing years, seeking out courses, workshops, and conferences that covered teaching methods promoting a deep understanding of mathematics. In particular, Meredith noted a course offered for middle school teachers called Calculus for Middle School Teachers that was extremely influential, both to her understanding of the mathematics of calculus and to her developing a teaching pedagogy based on problem-solving and sense making. It was in these conferences, workshops, and classes that Meredith increasingly encountered the use of technology, including computers and graphing calculators, for teaching mathematics in the classroom. These professional development opportunities captivated Meredith because she felt that such technologies could enable students to make sense of mathematics. However, these gatherings also "made her cry" because, although she desperately wanted to have the use of technology in her classroom, her school did not 
have the money to purchase such devices. She had used some graphing calculators at her school, but she felt more calculators and computers would augment her students' ability to make sense of mathematics.

During this period in her life, Meredith went back to college to pursue her master's degree in Secondary Mathematics Education, and one of the courses she enrolled in was Topology. There she met a professor who fortified her recently-adopted beliefs about learning and teaching mathematics. Meredith was drawn to the professor and the class because of the teaching methods he employed to demonstrate the topological concepts. The professor's explanations incorporated coherent drawings and visual models, which were revolutionary to Meredith in her study of advanced mathematics. Meredith referred to this professor as "my hero," and explained that his ability to explain "difficult concepts in a way that made them understandable to me" was the key to his effectiveness. She totally "got it!" Meredith was so encouraged by her newly developed understanding of topology that she elected to create a middle school topology curriculum unit as her master's project, for which the Topology professor advised her.

\section{Meredith's Narrative: Move to a New School With John's Help}

In 1990, Meredith was hired, with John's help, as a mathematics teacher at a middle school in an affluent community located 20 miles south of her home state's largest city. There she was able to continue using graphing calculators, and began using computers in her classroom. This pleased Meredith because she felt that her growth in mathematics teaching was promoted by her increased access to technology. 
At the new school, Meredith started using the department's adopted text, the NSF's Chicago Math. The curriculum was based on both standards-based and traditional mathematics concepts, and Meredith ended up supplementing it with materials she had used at her prior middle school. The following year, Meredith piloted an NSF middle school curriculum called the Connected Math Project in her classroom. This curriculum was so well developed, Meredith felt no need to supplement it, and instructed straight from the textbook. By this point in time, Meredith was feeling very comfortable with her methods for teaching problem-solving. John thought that she was a highly successful teacher and nominated her for the PAEMST in 1992. She was one of three state finalists for the award, but another "deserving" teacher ended up representing the state in Washington, DC. Meredith believed that she was an effective teacher in her current position, but other considerations led her to apply for a teaching position in a different state.

\section{Meredith's Narrative: Independence and New School}

In the summer of 1993, Meredith decided to move to the northern section of a southwestern state to teach at a small town's high school. Meredith was close to her family, but felt it was time to move away from her home state and achieve some independence. John supported her desire and recommended her to the high school's principal, a friend of his. However, upon arriving at the town and beginning her teaching, Meredith encountered an unforeseen dilemma.

On the first day Meredith entered the high school, she found out the mathematics program was using a highly traditionalist series of textbooks called Saxon Math. This 
series of textbooks is based on continuous review of previously covered mathematical skills and procedures. Every problem is solved using a prescribed skill that generates one answer. Meredith elected not to use the Algebra I or Geometry textbooks from the series. Instead, as she had done before, she created her own curriculum for each course based on problem-solving that developed her students' comprehension of mathematics. However, at the Algebra II level, she was forced to use the Saxon Math textbook because her previous teaching experiences had not involved subjects above Geometry, and she felt that she was not adequately prepared to write her own substitute curriculum. Meredith did use graphing calculators in these courses to help her students "see" the mathematics. After three years at the high school, she elected to move to the district's middle school, where she taught for four years. Then, after seven years of teaching in the rural community, Meredith elected to return to her home state to continue her teaching career.

\section{Meredith's Narrative: Return to the Home State}

Meredith's mother made her aware of a mathematics teaching job opening in the town where she lived, which was located in the central part of Meredith's home state. Meredith applied for and received the position, and, in 2000, she began teaching in the town's middle school. When Meredith started, she discovered that the school mathematics curriculum was a "hodgepodge"; each teacher was using his or her own choice of textbooks. Meredith believed that this "jumbled" curricula was a direct result of the recent history of principal turnover. The school had had four principals in five years, and none of the departments' curricula were coordinated because of this administrative inconsistency. 
The following year, the district adopted the NSF-funded curriculum called Core Plus at the Algebra level, and chose traditional textbooks for the remainder of the middle school mathematics classes. Meredith was not as excited by the Core Plus curriculum as she had been by the Connected Math curriculum. However, she felt that it emphasized the use of student-oriented teaching pedagogy, and that it was far superior to Saxon Math, the other series the department had considered. Initially, Meredith believed the choice of the Core Plus curriculum had produced a positive, collaborative relationship between her department members, prompting them to attend conferences and workshops emphasizing SBC teaching pedagogy together. The Core Plus curriculum came with some training in its application. However, once the training was completed, Meredith discovered that many of the teachers went back to their classroom and taught the Core Plus curriculum using teacher-directed methods.

The following summer, Meredith and a department colleague, Blake, taught a summer course together. Meredith taught the course using the reformist teaching methods that she had developed over the course of her career. Watching her teach, Blake was impressed with these methods, and he confessed to Meredith that he wanted to teach using a student-centered pedagogy. Unfortunately, Blake and Meredith did not collaborate any further, and Blake went back to his classroom, where he continued teaching directly from the textbook. He returned to a teacher-directed pedagogy because he was afraid that he would not cover the entire required curriculum, and he felt that he was not confident enough with student-oriented teaching pedagogy. 
Blake's return to teacher-directed pedagogy frustrated Meredith. She wanted other teachers to use a pedagogy that stressed problem-solving and sense making, allowing students to construct significant understanding of mathematics. During the remaining three years that she taught at this middle school, the administration hired a number of young teachers who taught exclusively using a teacher-directed pedagogy. These teachers exemplified the administration's emphasis on "research-based teaching," which equated student learning with their scores on state tests. In other words, good state scores equaled student learning, which in turn indicated good teaching. Even though her teaching methods and philosophy were ignored by both her department members and the administration, Meredith was honored by both the State Department of Education and the NSF. She became a recipient of the national PAEMST in 2004, and was the state's Mathematics Teacher of the Year.

\section{Meredith's Narrative: PAEMST and Politics}

Initially, Meredith did not want to reapply for the PAEMST. She had applied in 1992 and had been a state finalist. Again in 2004, she was nominated by her mentor, John, who by then was himself a recipient of the award. Even though the nomination flattered her, she was also apprehensive due to her fear of being on video, one of the components of the application. Nonetheless, she applied for the award out of respect for her mentor. The project she used for the application was based on inequalities. Students created pictures and graphs using a software application called Blue Globs. Through problem-solving and collaboration, her students constructed algebraic inequalities from these pictures and graphs. Meredith won the PAEMST and had a "blast" with the 
experience. The award came with money, a portion of which Meredith used to further mathematics education in the school through professional development of the mathematics department staff. Such offerings made Meredith feel that winning the PAEMST had positive consequences. However, Meredith believed there were negative consequences resulting from the award as well, namely that there was "negativity" at the national level in mathematics education in 2003. She believed that the federal government and many state governments were emphasizing students' procedural and skill acquisition rather than developing their problem-solving and reasoning skills.

At this point in her life, Meredith believed she had accomplished all that she felt was possible in her current position. She wanted to be closer to family and friends, and in 2004 she accepted a mathematics teaching position at a small high school in a coastal community located in her home state.

\section{Meredith's Narrative: Small High School Experience}

When Meredith changed schools, she became part of a two-person mathematics department. With her experience emphasizing the student construction of mathematical understanding, she believed she could influence the curriculum. She came to the job excited about starting a new position teaching at the high school level, and ready for more positive experiences. However, her first year experiences were dramatically different from what she expected as her department partner, Samuel, made this year a difficult one.

Samuel had taught in the community for some years and was well-established.

His teaching methods were strictly teacher-directed. His students considered mathematics the accumulation of isolated mathematical skills and procedures. For these students, a 
mathematics class was composed of a lecture and textbook work. When they entered Meredith's classroom, they encountered teaching that required them to develop comprehension of the mathematics they were studying. Meredith expected her students to write and talk about their thinking about mathematical problems. Furthermore, Meredith had her students collaborate on challenging mathematical tasks, rather than work independently on a series of textbook problems. For the first six months, Meredith's students rebelled against her teaching methods. During this time of change, Samuel actively criticized Meredith and her teaching techniques to her students, to the school's administration, and to the community. Parents of Meredith's students, accustomed to mathematics instruction being comprised of lectures and work on problems from textbooks, came to her to complain that their children were not receiving a good mathematics education. When asked how she went about dealing with this situation, Meredith answered, "I persisted in sticking to my expectations for my students."

Eventually, her students began to embrace Meredith's teaching techniques. They began to actively participate in the classroom, and, in due time, learned a new definition of mathematical rigor, one based on problem-solving and sense-making that created deep understanding. The following year, the uncomfortable situation with Samuel changed when he took a teaching position in another state and was replaced by another teacher, Bill. To Meredith's relief, Bill was very amenable to and respectful of Meredith's mathematical pedagogy, even though he believed in traditional mathematics teaching. For the remainder of Meredith's time at the high school, she and Bill had a good working relationship. 


\section{Meredith's Narrative: Current Community College Teaching}

In 2014, after 9 years of teaching high school in the coastal community, Meredith sought out a different teaching experience. She applied for and secured a mathematics teaching position at a local community college. In taking the position, Meredith felt that she could bring her problem-solving and sense-making approach to teaching to the different courses offered by the community college. She immediately began to employ teaching strategies that let her students develop an understanding of mathematics. To that end, Meredith frequently supplemented the school's official textbooks with nontraditional resources, such as the Lane County Math Project. Meredith emphasized the "big idea" concepts, such as proportionality, that run throughout mathematics. Ultimately, she continues to believe that this teaching approach has been successful. Starting in 2014-2015 school year, her mathematics department will adopt the mathematics curriculum of the state's largest community college. Meredith is excited about the curriculum because it is based on problem-solving, but she is concerned because with every new curriculum there are "unknowns involved." In this author's estimation, Meredith is an acknowledged, successful teacher, and she acquired instructional knowledge and methods that will help her succeed in this new adventure in her teaching career.

\section{Meredith's Narrative: Final Thoughts About Her Growth as a Teacher}

When asked, "What would your students from the first years you taught say about you and your teaching?" Meredith answered that she started teaching the same way she was taught, using lectures and demonstrations of mathematical procedures and skills. She 
deemed herself "boring and skill-based" at that point in time. Nonetheless, Meredith believed her students would say she cared about them and their learning of mathematics. She said that her caring for the students' mathematical education came through in many of the class projects, such as geometry "line designs" and "mosaics."

As noted earlier in this narrative, Meredith felt that she developed her studentcentered teaching pedagogy early in her teaching career with help from a highly regarded mentor and through taking advantage of professional development opportunities. Now, Meredith thinks that her students would say she has high expectations for them, particularly regarding their ability to construct an understanding of mathematics. According to Meredith, these same students would also add that she continuously helped them fulfill these expectations. They would state that Meredith used many different methods of teaching, such as employing visual and physical models, to help them construct mathematical understanding. Finally, her current students would say that Meredith continuously emphasized problem-solving and sense-making. According to Meredith, her faith in her students' ability to learn mathematics is essential to her teaching.

\section{Five Narratives, Mitch}

\section{Mitch's Narrative: Introduction}

In a meta-analysis and systematic review of existing literature on the impact of computer technology on mathematics education, Li and Ma (2010) found that the use of computer instruction coupled with constructivist teaching enhanced student learning more so than the direct teaching of mathematics. Similarly, Mitch contended that his use 
of technology coupled with the constructivist teaching methods he employed throughout the majority of his career created a positive learning environment for his students. In such a milieu, he felt his students were able to create an excellent grasp of mathematics. When thinking about this perceived positive impact on his students' learning, Mitch considers his choice to go into education a good one. Initially, his decision to go into education was based on chance more than on choice.

\section{Mitch's Narrative: Precollege Education}

Mitch grew up in a town in an upper Midwestern state. His mother was a housewife whose contribution to his education was typing his papers while he was in high school. Mitch depicted his father as an "engineer" who was highly influential in developing Mitch's fascination with technology. Mitch also described his dad as "very technical" and exceedingly interested in "newly developed technology." He purchased a Radio Shack TRS-80 computer when it first came on the market, and Mitch remembers learning computer programming on it. Mitch also recalls his dad purchasing one of the first programmable calculators, in which Mitch programmed the quadratic equation; he then used the program to solve quadratic equations in his high school Algebra classes. These experiences created Mitch's lifelong fascination with the power of technology for learning.

Mitch's love of and involvement with mathematics found its impetus in an incident in sixth grade. Prior to sixth grade, Mitch's memories of school and mathematics were not encouraging; he did not feel that he was good at math based on his performance on the multiplication tables. Mitch was not fast at recalling his "times table" and, because 
of this, was placed in the lowest math group. In the sixth grade, Mitch's attitude about his abilities in mathematics changed dramatically when his teacher "put his paper on the board with a gold star on it." From that point on in his schooling, he endeavored to earn the highest grade in each one of his mathematics classes throughout his precollege education. He remembered being "thrilled" and further motivated with each highest grade he received in his high school classes, and he particularly noted the "A+" grades he received in Algebra II. Even though he received high grades, Mitch recalled that he was receiving these grades because he was good at imitating his teachers' procedures and skills on his homework and assessments; he later learned that his precollege mathematics education did not provide him with the mathematical understanding he needed in college.

\section{Mitch's Narrative: College and Two Significant "Nos"}

In the fall of 1987, Mitch started attending a large public university located in his home state. He chose this university because a good friend of his was enrolled there, and he suspected that a large university would offer him more programs of study for his initial chosen majors of mathematics and science. For his first semester, Mitch enrolled in calculus, French, and chemistry, and, although he believed he was strong in science, chemistry class "blew [me] out the water!" Nonetheless, Mitch enjoyed his calculus class and continued with the next class in the sequence. He dropped chemistry and substituted a physics class, which he found "enjoyable because it involved numbers." However, even though he preferred the physics course to his chemistry course, Mitch found his mathematics courses easier, and he began to look at careers that involved mathematics rather than science. His research led him to consider becoming an actuary. The university 
had an actuarial program of study, and the program offered internships, which Mitch applied for. Prior to the interview for the actuary internship, Mitch had made a decision: If he did not receive the internship, he would go into the university's mathematics education program. Mitch did not receive the internship, so he changed his major to mathematics education. It was the first of two nos that proved to be profound in his life. By choosing this course of action, Mitch believed he was heeding a "deeper calling, one that left a 'footprint' that he was around." Having made his decision to enter the mathematics education program, Mitch would encounter a class that changed his teaching career, as well as a second profound no.

Before entering into the university Mathematics Education degree program, Mitch described his mathematical learning as "mimic the math." His teachers and professors would tell him what they wanted him to do and he would mimic their actions. In hindsight, Mitch sensed that he was not developing true mathematical understanding, but rather just going through the motions throughout his college mathematics classes. Additionally, Mitch felt that the college style led to him to put off studying and engage in last minute cramming before class examinations. He felt that he had turned into a "poor student." In 1989, during his junior year, his habits dramatically changed when he enrolled in a mathematics teaching methods class and came under the influence of an “amazing" professor. That same year, the NCTM had issued its influential publication Curriculum and Evaluation Standards. This publication, frequently referred to as "NCTM standards," advocated the teaching of mathematics using problem-solving and sense-making rather than focusing on a procedure and skill acquisition. Mitch's professor 
taught the entire course using the approach advocated by the NCTM publication. In fact, this same professor strongly urged the entire class to join both the state mathematical teachers association and the NCTM. Mitch did, and between joining both organizations and studying the NCTM standards, he began to change his thinking about the learning of mathematics. From that point on, Mitch embarked on a mathematical journey away from relying on learning mathematics as a set of procedures and skill acquisitions toward constructing a deep understanding of the mathematical concepts underlying these procedures and skills. His personal learning transformation progressed throughout his student teaching experience, where he encountered the second important no of his teaching life.

Mitch did his student teaching at a small high school with a student population of 200 that did not normally sponsor student teachers from his university. The high school was located near his family home, and far away from the university. This allowed Mitch to live at home while he was student teaching, and teach students not used to having a student teacher every year. However, this student teaching experience nearly did not happen. Prior to signing up for student teaching, Mitch discovered and applied for a teacher internship that would have put him in a paid teaching position without participating in a student teaching program. Initially, Mitch thought this would hasten his introduction to the teaching field, and instead of paying the university for the chance to student teach, he would be paid for learning to teach. However, a friend received the internship and Mitch was "stuck" with student teaching. Looking back, Mitch felt that the internship rejection turned out to be a positive event in his life. Instead of walking into a 
classroom with no supervision and beginning to teach, Mitch was placed with a master teacher as a supervisor. Because of this teacher, Mitch was made to reflect on each unit he taught prior to teaching it. He had to consider the mathematics of the unit, how he was going to teach the unit, and the type of assessments he was going to use to access student learning. The reflection involved in addressing these considerations forced Mitch to contemplate his students' thinking and their possible mathematical shortcomings. He began considering the students' needs in his planning, and this was one of his first steps in becoming a constructivist mathematics teacher. The cooperating teacher also exposed Mitch to great questioning techniques for eliciting student mathematical thinking and demonstrated to Mitch the use of technology (TI-82 and TI-85 graphing calculators) for helping students understand mathematical concepts in a classroom setting. Both of these teaching methods played a significant role in Mitch's future teaching. On the other hand, the friend who received the teaching internship had a miserable experience and eventually quit teaching. Again, a "no" turned out to be a positive for Mitch, and his student teaching experience allowed him to augment his newly developed perspective on teaching. Though he now felt he was ready for a full time teaching position, the jobs proved difficult to find. Ultimately, Mitch secured a mathematics teaching position at a small high school with a student population of 200 in his home state.

\section{Mitch's Narrative: First Teaching Experience}

In 1991, Mitch was hired to teach mathematics in a small community in his home state. Historically, this school was the first school in the state where the teachers had gone "on strike." Eventually, the strike was resolved and teachers returned to their jobs, 
but the event had two lasting consequences. The state legislature eventually legalized collective bargaining for public employees, and ill feelings for teachers and the schools were fostered in the local community.

Mitch's 1-year tenure at the school included teaching Algebra I and II and Geometry. During the year, Mitch reached out to both younger Physics and English teachers for help in developing his classroom environment. His reaching out to professionals for help would come to be a major source of professional growth for Mitch in his career. However, in this particular job, he was unable to befriend a mentor in the mathematics field. That would come later when, at the end of his first year of teaching, he accepted a teaching job in a larger high school located in his home state near his family.

\section{Mitch's Narrative: Second Teaching Experience and Professional Development}

The high school where Mitch began teaching in 1992 had a student population of 400. He was hired to teach Geometry and Consumer Math, and eventually to take over the Pre-Calculus class and develop a Calculus course, when the current Pre-Calculus teacher retired the following spring. During his first year of teaching, Mitch began taking his Geometry classes to the school's computer lab to work on their geometry class work and homework using the software Geometry Sketchpad. Mitch supplemented this software with material from an unpublished textbook, Michael Serra's Discovery Geometry, to allow students to construct their own definitions of geometry terms and concepts. The following year, Mitch took over the Pre-Calculus course and started the school's first Calculus course. After taking over these higher level classes, Mitch was "up every night until midnight or 1:00 a.m." preparing for the classes. Mitch realized that his 
college Calculus classes had not prepared him to teach the course; his "mimic math" learning style had not provided him the deep understanding of calculus required to teach the subject in a way that allowed his students to develop an understanding of the subject material. Mitch described his teaching methods during his first years at the school as "telling my students to read through the section, and taking copious notes on the demonstrations." Mitch also added that initially he relied on lecturing, though he kept working on his questioning techniques, attempting to ask open-ended questions to "elicit student thinking." Because Mitch believed that he needed to improve his teaching methods and knowledge so he could be a more effective teacher for his students, he began a lifelong pursuit of professional development and mentorship.

During the following summer, he registered in an inspirational class that helped teachers to teach calculus based on the NCTM standards. Influential mathematics teachers and professors from around the United States were brought in to teach. Technology in the form of computer software and graphing calculators was emphasized to help the workshop participants to better understand the skills and concepts of calculus. Following that conference, he attended another week long workshop on the mathematical software Mathematica. From that point on, Mitch continued to attend conferences in his and in neighboring states. Mitch emphasized that his attention to his state mathematics association annual conference was "the most definitive part of [my] career." It was at one of his first conferences that Mitch was befriended by the individual who would become one of his lifelong mentors. Besides encouraging Mitch to become more involved with the association (Mitch was secretary of the association for ten years), this mentor 
persuaded Mitch to present at a conference. From then on, Mitch presented at both state and regional mathematics education conferences, and in each conference, he sought out mentors, individuals who could help him become better at teaching mathematics. Mitch's involvement with the state and national association's conferences played a very influential role in his teaching. However, Mitch reported that his course working in his master's degree had little effect.

\section{Mitch's Narrative: Master's Degree and Influential Summer Course}

During his time at his second teaching job, Mitch enrolled at a Northeastern state's largest university to work on his master's degree during summers. When asked about this experience, Mitch indicated that he went through the degree coursework using "mimic the math," the same learning technique that he had used throughout the majority of his undergraduate education. When asked if all of his master's professors lectured, he said one professor was "a little more constructivist." This professor utilized computers and Geometry Sketchpad to teach the material. Nonetheless, Mitch believes that his other professional development activities were more influential in shaping him as a constructivist mathematics teacher.

Mitch attributes his transformation from a teacher-directed educator to a studentcentered, constructivist teacher to the conferences and workshops he attended and the mentors he accrued over the years. He mentioned classes he took on Geometry Sketchpad and, in particular, a summer course in California with the creator of the software, Nicholas Jackiw, as the instructor. Informed by those experiences, Mitch began to present on the Geometry Sketchpad at the state and NCTM regional conferences for mathematics 
teachers. Mitch reported that his deep-seated commitment to professional development and his dedication to his state and national professional teaching organizations still continue to guide his teaching.

\section{Mitch's Narrative: Political Obstacles at Second School}

In 1998, the environment of Mitch's high school changed. He recalled, “The school principal got upset with [me].” Mitch was certain some parents or students had complained about his teaching, and his principal forced him to write an "improvement plan." The principal wanted to take away his Pre-Calculus course and the tennis team that he coached. At the same time, the district transitioned into block scheduling and switched to the NSF's Core Plus mathematics curriculum. Mitch liked the Core Plus program, but he felt there were too many changes, so he began to seek out teaching positions at different schools. In 2000, he was offered a teaching position at a similarly sized school not far from where he was teaching, and he accepted the position.

\section{Mitch's Narrative: New School and Further Political Obstacles}

When Mitch started this new teaching position, it was understood that he would eventually be teaching Geometry because the woman who taught all the Geometry classes was retiring. His original teaching assignment was Consumer Math and Algebra II. However, the other teacher relinquished one of the Geometry classes so Mitch could grow accustomed to teaching Geometry in the new school setting. Mitch was very proactive and promoted the acquisition of a site license for Geometry Sketchpad software, the same software he had used at his previous school. The school's mathematics department chairman and principal supported Mitch's request and purchased the 
software. Mitch immediately began taking his students to the computer lab and introducing them to the use of technology for creating understanding mathematics. Mitch noticed that the school offered a Calculus course taught by a young teacher, Jack. During the first year at his new high school, Mitch realized Jack was using the course as a place to gather the brightest mathematics students, but he was not challenging these students. Mitch approached Jack in the spring of the year with the idea of making the Calculus course an Advanced Placement (AP) course. Jack refused to consider Mitch's proposition, and Mitch sensed that Jack did not feel comfortable with the rigor and pace of an AP Calculus course. Rebuffed by Jack, Mitch made the decision to approach the school's administration and convince them to allow the mathematics department to offer both an AP Calculus course and "regular" Calculus. According to Mitch, the administration supported his proposal because it would reflect well on the school's curriculum. The following school year, the school's mathematics department offered the two Calculus classes, and the majority of eligible students elected the AP Calculus course, and in the ensuing year, only AP Calculus was offered. Jack did not take this decision well, and over the years vented his displeasure with the course change and with Mitch in "scathing emails" to both the department and Mitch. Furthermore, Jack frequently opposed Mitch's further ideas and proposals for the mathematics department. However, another teacher, bolstered by Mitch's efforts to challenge students, introduced an AP Statistics/Probability course into the department curriculum.

At this same time, Mitch noticed that there was no Pre-Calculus course in the department's curriculum, but instead there was a year-long Trigonometry course taught 
by an older teacher, Bill, who had taken a semester-long course and stretched it into a year-long course. When Mitch approached Bill about offering a Pre-Calculus course in place of his Trigonometry course, Bill said he did not see the need for teaching other PreCalculus subjects that were not involved in Trigonometry. Luckily, this time Mitch did not suffer politically from changing the course offerings, because the following year the older teacher retired, and Mitch offered a Pre-Calculus course instead of the Trigonometry course. In four years, through Mitch's leadership, the school mathematics curriculum became more challenging for its students. However, even with this new emphasis on offering challenging courses, Mitch was still the only mathematics teacher who belonged to either the NCTM or his state's mathematical teaching association. To his consternation, although his commitment to professional development did not waver, it was not shared by his department mates.

\section{Mitch's Narrative: PAEMST Experience and Current Teaching Position}

In 2011, state politics created a situation that prompted Mitch to apply for the PAEMST. Prior to that year, Mitch had been frequently encouraged to apply for the award, but he did not want to go through the application process. However, that was before the state legislature passed and the governor signed a bill repealing the teachers'

collective bargaining rights. At that time, Mitch's wife stayed at home taking care of their two children, and Mitch's salary represented their entire income. Faced with the distinct possibility of earning less money for teaching, he chose to apply after being nominated by an official from the State's Department of Public Instruction. 
The classroom project Mitch created and used for the PAEMST application involved examining the multiplication of complex numbers in rectangular form and comparing the polar coordinates of each factor with the polar coordinates of the solution. Working in groups, students had to develop conjectures for their examinations, then created and tested possible theories. To assist their investigations, Mitch's students had access to computers equipped with the Geometry Sketchpad software. During this activity, Mitch took on the role of a "guide on the side," moving around the room, listening to students' thinking, questioning their work, and encouraging them to defend their ideas. Ultimately, Mitch believed that his students developed a deep mathematical understanding of the multiplication of complex numbers and polar coordinates, as well as other mathematical concepts such as the meaning of $i^{2}$, the use of the of the Pythagorean Theorem, and the trigonometric identities for $\cos (A+B)$ and $\sin (A+B)$. For Mitch, this was a true constructivist lesson.

\section{Mitch's Narrative: Mitch's Thoughts on His Teaching}

When Mitch was asked to speculate about what his students would have said about his first years of teaching and his most recent years of teaching, he made some stark comparisons. Mitch felt that his students during his first years of teaching would say he was not a very effective teacher. They would say, "He rambles on too much." He would go from trying to be a friend to being a "yelling fiend." He taught using teacherdirected methods that depended on lecturing. Mitch went on to compare his earlier years of teaching to his current years. He believed his current students would say that he is passionate about mathematics and about fostering his students' ability to make sense of it. 
Mitch felt his students would say that he had high expectations for them, but that he helped them meet these expectations. He also believed that the students would say that in helping them achieve an understanding of mathematical procedures and concepts, he created situations in his classroom that allowed them to make connections to the mathematics they studied. Mitch also stressed that his students would say they come away from his classroom viewing mathematics "graphically, numerically, and algebraically."

Mitch pointed out that his classroom is dedicated to mathematics. The evidence was displayed all around the classroom, which was decorated with beautiful yet instructive student-drawn paintings of mathematical ideas. The room had a feeling of being a "mathematical home." Mitch described himself as a firm believer that his students love to be engaging in mathematics, and said he works very hard from day one of the new school year when he dresses up in a tuxedo and gives a famous counterintuitive problem referred as the "Monte Hall" problem immediately after the students walk into the room. Mitch said that he uses this approach because he wants his new students to know that when they enter the classroom, they will be engaged in his passion, mathematics. He wears the tux to introduce the aspects of fun and humor in the classroom, two vital ingredients of his classroom environment. This inviting classroom is a direct product of Mitch's passion for both mathematics and for professional development, two attributes that have made Mitch an acknowledged, highly successful teacher.

\section{Five Narratives, Rachael}




\section{Rachael's Narrative: Introduction}

J. A. Thomas and Monroe (2006) conducted a self-study of a teacher changing his pedagogy. The teacher's initial self-described pedagogy was teacher-directed, which he described as, "I talked and I taught" (p. 170). He used this pedagogy because it was the way he was taught mathematics, and because he felt his teaching covered the entirety of the prescribed curricula. His methods began to dramatically change one summer when he enrolled in a brain-based learning workshop as part of his master's in Mathematics Education. In the workshop he encountered classroom activities during which he and his fellow participants were instructed to form collaborative groups that worked on complex learning tasks. He realized that these classroom environments allowed him to develop a deep understanding of the concepts covered in the class. As a dedicated teacher, he will go back to his teaching next fall convinced that he needed to develop a classroom environment for his students similar to those he had experienced in the workshop. Rachael's narrative is similar to the above teacher in that she began her teaching career using the same teaching methods that she had encountered as a student, but after experiencing training that significantly changed her ideas about learning, she shifted toward a teaching pedagogy that allowed students to construct an understanding of mathematics by creating meaningful connections between the course materials and their own lives.

\section{Rachael's Narrative: Childhood Through High School}


Because both of her parents were educators, Rachael grew up with the sense that she was born to be an educator. Her father was a History professor and her mother was an English teacher. Rachael and her seven sisters grew up in the Northwestern United States. She recalled that she loved to play the role of teacher with her five younger sisters and that in elementary school, she would help the teachers collect and pass out student papers. She earned this prestigious honor because she was an excellent reader and student.

She developed both the ability to read and to memorize patterns, and she credited these abilities for her success in school. Nonetheless, looking back upon her Precollege education, Rachael regretted that the majority of her teachers employed teacher-directed instruction. For her, these teachers just "talked and talked and talked, and the students were not allowed to work on assignments until the teacher had finished explaining." In the area of mathematics, Rachael believed that her ability to learn by rote served her well, particularly in the majority of her high school mathematics classes, which emphasized the learning of skills and procedures. In most of her classes, Rachael memorized algorithms for the summative chapter tests. She knew the teachers used the same algorithms on exams, only with different numbers. Rachael just substituted these different numbers into her memorized algorithms, and did well on the tests.

However, Rachael noted that not all of her high school experiences consisted of memorization and lecture. One particular teacher of Honors Geometry and Pre-Calculus was highly demanding. According to Rachael, this instructor insisted that her students come up with the justification or reasoning behind their answers. Rachael also remembered that this same teacher incorporated learning games, such as "Baseball," in 
her teaching, which Rachael found exciting and engaging. Rachael remembered an influential English teacher who used a teaching technique where she would write the beginning paragraph of an essay on the chalkboard and the students were asked to continue the writing. Rachael enjoyed this activity because it allowed her and her classmates to "have an entry point into the writing." Another attribute of this teacher was her meticulous responses to the students' writings. Rachael adopted this trait, and she believes it had served her well in both her professional and personal life. For Rachael, these two high school teachers were a rare breed in that they made their students think beyond simple memorization. However, for the majority of her high school education, her rote learning style was sufficient, allowing her to earn good grades.

\section{Rachael's Narrative: Undergraduate College Experience}

Rachael confessed that she continued to use this rote learning style during her first two years of college with similar results. She mentioned in particular that her memorization abilities facilitated her study of German and Calculus. At the time, she felt she did not need to concentrate on homework; instead she focused on passing tests using her "learning by heart" skills. However, this way of learning began to create trouble for Rachael during her junior year when she took a coursed titled Mathematical Analysis (Advanced Calculus). This course involved the study of the concepts underlying Calculus, and required a deep understanding of these foundational concepts. She realized both that her learning style and her habit of not working outside the classroom were inadequate and hurt her in this course. Rachael recognized that she had major limitations in learning, and from that point she began searching for different methods that would 
help her develop an understanding of the curriculum of the more advanced courses she enrolled in.

During her undergraduate studies, Rachael felt she encountered both poor and good professors, and she believed that both types of professors taught her valuable lessons that would prove useful in her future teaching experiences. She remembered a Physics professor in particular whose teaching style was detrimental to student learning. He verbally demeaned his students, whom he felt were "beneath him.” In her future teaching, Rachael said she would never demean her students, because she remembered how she felt when she suffered at the hands of her college Physics professor. On the other hand, her Statistics and Probability professor was inspirational to Rachael because he came up with thought-provoking tasks that helped her and her classmates connect with the concepts taught in class. This idea of having students work on challenging tasks would later become a guiding principle in Rachael's teaching; she continually looked for problems that both challenged her students and helped them make connections between mathematical concepts and their own lives. Another professor who influenced Rachael taught Chemistry. His enthusiasm for the subject caught her attention, which he conveyed to his students using a variety of methods for presenting the curriculum. Varying her teaching methods also became an operating principle in Rachael's future classrooms.

As mentioned earlier, Rachael realized demeaning remarks are very counterproductive in a classroom since they create an environment where students are frightened. Instead of belittling her students, Rachael adopted questioning techniques that furthered her students' thinking and promoted student engagement. 
Rachael encountered many notable positive, experiences in non-mathematical classes such as Dance or English that she connected with mathematics, and like her Probability/Statistics professor, she worked hard during her career to provide mathematical tasks that enabled student connections between other subjects and mathematics. Rachael considered those connections vital to students' enjoying and learning of mathematics. Motivated by this belief, she has also worked hard to develop a variety of teaching methods over the course of her career to help students build connections between mathematics and other subjects.

\section{Rachael's Narrative: Early Teaching Experiences in the Eastern U.S.}

After graduating from college in 1967, Rachael taught at a junior high school located in the Eastern United States. She found out about this job through a college friend. Rachael interviewed over the phone with the school's administration and received a job offer that she accepted.

Although Rachael entered the school as a new teacher, eager to teach and learn, she was disappointed by this teaching experience. Hoping for collaboration with and "tips" on teaching from her peers, she encountered teachers who during their time off went to the teacher's lounge and played bridge. Instead of finding engaged colleagues, Rachael met teachers who "didn't seem very excited about their teaching," and who seemed "interested in other things." Additionally, Rachael had to cope with an administration that did not back her efforts to discipline her students. According to Rachael, the one time she sent students to the principal's office for discipline "the students came back behaving worse than when they had left my classroom." This forced 
her to learn discipline "on the run," which went against her nature. She was confronted with ethnic and cultural groups whose mores and traditions she was admittedly ignorant of, and this sometimes proved problematic. The political and societal events of the time, such as Robert Kennedy and Martin Luther King's assassinations, compounded Rachael's difficulties adjusting, particularly when she witnessed rioting in response to King's assassination in a large metropolis near the town where she taught. The combination of these factors led her to take a teaching position at a junior high in her home state.

\section{Rachael's Narrative: Early Teaching Experiences in Her Home State}

In 1968, after one year teaching at the junior high in the Eastern U.S., Rachael took a junior high teaching position in her home state, and married her college sweetheart. Rachael's remembrances of that teaching experience included classes of close to 40 students, and a tough student body. She taught two years at the school, and then moved to another school district in the same state to teach a self-contained sixth grade. The school district was located in a city that housed a large state university where her husband had been accepted into a master's program. Rachael also took Education classes at the university as part of the requirement for the provisional teaching certificate that allowed her to teach at the elementary level. Rachael taught one year in this position, after which she and her husband decided to take teaching positions in the Peace Corps.

\section{Rachael's Narrative: Early Teaching Experiences in the Peace Corps}

After her training with the Peace Corps, she and her husband were sent to teach in a North African country. Instead of mathematics, Rachael taught English as a foreign 
language and was assigned to coach track. When Rachael failed Atomic Physics in college and did not receive a Physics minor, she elected to earn a Physical Education minor. Although ultimately she did not coach track in the Peace Corps, Rachael regarded the minor as an advantage later in her teaching career because it helped her to secure teaching positions where she coached the school's pep squads, rally teams, or dance teams.

During her time in the Peace Corps, Rachael was confronted again with the problem that her rote learning style was not adequate for learning new concepts. She struggled while learning to speak French because, even though she could memorize French words and phrases by listening to recordings, she was unable to see the written word as she was going through the memorization process. Consequently, she had difficulty putting them together and conversing with the native population. Her Peace Corps experience ended earlier than was specified in her signed a 2-year agreement because she became pregnant. She moved back to her home state to have her baby in 1972.

\section{Rachael's Narrative: Restarting Teaching}

Rachael took time off from teaching to raise her child. Her husband had acquired a teaching position at a school in the small town where they lived. However, when her husband lost his position after a year, he moved back to her hometown and continued pursuing his master's degree. Rachael and her husband later divorced in 1974, and she began substitute teaching. In 1976, when her son turned four, she went back to full-time teaching and acquired a sixth-grade teaching position in her home town. 
Rachael considered her time teaching sixth-grade a "delightful, rare experience." She felt that the level of collaboration with the teaching faculty and administration was excellent. She was able to trade her Social Studies teaching responsibilities to another sixth grade teacher for that teacher's mathematics teaching responsibility. Drawing on her own experience in college taking an interdisciplinary approach to mathematics, Rachael began to integrate topics outside of traditional mathematics curricula that allowed students to connect mathematics to non-mathematical concepts.

One particular project caught the attention of the local press, which led to public acknowledgement of her students on national television. Rachael had her students create "inventions" that they felt the world needed. A local newspaper reporter found out about the project and wrote a humorous article that appeared in the main section of the newspaper. This caught the attention of the Tonight Show's producers, who scheduled some of her students to appear on the show. Because of Mr. Carson's unavailability due to divorce proceedings, the interview was eventually cancelled. However, the article also "caught the eye" of the producers of Good Morning America, and the host of the show did a live interview with three of Rachael's students.

As enjoyable as this teaching experience was, Rachael still missed teaching mathematics exclusively. In 1985, when a new administrator took over for her school's beloved administrator, she took that opportunity to transfer to a mathematics teaching position at a junior high in the same school district. Rachael taught at the junior high for four years, and during that time served as the department chairman. While at the junior high, Rachael applied for a mathematics teaching opening at a high school in the district. 
She was not offered the job because, she believed, she was viewed as a sixth grade teacher, and, as such, was not properly trained to teach high school students. This bothered Rachael, because she had earned her Bachelor's degree in Advanced Mathematics and she believed that she was very capable of teaching at the high school level.

Between 1989 and 1990, her school district built a new high school, and Rachael applied for a mathematics teaching and dance team coaching position there. This time she received the position, which entailed teaching mathematics courses that ranged from PreAlgebra to Calculus. Rachael confessed that she considered herself ill-prepared to teach Calculus in terms of connecting the curriculum to the world outside of the classroom. Rachael dealt with this perceived shortcoming the same way she always confronted a deficiency in her teaching: she sought professional development.

In this case, the professional development she found was a workshop taught by Deborah Hughes Hallett, a nationally recognized professor who had designed and promoted innovative curriculum and pedagogy for teaching calculus for understanding. In the workshop Rachael learned teaching methods and received curriculum that allowed students to develop connections between calculus concepts and the real world. The technology used in the workshop, in the form of TI-graphing calculators, helped Rachael visualize the concepts of calculus. The calculators played an enormous role for Rachael in creating understanding of calculus concepts, and as a result, she became an advocate for the use of various forms of technology in helping her students to create an understanding of mathematics. 
During this same period of time, Rachael began her master's program at a large university located in a town in the same state. The distance between the university and the town she lived in was too great for her to take night classes, so she took summer courses for three years to complete her master's. She enrolled in the program with help from a grant from the NSF, and she approached each course she registered for with a newfound confidence in her ability to learn. Because of this belief in herself, she thoroughly enjoyed the courses she took in the master's program. While in the program, she became involved in an NSF-funded program called IMPACT, which looked at the integration of mathematics and technology. Rachael regarded the IMPACT experience as having a positive effect on her teaching. In her master's program, she also came into contact with professors who were the head of a new NSF-funded project, an integrated high school mathematics curriculum called the Systemic Initiative for Montana Mathematics and Science, commonly referred to as the SIMMS Project.

\section{Rachael's Narrative: Writing for the SIMMS Project}

Through the professors she met while she was in her master's program, Rachael was recruited as a writer for the SIMMS project in 1992. The goal of this project was to create an integrated, NCTM standards-based mathematics curriculum spanning grades 912. This experience was "life-changing" for Rachael. Her transformation began with the survey she and the rest of the recruits took prior to beginning the project. Previously, Rachael had viewed mathematics as "a series of algorithms, rules, and definitions." After answering the survey questions, Rachael reflected on their implications and came to believe that her definition of mathematics was "too narrow and flawed." She began to 
realize that "teaching mathematics was much more then teaching algorithms; it was more about the idea of what it meant to do mathematics." Working in collaboration with other recruited teachers and professors from several large universities, she came to see that developing student connections to mathematical procedures and concepts was paramount to the process of their acquiring a deep understanding of mathematics. Rachael loved working on the SIMMS project. She found the experience "life-changing" because she was able to collaborate with other committed teachers, learn new material, use new problem methods, and be treated and paid as a professional. Rachael came away from the experience with a new definition of "mathematical rigor," one based on problem-solving and sense-making.

Rachael continued to write for the SIMMS project during the summers of 1994 and 1995. Her work with the project renewed her commitment to taking part in professional development opportunities. She continued attending and presenting at NCTM conferences and became involved with the state mathematics teacher council, which she deemed "very influential" in her teaching career. At her high school, Rachael continued her practice of integrating non-mathematical topics with mathematical concepts, which helped her students develop a "deeper understanding of mathematics." Rachael's challenges with calculus concepts also lessened, and she enjoyed teaching Calculus with her newfound confidence and teaching methods.

During this same period of time, Rachael was nominated for the NSF's PAEMST by her department chairman, and she won the award for her state. The lesson Rachael chose for her application required students to create a cone with maximum volume from 
an 8.5 " by 11 " sheet of paper. The students used various methods to calculate the volume of the cones they designed that ranged from filling them with rice and calculating the weight to using integral calculus. Rachael felt that the project allowed for the integration of topics that encouraged her students' development of mathematical understanding.

Teaching Calculus and winning the PAEMST increased both Rachael's confidence and her appetite for learning more advanced mathematics, and in 1998 she entered a large university in another Western state and began her work on a PhD, initially in mathematics, but later in mathematics education.

\section{Rachael's Narrative: PhD Experience}

In 1998, when Rachael began her studies to obtain a PhD degree in Pure Mathematics from a large public university, she had to confront her old nemesis, Advanced Calculus. She was required to pass a qualifying examination in Advanced Calculus to enter the $\mathrm{PhD}$ program, but failed the examination. Rachael noted that "I took all the courses required for the $\mathrm{PhD}$ degree, and I loved being a student again. I enjoyed every class." Nonetheless, it was her failure to pass the qualifying examination that forced Rachael to change her PhD area of study from Pure Mathematics to Mathematics Education.

Rachael taught mathematics courses such as College Algebra, Calculus for Business and Economics, and Introduction to Mathematical Analysis at the university while she was working on her $\mathrm{PhD}$. The university also utilized her expertise in teaching by assigning her to teach Mathematics for Elementary Teachers. From 1998 to 2001, Rachael worked on her degree and taught for the university, and in 2001 she accepted a 
mathematics teaching position at a high school in a large town close to the university. She did this in hopes of teaching while finishing her PhD degree in the coming years. She achieved her goal of earning her PhD in Mathematics Education in 2006.

\section{Rachael's Narrative: High School Teaching Experience}

In 2001, Rachael stepped into her new high school teaching position feeling enthusiastic and confident about teaching. She had worked at many levels of education. She also had experience working on an NSF-funded high school curriculum with dynamic teachers who were completely involved in redefining mathematical rigor in the classroom. She had just completed three years of teaching college courses and taking courses that motivated her. Rachael was ready to apply her reform mathematics teaching in her classroom, and she was looking forward to collaborating with her new department members.

However, reality was much different from what Rachael expected. The faculty, on the whole, was committed to teaching mathematics using teacher-directed methods that emphasized the learning of isolated facts, skills, and procedures. They believed that there was no need for change, and they viewed her teaching methods with a great deal of skepticism. According to Rachael, some members of the department viewed her classroom as all "fun and games." Rachael also confessed that some of her students had the same reaction to her classes. For these teachers and students, real math was done sitting quietly at a desk, working on a series of problems involving a particular demonstrated mathematic procedure or skill. Even when Rachael arranged for a nationally recognized mathematics educator to speak to her colleagues about a different 
way of viewing mathematical learning based on problem-solving and sense-making, the speaker had little or no effect on the teachers' thinking. Her peers did not want to change, and they did not want to enter into a discussion about "What is mathematics?" Furthermore, some parents also complained about Rachael's teaching methods and her emphasis on problem-solving; they, too, were used to mathematics being defined as the acquisition of mathematical skills and procedures.

When it came time to adopt new mathematics textbooks, the department did not consider any "reformist textbooks." Even when a nationally recognized mathematics educator wrote a letter to the board listing the merits of adopting a "reformist textbook" based on the NCTM standards, several parents criticized the educator, his letter, his beliefs, and the book he recommended. The school board adopted instead a traditional series of mathematics textbooks.

However, even though her initial teaching experiences were not encouraging, Rachael noted that the school district later adopted standards-based learning, which forced the members of her department to change their focus in the classroom from emphasizing procedure and skill acquisition to stressing problem-solving and sensemaking. This new focus prompted teachers to look for mathematical tasks that emphasized the "big ideas" such as modeling inverses and proportionality.

\section{Rachael's Narrative: Retirement and Final Remarks}

Rachael retired from teaching in 2012. She left feeling that she had experienced tremendous growth as a teacher over the years she taught. She commented that "I was motivated by collaborations with both fellow teachers and students over my teaching 
career." Attending conferences, classes, and workshops were instrumental in Rachael's evolution into a "constructivist teacher" during her teaching career, but she confessed that she found the change difficult. However, she persisted in developing "constructivist teaching methods." She drew inspiration from the words of James Rubillo, the retired Executive Director of NCTM, who called for "seeking incremental improvement rather postponed perfection” (Vennebush, 2013).

Rachael's narrative: First years of teaching. When asked to compare her first years of teaching in her last years of teaching, she spoke of the difference in the way she thought about students and how they learned mathematics. During her first years of teaching, she was "oblivious to understanding." Rachael added that she wanted "to see if the students could do the things they needed to get done in her math class."

Rachael's narrative: Last years of teaching. In describing her teaching in the latter part of her career, Rachael spoke of developing mathematically rich tasks that allowed students to problem solve and construct connections that let them make sense of mathematics. She also talked about how, over the years, she had continuously taught with respect for her students, and how each student employs "different ways of learning." The concept of honoring different ways of learning was evident in her classroom. Rachael noted her students' different ways of viewing mathematics by posting their work around the classroom. Besides the articles and posters she had displayed around her classroom, she posted her students' mathematical drawings demonstrating such things as finding the volume of different three-dimensional shapes. Finally, Rachael emphasized that she respected both her students' emotions and intelligence. Her students were instrumental in 
her decisions about what professional development opportunities she sought. For Rachael, her students constituted the "joy of being a teacher and a learner." Rachael's success in teaching was made possible by her lifelong commitment to changing her teaching pedagogy so that it promoted her students' mathematical understanding.

\section{Five Narratives, Damon}

\section{Damon's Narrative: Introduction}

Dolgos (1990) asserted that with the world's ever-increasing use of technology, problem-solving, and critical thinking, the inclusion of both discrete mathematics and statistics/probability in a high school curriculum takes on growing significance. S. P. M. Gordon (1984) claimed that teaching discrete mathematics topics such as counting, graph theory, probability, and logic would stimulate students' interest in mathematics, allowing them to see its many connections to and applications in the world outside the classroom. For Damon, attending a regional NCTM conference and taking several workshops on incorporating discrete mathematics at the high school level dramatically affected his teaching career. From that point on, he began to teach with the goal of developing his students' ability to make connections between school mathematics and the world outside of the classroom. Discrete mathematics and probability/statistics became his tools for accomplishing this goal.

\section{Damon's Narrative: Familial and Precollege Education}

Damon's early life was very unique. He was born and raised in the northern section of a Northeastern state, and was one of the youngest of seven children. His father 
was a Lutheran pastor and his mother was a reading teacher. What made this living situation so distinctive was the fact that all of his brothers and sisters grew up to be educators. Damon commented that "the table conversations were more often than not concerned about education." In a sense, he felt he was raised to be a teacher. Encouragement to become a teacher also showed up early in his formal education. Damon distinctly remembered an exceptional first grade teacher who was so talented he felt that "it would be nice to be a teacher." This teacher's methods sparked Damon's imagination, and from that point on Damon sensed that teaching could possibly be for him a worthy life goal. In high school, he was influenced positively by a Trigonometry teacher and his wife, an English teacher. Damon was impressed with the Trigonometry teacher's knowledge of the material, classroom organization, humor, and the feeling that the teacher really cared for him. The English teacher also had a wonderful caring attitude toward her students coupled with high expectations, which truly made an impact on Damon. One of Damon's siblings also played an important part in his decision to go into mathematics education; his next oldest brother majored in mathematics and went on to teach mathematics. This brother would later serve as a mentor for Damon, helping him through his student teaching experience.

In 1982, prior to his senior year, Damon's family moved to a Midwestern state, where he finished high school. In 1983, Damon enrolled in a private college in the same state. For the first two years he attended the college, he was unsure "what he wanted to do." This uncertainty was resolved in 1985 , when two events put him on a path toward becoming a highly successful mathematics teacher. The first event was registering for a 
College Algebra course taught by a professor whose teaching style was highly engaging and informative. Damon recalls a particular lesson on parabolas, for which the professor marched into the class and made the pronouncement, "What would be the parabolic arc made by bombing Professors Davis' house from this classroom?" Another time, Damon remembers the professor conducting a lesson on "dry mathematics concepts" while standing in a waste basket. These two examples of the professor's teaching style illustrate the approaches to teaching that Damon took away from the class: Beginning a mathematics class with application problems, and attempting to establish student connections to mathematics. Damon has endeavored to use both of these methods throughout his teaching career.

His college student teaching experience in 1986 proved to be just as noteworthy. Damon completed student teaching in a state bordering the state in which he attended college. Living with his brother, Dean, who was teaching mathematics in the area, enabled Damon to student teach away from his college. This living situation worked to Damon's benefit because at the dinner table every night he was able to collaborate with Dean, and could seek out his brother's opinions on his teaching experience. At his school, Damon's experience was also enriched by one of his three cooperating teachers. Damon described this particular teacher as "an outstanding cooperative teacher" who was a true constructivist. The teacher employed the teaching pedagogy described as being a "guide on the side" rather than the "sage on the stage." This was the first time Damon had witnessed such teaching, which thoroughly captured his imagination and greatly influenced his future teaching pedagogy. Damon's second cooperating teacher was 
preparing to retire, and when Damon started to take over his classes, he left the room and did not return until Damon was done with his student teaching. Damon viewed this as an opportunity to utilize some of the teaching methods he had observed with his constructivist cooperating teacher. The third cooperating teacher was excellent at supplying daily feedback to Damon on his teaching. For Damon, both his living situation and the school student teaching program provided fabulous learning experiences, which made him believe he was ready to teach when he secured his first teaching position. $\mathrm{He}$ received his chance in 1987 , when he was hired to teach mathematics and computer programming at a neighboring state's largest Lutheran private school.

\section{Damon's Narrative: First Teaching Experience and an Amazing Department Chairman}

When Damon entered his new school, he immediately noted how big it was; the student population was more than 1,000 . But for the fact that his mathematics department chairman was a dynamic individual who, besides being a former PAEMST winner, was a fearless advocate for department collaboration, Damon, who was used to smaller schools, might have felt overwhelmed. Prior to Damon arriving at the school, the department chairman was able to convince the school's administration to agree to have all mathematics department members share both the same preparation period and lunch. This created a very congenial, collaborative atmosphere in the department that immediately aided Damon's transition into his new teaching position, and continued to be a tremendous help to him throughout his years of teaching there. Furthermore, Damon was advised by the chairman that he needed to become a member of the state mathematics teacher association. Damon's membership in the association would play a significant part 
in his development as a teacher. Damon believed that he had fallen into the perfect job, and yet he was not totally happy with his classroom.

Damon was hired to teach both mathematics and computer programming. Even with his wonderful student teaching experience and the fruitful departmental collaboration, Damon confessed that he during his first years he used a teacher-directed approach, and toward the end of his third year, he began wondering whether teaching was right for him. These feelings changed dramatically in 1990, when Damon, following the advice of his department chairman, attended an NCTM regional conference in this own state. Damon was highly impressed with the presentations at the conference, which served as a catalyst of change for Damon, as well as the starting point for a lifelong pursuit of professional development. Once again, family aided Damon's journey; in this case, his wife, a fellow mathematics teacher at the school, offered her support. As a mathematics teacher, she attended the same conferences as Damon, and they frequently collaborated during the presentations and workshops they attended. The following year, 1991, they attended another NCTM regional conference in a neighboring state, which inspired Damon to begin fundamentally changing his teaching pedagogy.

During the same year, the NCTM followed up by releasing their annual yearbook dedicated to Discrete Mathematics in schools, titled Discrete Mathematics across the Curriculum, K-12: 1991 Yearbook. Derived from these two publications, the theme of the 1991 NCTM regional conferences was the inclusion of Discrete Mathematics in the Mathematics Curricula of United States' Schools. 
Damon came away from the conference completely convinced that he needed to start incorporating Discrete Mathematics topics and technology in his classes. He believed that the inclusion of these topics would allow his students to see the "usefulness" of mathematics. He reasoned that students needed to make connections between school mathematics and the world outside of the classroom. Along with including Discrete Mathematics topics and use of the graphing calculators in classes, Damon decided to change of his teaching methods by shifting to a teaching pedagogy that stressed problem-solving and student collaboration. To that end, he began to start his classes with multi-step mathematical tasks that allowed his students to problem solve and collaborate. Damon also initiated the use of classroom projects that immediately engaged his student in both collaborating and problem-solving. Furthermore, using material that he received from the NCTM regional conference and a piloted paperback version of Discovering Advanced Algebra from Key Curriculum Press, Damon developed and initiated the first Discrete Mathematics course at his school. After teaching this course for seven years, Damon became entirely convinced that by creating mathematically rich tasks that allowed his students to construct connections between the mathematics and the world outside the classroom, his students would develop a deep understanding of mathematical concepts and procedures. In 2001, acting on this conviction and the fact that in 1995 he was his state's mathematical recipient of the PAEMST, Damon convinced his department chairman and his colleagues that including an AP Statistics/Probability course in the school's curriculum would give students another avenue for understanding mathematics through constructing real-world connections. The department accepted Damon's 
proposal, and during the following summer Damon went to a "tough" 1-week workshop to prepare himself for teaching the course.

Damon's Narrative: PAEMST Nominations and Their Positive Aftermath. In 1993 and 1994, Damon was nominated for the PAEMST by his school's mathematics department chairman. As a state's three mathematics finalist Damon was introduced to his state's Mathematics Consultant, who believed that the state's three finalists were strong teaching role models. She made sure that each summer all the current and previous state mathematics finalists met for 3 days and created 2- or 3-day workshops on mathematical topics and teaching methods. These PAEMST finalists would then travel around the state conducting workshops for different school districts. Damon considered his experiences conducting workshops instrumental in his development as a teacher. As he put it, "You were working with the [PAEMST] state finalists, who were really, really strong teachers!" Damon felt that this experience enabled him to experience tremendous, positive growth in his teaching.

Again, in 1995, prompted by both his department chairman and the state's Mathematics Consultant, Damon reapplied for the national award, and he became his state's PAEMST recipient. Damon attributes his winning the award both to the impressive teachers he worked with and to his commitment to making mathematics for his students "useful." Damon used his Discrete Mathematics classes and their utilization of graph theory for his PAEMST application. The unit he used for his application entailed having his students initially work in groups trying to solve several problems, for example, approaching Euler's "Konigsberg Bridge” problem by investigating Euler graphs, and 
tackling the "Traveling Salesman" problem by exploring Hamilton graphs. Damon then had his student groups investigate modern day problems involving the school and their community using what they learned from the above problems. The student groups chose such projects as measuring traffic flow in the school cafeteria and auditoriums, as well as proposing efficient local postal delivery and garbage collection routes. Again, Damon was promoting making real world connections to mathematics among his students. He felt that the entire PAEMST experience was very powerful and positive in terms of its influence on his teaching. The following year, when Damon started his master's program, he experienced a collaborative learning dynamic similar what he had experienced in association with his state's PAEMST finalists. Both of these events positively affected his teaching.

\section{Damon's Narrative: Master's Experience and the Power of Peer Collaboration}

In 1996, Damon entered a private university to begin his work on his master's in education. He commented that the professors he encountered in the program were not very influential to his teaching. However, he found the design of the master's program tremendously beneficial. The enrolled students were clustered in cohorts, and Damon was placed in a cohort consisting of 18 teachers. Throughout the duration of the master's program, these 18 individuals collaborated and supported each other as they designed and wrote their capstone master's project. In Damon's case, he received valuable assistance with his project, which entailed developing a mathematics course for the state titled "Discrete and Finite Mathematics." Damon believed that his involvement in his master's work enhanced his commitment to his students' mathematical growth and to his personal 
professional growth. He also felt that his involvement in the mathematical leadership of his state had helped make him an effective teacher. However, it was a family member who caused Damon to consider another "big" professional step.

\section{Damon's Narrative: New School and Continued Growth}

Damon's older brother, Dean, continued teaching mathematics after Damon's student teaching experience, but eventually he went into school administration. Using his administrative experience, Dean pioneered a new Lutheran high school in 1999, and he became its first principal. The school was located in the same Midwestern state where he had taught mathematics. Starting with 40 students, the population continued to grow until, by 2002, a brand new school had been built for a population of 200 students. Damon and his wife frequently visited Dean during the years he developed the new high school, and Dean consistently tried to recruit Damon to teach mathematics at the school. Damon kept putting Dean off because the school could not offer his wife a teaching position. This problem was resolved when, because of the increased enrollment, the school began to offer student activities such as football and baseball, and therefore needed an activity director. Dean offered this position to Damon's wife, and in 2003, Damon accepted the position of mathematics teacher at his brother's new school.

Damon had loved his original school because of his relationship with his department chairman, the congenial atmosphere at both the school and department, and the school's high expectations for its students. Nonetheless, Damon was bothered by the size of the school, since it was too large for Damon to get to know all the students. The population of his new school was more to his liking. As Damon put it, "In a school this 
size, no student can hide." That is, no student can go undetected when he or she is having trouble with math, which Damon deemed a "huge selling point for the school."

Furthermore, Damon was asked to coach both football and baseball, which he felt contributed to his developing positive relationships with the students. Once he and his wife had moved, Damon commenced taking what he had learned from his previous teaching position and applying it to his classes and the school.

\section{Damon's Narrative: New School and New Challenges}

Hammerness (2008) conducted a case study of four teachers who had changed schools over a period of eight years. She found that teachers' decisions to leave a school are highly personal, and that these decisions were based on the teacher's pedagogical vision of his or her classroom. In changing schools, these teachers were hoping to create a classroom that agreed with their vision. In Damon's case, his vision included teaching in a school where he knew most or all the students. He believed that his contribution to the school would be more constructive because of these positive relationships.

Despite his worthy intentions, Damon encountered challenges in his classroom regarding students accepting his high expectations for their learning. He had to "work hard" to convince his students to accept his teaching methodology, which was based on problem-solving, working on mathematical tasks, and collaborating. Damon felt that if the students put effort into delving into the mathematically rich tasks required in his courses they would develop problem-solving, sense making, deep understanding of mathematical skills and procedures, and collaboration skills. Damon also stressed that the 
students would improve their technical reading skills and construct real-world mathematical connections.

Damon started at his new school teaching Algebra I and Algebra II. He initiated a Discrete Mathematics class, and he also insisted that he be allowed to start an AP Statistics/Probability class when he accepted the teaching position. The following year the mathematics department added an AP Calculus class. In two years, Damon had increased the rigor of the school's mathematical curriculum and raised student expectations. This change came with support from his administration and a fellow mathematics teacher named Gary. Gary was a traditional mathematics teacher, but he and Damon worked well together. Damon stated that they "complemented each other," and he saw their working relationship as a benefit to the students. The lessons Damon had learned from his department chairman and colleagues at his former school were not wasted, as collaboration and congeniality among teaching faculty helped everyone, especially the students.

Damon's current focus at his school is no longer totally centered on his classes and department. He is the head of the school's peer-review and mentor teacher processes. He also represents the school on an intra-school council formed by the three Lutheran schools in the region. Since moving to the new school, Damon has shown leadership, both in and out of school.

\section{Damon's Narrative: Thoughts on His Teaching, Then and Now}


Damon stated that he loves teaching both the AP Statistics/Probability and Discrete Mathematics classes because the mathematics involved demonstrate the "usefulness" of mathematics to his students. In particular, Damon spoke of his affection for teaching the AP Statistic/Probability class, adding that he believes the course involves more than just mathematics. Damon estimated that "one-fourth of the class is mathematics and three fourths is a problem-solving process comprised of (a) stating the problem, (b) making a plan to resolve the problem, and (c) working through the problem and [interpreting] the results." Courses like AP Statistics/Probability and Discrete Mathematics illustrate Damon's evolved ideas about student mathematical thinking. When asked what the students he first taught would say about his teaching, Damon stated that they would say (a) he was fairly organized, (b) he cared about his students, (c) he had passion for mathematics, (d) he was quirky (as he would say or do anything to get the students interested), (e) his teaching consisted of lecturing with problem demonstrations, and (f) his assessments were summative tests involving "40 solving equations problems." Damon emphasized that at this time in his life, he was not ready to address "the usefulness of mathematics." Damon began to refine his teaching when he realized that he "wasn't going to be the youngest teacher on the staff, and [he] had to answer the question, "How do I keep the students' interest?" At that point, Damon elected to change his teaching methodology to reflect his changing thinking about how students construct an understanding of mathematics.

According to Damon, if asked about his current teaching his students would say he a) has good classroom organization that allows him "freedom" to teach; b) is very 
observant of students as he communicates with them; c) teaches the "big ideas" of mathematics d) has a way of "weaving a story into a problem," often an "outrageous" story, which piques their interest; e) he is passionate about teaching; f) he is not trying to be their friend or favorite teacher, but, instead, he provides them a quality education; g) he starts each class with an application problem; h) his assessments are frequently 2-day affairs that emphasize problem-solving; and, most important, i) he is thoroughly focused on their learning mathematics. Damon added to this list by stating that over the years he has shifted toward assigning more projects in his classes. For example, in the first semester of Algebra II, he has students run a candy bar company using linear programming. During the second semester, students take pictures of various conic sections they encounter in their daily lives, and then construct equations for these conic sections. In the first semester of his Discrete Mathematics class, Damon has his students "run a city" by running elections, designing efficient garbage and bus routes, and mapping or graphing the city. During the second semester, the students use matrices with 15 variables to run an ice cream company. Such projects were not a part of Damon's classes when he started his teaching journey in 1987. Motivated by his desire to truly benefitting his students, he sought out mathematical materials and developed a teaching pedagogy that promoted an understanding of the "usefulness" of mathematics for his students. For Damon, teaching has always been "about the student." 


\section{Five Narratives: Cole}

\section{Cole's Narrative: Introduction}

According to Ball (1992), the NCTM publication Professional Standards for

Teaching Mathematics (NCTM, 1991) presented an "ambitious vision" for mathematics teaching in the United States. It called for the promotion of mathematics curricula that emphasized the development of students' abilities to reason, problem solve, and communicate mathematically, and de-emphasized pencil-and-paper computation and recollection of algorithms. Instead, students would spend more time on performing mathematically rich tasks. This new vision of mathematics in the United States classroom was about what the "students should learn" rather than "what should be taught" (p. 6). Ingvarson (1998) maintained that for such a vision to be realized there needed to be professional development opportunities allowing teachers to learn new teaching methods. He added that the tradition of having universities and colleges guide professional development needed to change so that teacher-led organizations are able to “conceptualize their own professional development" (p. 127). For Cole, it was important that the vision set out by the above NCTM publication be reflected in his classroom practices and in his commitment to aid fellow teachers in transforming their classrooms.

During his teaching career, Cole devoted himself to this vision and became actively involved in professional development groups that shared and advocated the same values.

\section{Cole's Narrative: Childhood and Precollege Education}

Cole was born in the Eastern United States and was one of four siblings. His mother was a homemaker before becoming a manager of various restaurants and a dinner 
theater. She also served as a college dorm mother. At the time of Cole's birth, his father was a manager at a large paper company, and when Cole was in first grade, the family moved to a state in the Western United States because his father was reassigned. However, Cole's father resigned and enrolled in a local university to pursue a degree in medicine. After graduating with a degree in pediatrics, his father practiced medicine while also teaching at a local private university known for its exceptional medical faculty. During Cole's sixth grade year, his father accepted a teaching position as a doctor at a highly prestigious university hospital located in a large East Coast city. Cole was placed in a boarding school in the same city, where he received "a formal, classical education." Cole's parents chose the school because it offered a strong regimen of drill and practice; they believed that was the way successful individuals learn. Nonetheless, in hindsight, Cole deemed his Precollege educational experience insufficient, particularly in terms of mathematics. When he entered a prominent, progressive Midwestern college, Cole was confronted with this truth about his mathematics education.

\section{Cole's Narrative: College and Pre-Teaching Experiences}

The college, Cole attended was nationally known for its innovative educational plan. Introduced in the 1960s, this plan stressed investigational learning, learner active engagement, and reflection connection development. Emphasis was placed on creating relationships between in-class teachings and out-of-classroom experiences, as well as on interdisciplinary studies. Even though Cole found the college's learning environment invigorating, he struggled with his mathematics classes. His college mathematics professors focused on the "how" of mathematics, stressing competency in performing 
mathematical procedures and processes. The professors assumed that their students would provide the "why" on their own. When confronted with the problem of discovering the "why" of mathematics, which required an understanding of procedures and processes, Cole fell short. He commented that although he endeavored to develop an understanding of the mathematics, he "did not accept the challenge." Cole believed the "struggle was beneficial" because in future years as a teacher he could empathize with his students' struggles.

Cole's college had a long-standing commitment to international education in urban settings. The college had reached out to large urban universities around the world, soliciting opportunities for its students to study abroad. In the second semester of his sophomore year and the first semester of his junior year, Cole studied in Turkey. His major at that time was International Relations, and he was fascinated by the college's international education program. The program was founded on the belief that immersion into a culture facilitates learning about that culture. This principle would stay with Cole during his career as a teacher; he strived to "immerse" his students in mathematics' "culture of problem-solving and sense-making."

\section{Cole's Narrative: Master's and the "Teaching for Student Learning"}

In 1972, Cole applied to and was accepted in a major Southern university's

Teacher Corps program. The goal of the program was to attract highly motivated graduates from prominent universities and colleges in the Eastern and Midwestern United States and train them to be successful teachers (Marriott, 1990). During the 2 years Cole was in the Teacher Corps program, he fostered the "seed for teaching for student 
learning." The program brought in nationally-known consultants to teach courses, which Cole found very stimulating. When Cole obtained his master's degree in education, he was eager to enter the education field, but not locally.

\section{Cole's Narrative: After Graduate School}

In 1975, after obtaining his master's degree, Cole applied for a teaching job in Libya, but was not hired. Instead, he took a job in Saudi Arabia teaching second and sixth grade. The school's students were children of American employees of the Saudi Arabian oil company Aramco. This job stimulated Cole's interest in "the learning process." His curiosity about how students take in information and process it would become a defining focus of Cole's professional life.

In 1977, Cole continued teaching abroad, taking a job in Spain at the American School of Mallorca. His duties were teaching fifth grade and acting as the Head Master of the Lower School. By 1979, Cole decided that he wanted to "move back to the states," and elected to move to a Western state. He chose this part of the United States because of his fond remembrances of his time in the West, and one of his Teacher Corps members lived in a city near where Cole settled. Cole was unable to obtain a teaching position immediately, and, instead, took a position in the restaurant supply business. Cole took the opportunity during this non-teaching year to obtain his state teaching license. In 1980, he received a chance to use this newly acquired license when he was hired by the largest school district in the state to teach at a middle school. 


\section{Cole's Narrative: First Teaching Position and Professional Development}

Cole taught sixth grade at the middle school for five years, and during this period of time, Cole's evolution in both his teaching pedagogy and professional leadership began. A colleague, Janice, involved Cole in the NSF's Lane County Math Project, which entailed writing and piloting mathematical problem-solving material for grades four through nine. While participating, Cole met Rich, a writer for the project and a fellow district colleague. At this same time, both Janice and Rich strongly encouraged Cole to become a member of the state mathematics teacher association. Once he joined, Cole became an active, contributing member, writing a series of articles for the association's monthly magazine, and also serving on its governing board as vicepresident. Through his involvement with this association, Cole met a high school mathematics teacher, Lydia, who would eventually become one of the most significant mentors in his professional life. Lydia persuaded Cole to take part in the annual meeting of the state's mathematics leaders, where he became acquainted with mathematics teacher-leaders from around the state. These acquaintances had an enduring constructive effect on Cole both inside and outside of his classroom. In the classroom, Cole began to develop a conscious awareness of his teaching pedagogy, and realized that he needed to make further changes to it based on his newly-formed beliefs about how students learn mathematics. He recognized that he needed to cultivate new teaching methods that help establish "collaboration and problem-solving" in his classroom. Outside of his classroom, Cole worked to support his fellow mathematics teachers in their efforts to become more effective at their jobs. With Rich's support, Cole conducted individual and group in- 
service sessions on the LCMP material in 16 of his district's elementary and middle schools. Over the course of conducting these sessions Cole met an individual, Jim, who was working for the local county's Educational Service District.

EQUALS and family math. In 1986, Jim offered Cole a job that involved working with school districts within the county, helping them develop mathematical curricula and designing teacher workshops. Cole accepted the offer, and stayed with the job for three years, during which he expanded both his curriculum writing skills and leadership skills. He created a problem-solving course that utilized many applied learning concepts. In designing and conducting mathematic problem-solving workshops for teachers around the county, Cole honed his leadership skills. Furthermore, he showed leadership in guiding the curriculum in his own school district by serving on its textbook adoption committee. The position also allowed him to become acquainted with many mathematics teachers in his country. One of these newly found teacher connections, May, made Cole aware of a program called EQUALS, which was developed by the Education Department of prominent university located in a neighboring state. The aim of the program was to entice more female and minority students to become involved in careers involving mathematics.

May was a mathematics educator and member of a local women's equity advocacy group, who with Cole formed an association in his district that advocated for teaching that promoted equity in mathematics for girls and minority students. Cole and May reached out to the local EQUALS program for help in writing grant applications for funding the program. Their applications were accepted, and using the grant money, Cole 
and May worked with various districts' K-12 mathematics teachers, helping them initiate and run the EQUALS-developed Family Math curriculum. This curriculum emphasized the family's role in helping, supporting, and encouraging minority students and women in their mathematical studies. His successful association with May lasted three years. After the third, they lacked funds to keep Cole at full time, so he began looking for a different position in the district. In 1989, at the urging of the district's superintendent, the principal of the largest high school in the district offered Cole the opportunity to create a school within a school that promoted mathematics and science for non-white students who had traditionally had low enrollment in mathematics and science high school courses. Cole accepted the position, and together with Sarah, a mathematics teacher from the high school, co-founded the Institute for Mathematics and Science.

\section{Cole's Narrative: IMP and the Institute}

The Institute was funded by money from the district superintendent's fund and was housed in the district's largest high school. This high school had the most diverse student population in the district, and the Institute was set up to address the issue of equity in science and mathematics programs. Its goal was to encourage more non-white students to enroll in mathematics and science classes. The Institute served as a school within a school, and students from the high school next door signed up for additional help with their mathematics and science coursework. Cole and Sarah also provided professional development for the high school's mathematics and science teachers. The goal of this professional development was to familiarize teachers with and help them develop "problem-solving and NCTM Standards-based" teaching methods. Through his 
association with EQUALS, Cole became aware of an NSF-funded high school mathematics curriculum titled Interactive Mathematics Project (IMP). With Sarah's help, Cole obtained his district's permission to pilot the IMP at Sarah's high school. The program included curriculum material and professional development that covered how to use "standards-based teaching techniques." According to Cole, the IMP's goal was the development of students" "mathematical understanding," and it placed "less emphasis on pencil and paper mathematical procedure work." The institute also stressed Family Math, with its focus on developing women and minority students' interest in mathematics. The institute was operational for ten years, from 1989 to 1999. The combination of a change of administration and the high school mathematics teachers' open resistance to "standards-based teaching" eventually forced the district to close the Institute and the high school to drop the IMP program from the mathematics class offerings.

Prior to the school dropping the IMP program, the mathematics department offered two tracks that students could choose from, the IMP track and a traditional track. Many of the mathematics department's teachers who preferred the IMP began feeling pressure from the district and the state's education administration to get their students to pass the state's yearly objective tests. They left the IMP program and reverted to teacherdirected pedagogy so they could "cover the whole curriculum." According to Cole, mathematics department teachers who "felt threatened by IMP's standards-based teaching pedagogy" actively pursued its ouster. They were instrumental in convincing parents to go to district school board meetings and demand the elimination of the IMP program. These same teachers also actively recruited students to the traditional program 
by "bad-mouthing" the IMP program. With both teachers and students abandoning the program, the district finally eliminated the IMP from the school's mathematics department class offerings in 1999, and the Institute closed its doors the same year. Afterwards, Cole accepted a teaching job in one of the district's middle schools.

\section{Cole's Narrative: Second Teaching Experience and More Professional Development}

In 1999, Cole accepted a position teaching mathematics to sixth, seventh, and eighth grade students in a middle school in the same district. The school was part of the Japanese Magnet Program and the classes were mixed-aged. Cole found the school environment extremely stimulating. He attributed the school's positive teaching atmosphere to its principal, who enthusiastically supported the professional development of the staff. Cole took full advantage of this support, and became actively involved in a nationally recognized program called Assessment of Learning. Based on research by Black and Wiliam (1998), the program operates on the premise that formative assessments such as journal writing and interviews improve student achievement, creating better understanding of content knowledge than summative written assessments. With the principal's support, Cole arranges for a nationally-known author, Rick Stiggins from the Assessment Institute, to conduct professional development regarding this program.

\section{Cole's Narrative: Fellowship and Nonprofit Professional Development}

In 2009, Cole retired from teaching, but he accepted a 3-year fellowship from a nonprofit organization named The Teacher Development Group (TDG). This group has as its mission "increasing all students' mathematical understanding and achievement 
through effective professional development" (TDG, 2014). During his tenure as a fellow, Cole was a student at a week long summer institute and also an instructor in an NSFfunded mathematics leadership workshop for teachers. The institute met for three weeks at a time for three consecutive summers, and during these sessions, teachers worked toward the TDG's mission quoted above. Ever since, Cole has been actively involved with the TDG conducting teacher professional development in his and other states. Cole's Narrative: Final Remarks on His Growth as a Mathematics Educator

Cole's remembrances of his career revolve around the changes he has gone through as a mathematics educator. He characterized his first years of teaching as "quicker to tell." That is, he felt that he did not allow his students to work through their own thinking about mathematical concepts and procedures. Even though he used visual and physical manipulative in his lessons, he had a "narrow scope" regarding what constituted understanding of mathematics. For example, Cole felt that his ideas about rational numbers adhered to the part to the whole model. Consequently, when a student came up with a different correct explanation of rational numbers, he had a hard time not correcting the student's thinking. This "fixed mind set" changed for Cole during his involvement with the IMP and Connected Math. These NSF-funded curricula facilitated a deeper understanding of the mathematical procedures and concepts for Cole. Building on his expanded understanding, Cole continued to develop teaching methods that fostered his students' meaningful understanding. In his last years of teaching, Cole felt he had developed questioning techniques that assisted his students" "construction of mathematics." He further believed that he had worked diligently on increasing his 
students' metacognition, continuously asking them to be aware of and to understand their own thought processes. His teaching also included an increased emphasis on the big ideas of mathematics, such as proportional reasoning. Cole ended his teaching career knowing that he was an effective mathematics teacher, and that this effect was achieved, in part, because of his dedication to professional development. In the future, Cole intends to continue facilitating professional development for younger teachers, whom he "appreciate[s] for staying the course in developing a mathematical pedagogy that emphasizes the creation of mathematics understanding for their students."

\section{Emerging Research Themes}

\section{Introduction}

Each research participant's narrative was created from an interview and, depending when the participant received the PAEMST, either Evidence of Learning (prior to 2004) or Narrative Prompt (2004 to current) section of their application. Data from these sources was used to write a narrative of each participant's journey toward becoming a nationally recognized effective mathematics teacher. The researcher collaborated with each participant in the initial narrative via telephone, and from this collaboration further data were gathered. This data informed the revision of the original narrative. The next step was to analyze all five narratives in search of common themes.

\section{Research Themes}

Miles and Huberman (1994) contended that when coding qualitative data and developing themes, the researcher must keep the research questions in mind. The 
following themes were derived from coding each participant's narrative using the three research questions as a guide:

- Influences: family, mentors, teachers/professors, and educational organizations

- Education: Precollege, undergraduate, and graduate

- Professional development

- National Council of Teachers of Mathematics standards

- Teaching style: beginning, current, or end of career

- Obstacles

- Common personal beliefs and personality characteristics

- Students' influence

As noted in chapter 3, I created a data matrix using the five participants' names as labels for the rows and the above themes as labels for the columns. This matrix is in Appendix E. The following is a description of each theme with data from the five narratives supporting each theme.

\section{Influences: Family, Mentors, Teacher/Professors, and Educational Organizations}

Each participant had influences that helped shape their decision to enter the mathematics education field. Once they entered the profession, other influences impacted their development. These influences also facilitated and supported their metamorphoses into mathematics teachers who advocated and employed an NCTM SBC teaching pedagogy.

Family. The family's influence on the participants ranged in intensity from very notable to very slight. On one end of the spectrum of family influence is Damon, whose 
entire family were educators. During his Precollege years, Damon stated that the dinner table conversations always revolved around education issues. In college, Damon's older brother, a mathematics teacher, was a tremendous help during his student teacher experience, and later in Damon's teaching career the same brother, then a principal of a Lutheran high school, hired him as a mathematics teacher. Meredith and Rachael had similar memories of their family's influence. Both remember teaching their younger siblings, and working in their mother's classrooms. Both acquired personality characteristics from their parents that served them well in their future teaching. Meredith developed an attitude of viewing "every problem as an opportunity to grow." She attributed this trait to her father. Rachael attributed her persistence and love of learning to her father, who was a History professor. Mitch credited his father, an engineer, with exposing him to technology as excellent teaching tools. Although Cole's parents were influential in developing his curiosity, they did not influence him in choosing the field of mathematics teaching. He did not develop an interest in teaching until graduate school. It should be noted here that as inspirational as each family was, none of the participants entered college wanting to enter into mathematics education.

Mentors. All of the research participants mentioned extremely significant individuals who helped them in their careers. Some participants, like Meredith, Damon, and Fred, were fortunate enough to meet their mentors at the beginning of their teaching careers, and in the same school where they taught.

- Meredith initially met her mentor while she was student teaching, and with his help she was hired by the same school the following year. 
- Damon's mentor was the department chairman at his first job. This chairman made sure Damon collaborated with the rest of the department, which proved exceedingly beneficial to him.

- Cole's mentor, Janice, was a teacher at his school. She persuaded Cole to become involved in an NSF-funded problem-solving curriculum project where he met another influential mentor, Rick. Both Janice and Rick encouraged Cole to attend an annual meeting of his state's mathematical leaders. There Cole met Lydia, who was then a high school mathematics teacher. Lydia would eventually play a highly significant role in Cole's development as a mathematics leader.

- Mitch also drew inspiration from several mentors during his teaching career. His first mentor was the instructor of a Mathematics Teaching Methods course he took during his junior year in college. This professor insisted that her students join both the NCTM and the state mathematics teaching organization. She also taught from the NCTM's recently released Publication, Curriculum and Evaluation Standards. Both her actions and instructions directly affected Mitch. He joined the state's mathematics teaching organization, and during one of the organization's annual state conferences, Mitch was befriended by an individual, Brian, who would become Mitch's most influential mentor. Mitch's involvement with the organization created numerous opportunities to encounter more mentors.

- Rachael met her mentor while working on her master's degree. He recruited her as a writer for an NSF-funded program that created a standards-based, integrated high school curriculum entitled the SIMMS project. During those three years, Rachael's concept of learning mathematics expanded from the "acquisition of isolated mathematics, algorithms" into a constructivist view of learning mathematics, a view that stressed the development of mathematical understanding through problem-solving and developing real-world connections to the course material.

Education organizations. For the research participants, three organizations profoundly influenced their teaching careers: the National Council of Teachers of Mathematics, the NSF, and their respective state mathematics teaching organizations.

- For Rachael, the NSF provided a grant to pursue her master's degree. As noted above, she wrote for the SIMMS project, which was funded by the NSF and based on the NCTM's Standards and Curriculum publication. Her state mathematics teaching organization provided her professional support in terms of curriculum ideas, constructivist teaching methods, and colleague collaboration. 
- Meredith was decidedly affected by the NSF; she used the NSF-funded curricula, Lane County Mathematics Project (LCMP), Visual Mathematics, and Connected Math in her classroom. Early in her teaching career, she attended an NSF-funded workshop that dramatically changed her teaching pedagogy. She became heavily influenced by her state mathematics teaching organization, severing on the board as its President and NCTM representative.

- Cole worked with NSF-funded curriculum: LCMP, Visual Mathematics, Connected Mathematics, and Interactive Mathematics Project (IMP). After retiring from teaching in the classroom, the NSF continued to shape Cole's professional teaching leadership by funding a grant for a 3-year Mathematics Institute. Cole was an instructor at the Institute and he assisted in training teachers in the use NCTM standards-based teaching in their classrooms.

- Damon's involvement in his state mathematics teaching organization allowed him opportunities to increase his knowledge of Discrete Mathematics and Probability/Statistics, which he applied in his classroom.

All the participants attended NCTM regional and national conferences. All of the participants are recipients of the PAEMST and, therefore, received money from the NSF that they used to further their students' education.

\section{Education: Precollege, Undergraduate, Graduate}

The influence of the participants' formal education on their teaching methods varied. This variance can be attributed to the teachers and professors they encountered during the process of their education. As noted in the literature review, prior to the 1990s, the majority of mathematics teaching candidates' education in mathematics involved an exclusive teacher-directed pedagogy (Stigler \& Hiebert, 2004). Such was the case for all five of the research participants. However, all of the participants' formal education was where, as Cole noted, "the seed for looking at learning was planted."

Precollege education. When asked about their Precollege experiences, each participant, with Cole's exception, said they were good at replicating mathematical procedures and skills at the Precollege level of their education. 
- Mitch nicknamed this replication process "mimic the math."

- Rachael said that her highly-developed memorization process was sufficient for most of her Precollege experiences. She said, "I memorized the algorithms the teachers presented. I realized that they would use the same algorithms for the tests, but with different numbers."

- Meredith felt that she was good at mathematics based on the fact that she could perform well on the "end-of-the chapter tests comprised of 25, single-answer questions."

- Cole did not succeed in mathematics classes, which he attributed to the fact that he wondered about the "why" of mathematics. He wanted to understand the ideas that underlie mathematical procedures and skills. For him, the isolated procedures and skills were meaningless, since there were no connections among them.

Undergraduate education. Ferrini and Gaudard (1992) maintained that a

majority of students who enroll in calculus enter the course with procedural knowledge of mathematics rather than the conceptional knowledge needed to understand the underlying suppositions guiding the field of study. This was true for all of the research participants except Cole. Meredith's story is very similar to Rachael, Mitch, and Damon's.

- Meredith felt that, based on her performance in her Precollege mathematics classes, "I was good at math." She performed well in her Calculus courses, but when she went on to take advanced courses beyond calculus, her lack of understanding of calculus concepts caused her to struggle.

- Rachael ran into the same predicament when she enrolled in Mathematical Analysis (an Advanced Algebra class).

- Mitch and Damon also confronted their lack of mathematical understanding in mathematical courses they enrolled in beyond calculus.

- Cole struggled with mathematics in college, as he had during his Precollege education, but he did not have to confront his lack of mathematical understanding until he received his first teaching job.

The other research participants initiated their development of deep mathematical, conceptual understanding at different points in their teaching career. As noted in the 
literature review, this form of mathematical knowledge is needed for a teacher to effectively use a standards-based pedagogy (Ball et al., 2008).

Though all the research participants entered their undergraduate education not considering teaching, by their junior year all except Cole, who earned an undergraduate degree in International Relations, were on track to graduate as mathematics teachers.

- For Rachael, her undergraduate mathematics methods for teaching courses were "worthless." Her professors had not taught in schools and had a poor idea of what was needed to be an effective teacher.

- Mitch, on the other hand, credited the professor in his Mathematics Methods for Secondary Teachers course for "making [me] a constructivist teacher." The Professor taught from the NCTM's Curriculum and Evaluation Standards publication. She also required each student to register for both the NCTM and their state mathematics teaching organizations. Mitch rated his student teaching experience as strongly significant because his cooperating teacher taught him how to anticipate student needs when he was planning his lessons.

- Damon did not mention his methods course, but he described his student teaching experience as inspirational. One of his three cooperating teachers was an "outstanding constructivist teacher." Prior to his student teaching experience, Damon had never encountered constructivist teaching. He was able to observe constructivist teaching methods, and eventually used and perfected them in his own teaching. Meredith's student teaching experience was poor, but she ended up meeting her lifelong mentor during the experience.

- Cole completed his student teaching during his Graduate School education, having majored in Elementary Education.

Graduate education. The participants had differing views about the influence of

their graduate school education on their teaching.

- Mitch admitted that the experience had little influence on his teaching.

- Meredith credited two courses in her graduate studies, Topology and Calculus for Middle School Teachers, with having a pronounced effect on her teaching. After taking the courses, she began changing the way she taught, emphasizing problem-solving and sense-making. 
- Rachael described her graduate school experience as allowing her to meet highly influential individuals who supported her transformation to constructivist teaching.

- Damon's graduate school education was a "wonderful" experience, involving a cohort of 18 teachers who collaborated and helped each other with their master's final project.

- Cole described his time in graduate school and student teaching, as when the "seed for teaching, for student learning" was planted in his consciousness.

Their formal education was mildly influential. However, all five research participants insisted that their professional development opportunities were remarkably noteworthy.

They all attributed their development as teachers to their involvement in professional development

\section{Professional Development}

Spillane and Zeuli (1999) contended that the changes required by reforms such as those advocated by the NCTM fall on the shoulders of the classroom teacher. All five of the research participants felt pressure to seek out professional development in an effort to change their teaching so that it reflected the NCTM standards. The first place they went was their state mathematics teaching organization. They all became members of the organization and began attending conferences and workshops the organization sponsored. During these conferences, they made connections with teachers and professors who guided them toward other professional development opportunities.

- Meredith was invited to attend an NSF-funded professional development while at her state mathematics teaching organization conference.

- Damon was encouraged to attend an NCTM regional conference. After attending, Damon was motivated to attend the next NCTM regional conference, at which he attended presentations and workshops on Discrete Mathematics. Damon came away from the experience determined to change his classroom practices from teaching isolated mathematical procedures and 
skills to encouraging students to create an understanding of mathematics through problem-solving and other rich mathematical tasks.

- At his state mathematics teaching organization conference, Cole met several teachers who became involved in both standards-based curricula and teacher leadership.

- In Rachael's case, her state's mathematics teaching organization eventually encouraged her to become a writer for an NSF-funded high school curriculum program called SIMMS.

- Mitch expanded both his knowledge and classroom curricula by attending his state's mathematics teaching organization conference. Furthermore, as noted earlier, Mitch met one of his most influential mentors at one of these conferences.

Except for Mitch, it was at these state mathematics teaching conferences and during subsequent professional development opportunities that the research participants became aware of the NCTM's recommended teaching standards and curricula. Both the standards and curricula played an enormous role in all of the participants' future teaching.

\section{NCTM Standards}

Each research participant was considerably affected during their teaching careers by the NCTM standards and by curricula based on these standards. Meredith and Rachael both noted that encountering the NCTM standards "changed their definition of mathematical rigor." Rachael said her previous definition was "too narrow," defined as the acquisition of procedures and skills, and according to which all student knowledge was gained from practicing textbook exercises with pencil and paper. Since their introduction to the NCTM standards, both Rachael and Meredith changed to using a teaching pedagogy that emphasized problem-solving involving rich, mathematical tasks. They learned many of these mathematically rich tasks from curricula designed to support NCTM standards. 
- Meredith used LCMP, Connected Math, and Core Plus during her teaching career.

- Rachael was part of the team that developed SIMMS and used throughout the remainder of her teaching career.

- Mitch also employed a curriculum designed according to the NCTM standards, Key Curriculum Press's Discovering Geometry. Mitch coupled this curriculum with technology in the form of computers and the computer software program, Geometry Sketchpad, to create classroom activities that allowed students to "construct their own knowledge" of mathematics.

- Damon used another Key Curriculum Press publication based on the NCTM standards, entitled Discovering Advanced Algebra, to create the curriculum for a Discrete Mathematics course he designed and taught. His curriculum focused on the concepts and ideas he discovered in the 1991 NCTM yearbook publication, Discrete Mathematics Across the Curriculum K-12.

- During his career, Cole used mathematics curricula based on the NCTM standards at three different levels of Precollege education. At the elementary level he used $L C M P$, at the middle school level he used LCMP and Connected Math, and at the high school level he employed IMP.

Clearly, the NCTM played an important role in each of the participant's developing and changing his or her teaching. However, as Rachael pointed out, the changes for all of them were incremental. Except for Mitch, standards-based teaching was not covered in the participants' undergraduate mathematics teaching methods course. All of them had to seek out pragmatic teaching methods to fulfill their vision of creating a mathematics classroom where their students had the chance to construct their own understanding.

\section{Teaching Style: Beginning, Current, or End of Career}

Research has documented the difficulties teachers confront when they attempt to change their teacher-directed pedagogy to an SBC pedagogy (Smith, 1996; Stigler \& Hiebert, 2004; J. A. Thomas \& Monroe, 2006; P. Wilson et al., 2005). When the majority 
of mathematics teachers start their careers, they frequently "teach like they taught." The research participants' narratives reflect this fact.

Teaching: Beginning of career. When asked how their students viewed their teaching during the beginning of their career, each participant echoed the same theme: they cared deeply for their students, but they taught using lectures and problem demonstrations.

- Rachael stated that she was "oblivious to understanding" and she taught her classes in order "to see if the students did the things they needed to get done in math class."

- Cole said he was "quicker to tell" students what to do even though he was using visual and physical models in the classroom. By his own account, he worked from a fixed mind set.

- Mitch said he "rambled too much." He tried to befriend his students, but instead turned into a "yelling friend."

- Damon used teacher-directed instruction methods, and his assessments of his students' knowledge were strictly limited to an end-of-unit test consisting of "40 one-step problems."

- Meredith stated that she would use projects in the classroom, such as "line designs." However, the majority of her instruction was "skills-based and boring."

As noted above, all of these individuals eventually transformed their teaching to using an SBC pedagogy. This fact is reflected in their comments about their end-of-career or current teaching.

Teaching: End-of-career or current. When asked how their students would view their current teaching or their last years of teaching, all the participants agreed on several points. The research participants said their students would say that they had high expectations for their learning. The participants also reported that their students were 
aware of the extent to which their instructor believed in their ability to learn mathematics. Their students would also say that their teachers did not use lecturing to teach, but instead used mathematical tasks to engage them. Four of the participants said that they used "constructivist principles" to conduct their classes, and that problem-solving was the mainstay of their classrooms. Cole stated that he worked on creating "a culture of problem-solving in [his] class." Both Damon and Cole mentioned that they worked on developing their students' metacognition. They felt it was important for students to understand how their "thinking operates." The transformation of the participants' teaching over the course of their career was not smooth. Besides the obstacles the five participants encountered in their classroom, they also discovered obstacles outside of their classroom.

\section{Obstacles to Their Teaching}

As noted in the literature review, teachers who employ SBC teaching in their classroom frequently run into obstacles. The participants in this study were no exception, as they all encountered obstacles when moving away from using curricula based on the teaching of isolated mathematical skills and concepts. The traditional textbooks they initially used were part of a larger culture of traditional mathematics, which had to be addressed before it was abandoned. The majority of the participants' mathematics teaching colleagues taught using teacher-directed pedagogies, and some of these individuals erected barriers to the participants' teaching that the participants had to overcome. Besides their colleagues' objections, the participants had to face and overcome 
political obstacles in the form of students, parents, and administrators' opposition to their teaching.

Cultural obstacles. Spillane and Zeuli (1999) maintained that American educational culture is generally resistant to the changes called for by the teaching standards advocated by such organizations as the NCTM. Rachael experienced such resistance when she tried to convince her high school mathematics department to adopt the SIMMS curriculum. Even after the NCTM President came to her school to address the department's concerns, the department adopted a traditional mathematics textbook series. When Damon convinced his department to add a Discrete Mathematics course to their mathematics offerings, he had to write his own standards-based curriculum because there were no published textbooks that used such methods. When Cole and Sarah, his high school teaching colleague, introduced the standards-based curriculum IMP in their high school, several mathematics teachers vehemently opposed the move. Cole felt that these teachers felt threatened by the standards-based teaching methods that the curriculum's authors advocated.

Pedagogical obstacles. Every one of the research participants admitted that they had employed a teacher-directed pedagogy when they first started teaching. Cavanagh and Prescott (2010) noted that teachers who elect to change their teacher-directed pedagogy to an SBC pedagogy experience many difficulties. This was true for all of the research participants. Mitch acknowledged that, even though he had a "fabulous" mathematics methods professor in his undergraduate education who wholeheartedly advocated the use of SBC teaching in the classroom, he was slow to adopt the pedagogy 
in his own classroom. Though he initially taught using a teacher-directed pedagogy, he was consciously trying to use open-ended questioning techniques to draw out students' thinking. Meredith and Cole had similar early teaching experiences, and they also focused on teaching methods that elicited student thinking and conversation. Both Damon and Rachael made changes to their classroom operations by having their students immediately start on mathematically rich tasks once the class began. They both encouraged their students to make connections between the mathematics in the classroom and the world outside the classroom.

The biggest pedagogical obstacle that each research participant confronted was their own lack of a deep understanding of mathematical concepts. Ball et al. (2001) contended that the most important factor in student learning in the classroom is teacher knowledge. Having a deep understanding of the mathematics covered in a classroom allows a teacher to appreciate and understand the various ways their students interpret mathematics. Damon was confronted by his deficiency of mathematics knowledge when he persuaded his administration to allow him to add an AP Probability/Statistics course to his school's mathematics offerings. Fortunately, he recognized this shortcoming prior to teaching the course and registered for a 2-week intensive course in teaching AP Probability/Statistics. He came away from the course with a better command of the subject. Rachael and Mitch faced a similar predicament in preparing to teach calculus, and, like Damon, both enrolled in the in summer courses that promoted an innovative calculus curriculum and pedagogy. Cole and Meredith came to the conclusion that their mathematics knowledge was "too narrow" when they attended workshops covering the 
NSF-funded curriculum Visual Mathematics. They, too, went about remedying their lack of deep conceptional mathematical knowledge by seeking out further professional development. They enrolled in numerous courses and workshops that were modeled on the NCTM standards.

Political obstacles. Mirel (2003) asserted that constructivist teaching frequently generates controversy and conflicts that impede its further implementation. One of Meredith's colleagues admired her teaching methods when he collaborated with her during a summer course. Though he told Meredith that he wanted to try some of her teaching methods in his classroom, the following fall he returned to his class and began using teacher-directed methods. He confessed to Meredith that he felt a need to cover the entire curriculum, and lecturing and demonstrating was efficient for accomplishing that. In the ensuing years, Meredith observed the new young teachers hired to teach mathematics at the school, and all of them used a teacher-directed pedagogy. The school's administration stressed outcome-based research that equates student learning with high scores on written objective tests. Because the new teachers felt pressure to "teach to the test," they reverted to using traditional mathematics textbooks and pedagogies. Because she was the only mathematics teacher using SBC teaching, Meredith felt isolated in this teaching position and wanted to collaborate with someone on her teaching. At the last high school where she taught, Rachael faced opposition to her SBC teaching from the other members of her department. They thought that she was not teaching "real math," but was promoting "fun and games" in her classroom. When the school was given an opportunity to adopt the SIMMS curriculum, Rachael faced 
opposition in promoting the curriculum from both her fellow teachers and parents. Parents and fellow mathematics department members also openly opposed the IMP curriculum that Cole and his mathematics colleague Sarah were attempting to use at their school. When Meredith moved to a small high school, she faced a very hostile fellow mathematics teacher, who openly spoke ill of her teaching methods to students, parents, and her administration. Students who were unaccustomed to SBC teaching methods at times complained about all five of the research participants' teaching, yet all five persisted in expecting their students to problem solve, communicate, share, and defend their thinking. All five succeeded in changing the majority of their students' thinking about what it meant to do mathematics.

\section{Personality Characteristics and Personal Beliefs}

As noted in the Literature Review, Traina's (1999) research identified three distinguishing characteristics of 125 successful teachers, and one of the characteristics he labeled "distinctive trait." This trait made successful teachers unique in their students' eyes.

- Damon felt that his practice of "saying almost anything" to engage his students was what distinguished him.

- Mitch thought that his unique characteristic was the way he started his class with a story that led to the introduction of the opening mathematical tasks.

- Cole felt his students would say that his constant emphasis on their metacognition set him apart.

- Both Meredith and Rachael cited their deep caring about their students' learning as their "distinctive" trait.

These were the teaching and personality characteristics the participants felt were distinctively their own. However, all five shared distinguishing personality characteristics 
and personal beliefs as well, which helped them become recognized as highly successful high school mathematics teachers. The participants did not directly speak about these personality characteristics and personal beliefs, but their interviews and the subsequent narratives distinctly revealed them.

\section{Common Personal Beliefs and Personality Characteristics}

The personal belief that presents itself almost immediately upon talking about mathematics teaching with the five participants is their absolute conviction that all their students are capable of learning mathematics. From that belief, another personal belief surfaces among all five participants: They have very high expectations of their students. They insist that their students have the ability to construct a deep understanding of mathematics and to connect the mathematics studied in the classroom to their lives. Persistence is also a common personality trait, which, as noted previously, was exhibited in their classroom teaching, and also was exemplified by their handling of the previously mentioned obstacles. All five of the participants "stayed the course" when challenged by students, parents, fellow teaching colleagues, or administrators. All remained committed to learning, and continually sought out professional development that helped them in the classroom. This love of learning was the foremost reason all of the participants viewed their membership in both the NCTM and their state's mathematics teaching organization an essential ingredient of their teaching. They were frequently the only teacher in their department who belonged to these mathematics teaching organizations. They furthermore displayed leadership qualities both inside and outside of the classroom. Finally, they 
remained passionate about mathematics and worked endlessly to ignite this passionate love in their students.

\section{Student Influence}

As noted in the literature review, one of the five constructivist principles is adapting curriculum to address students' suppositions. For mathematics teachers using an SBC pedagogy using students' suppositions allows them to build an effective learning environment. The five research participants used their students' suppositions to determine the direction to proceed in the classroom. However, they also used their students' input about their teaching as motivation to increase their personal knowledge about teaching methods and mathematics through seeking out professional development opportunities. For example, when confronted by his students' questions about calculus concepts, Mitch realized that his college calculus classes had not prepared him to provide compelling answers. Motivated by his desire to use his students' suppositions in his teaching, Mitch registered for a calculus workshop that "revolutionized his content and pedagogical knowledge," enabling him to effectively teach calculus. Rachael experienced a similar difficulty when she taught calculus, and, like Mitch, she sought out help. She registered for a nationally recognized program that promoted standards-based teaching methods and the use of technology in the teaching of calculus. Finally, all five participants pointed out that their students' suggestions were instrumental in structuring their classroom environments in such a way as to support student learning. Their students' involvement in their classrooms allowed each participant to continue on their SBC mathematical journey, 
and to overcome the obstacles that arose along the way. To that end, all five were actively seeking out their students' ideas of the curriculum and their teaching.

\section{Conclusion: Addressing the Research Questions}

Coulter and Smith (2009) argued that Narrative Inquiry is a complex process that requires collaboration between the researcher and participant. Researchers must exercise caution so that while they code the finished narratives the research questions serve as the guiding standards for determining themes. In the following discussion, the research questions are addressed in terms of the research themes that emerged.

\section{Question 1}

What are the paths SBC secondary mathematics teachers who received the PAEMST pursued to become highly effective? Each participant took a different path in becoming a PAEMST recipient and highly effective teacher; however, there were many similarities between their journeys. They experienced influences that led them toward becoming an SBC teacher. Chief among those influences were mentors, professional development, the NCTM standards, and most importantly, their students. Personality values developed in their youth aided the participants in following the paths they chose. Their love of learning motivated them to continually seek out educational opportunities that improved their classroom teaching methods and augmented their mathematical knowledge. Their belief in their students' abilities to learn mathematics also motivated them to continually search for better teaching methods to facilitate student learning. One of the most significant findings of this research study was how the participants used their students' classroom observations and suppositions to guide them both inside and outside 
of the classroom. In the classroom, the participants changed their teaching methods and curriculum to better help their students. Outside the classroom, the research showed all the participants sought out further education based on their students' classroom input.

\section{Question 2}

What obstacles and challenges did they encounter and how were these obstacles overcome? According to the research findings, all five participants encountered and struggled with obstacles on their journey to becoming a PAEMST recipient and highly effective mathematics teacher employing an SBC pedagogy. All the participants faced curricular challenges, having taught using SBC teaching methods with mathematics textbooks that were designed for a traditional, teacher-directed classroom. All of the participants managed the situation by seeking out or developing classroom material that enabled them to teach their students using SBC teaching methods. All the participants sought out and eventually employed NSF-funded, standards-based curricula, which enabled them to be more efficient in their SBC teaching.

This research also found that parents, students, and colleagues also created obstacles for the participants as they attempted to employ SBC teaching methods and curricula. The research showed that the participants overcame these obstacles using their personality traits and the leadership skills they had developed.

\section{Question 3}

What sustained them on their journeys? The research showed that participants were sustained by their mentors, their membership in both their state mathematics teaching association and the NCTM, their involvement with professional development, 
and, most importantly, their students' influence. These factors all played an enormous role in their development and use of SBC teaching methods in their classroom. 


\section{CHAPTER 5}

\section{INTERPRETATIONS, RECOMMENDATIONS, IMPLICATIONS, LIMITATIONS, AND CONCLUSION}

\section{Interpretations of Results}

\section{Summary}

The analysis of the five narratives yielded six major themes that were supported by previous research noted in the Literature Review: Influences, Education, Professional Development, National Council of Teacher of Mathematics Standards, Obstacles to Teaching, and Teaching Style: Beginning and Current or End of Career. However, in analyzing the narratives, two unique themes not covered in previous research emerged: Personality Characteristics and Personal Beliefs, and Students' Influence. All eight themes played a part in each participant's journey to becoming a distinguished and successful mathematics teacher.

\section{Unique Themes}

The themes of Characteristics and Personal Beliefs, and Students' Influence are unique because they address a special group of high school mathematics teachers who developed and persisted in using an SBC pedagogy in their classroom. There is research addressing the use of an SBC pedagogy in high school mathematics classes, but these studies address why teachers ceased using an SBC pedagogy (Educational Resources Information Center, 1997; LaBerge \& Sons, 1999; Manouchehri \& Goodman, 2000; Pedersen \& Liu, 2003). 
Unique theme: Personality characteristics and personal beliefs. In discussing the personality characteristics of the five participants, it should be noted that they are high school mathematics teachers who are both PAEMST recipients and advocates of SBC teaching pedagogy. Research has not yet addressed the personality characteristics and personal beliefs of this category of high school mathematics teachers, though there has been research on the personality characteristics and personal beliefs of traditional, teacher-directed high school mathematics teachers (Cobb, Yackel, \& Wood, 1992: Pedersen \& Liu, 2003; Prawat, 1992; Simmons, et al. 1999; Sirotnik, 1983; Smith, 1996). Ibarra's (2005) research on the teaching behaviors of PAEMST recipients was confined to science teachers. This research study produced results that address the personality characteristics and personal beliefs of five PAEMST recipients who are high school mathematics teachers.

In the initial one-on-one interviews and subsequent collaborative interviews, all five of the participants shared a surprising number of traits, beliefs, and experiences. The participants reported that they worked tirelessly to create an SBC classroom environment that aided their students' learning. All of the participants demonstrated a commitment to developing their students' problem-solving and reasoning skills. They all felt that demanding, mathematically rich tasks were invaluable tools for teaching problem-solving and developing students' mathematical understanding. Quoting Meredith, all five participants "view a problem as an opportunity to learn" for their students. In their interviews, each participant spoke frequently about their love of learning, and they selfreported working continuously in their classrooms to foster this same affection in their 
students. The participants' perseverance, coupled with their aforementioned emphasis on problem-solving, allowed them to successfully address the obstacles that arose because of the lack of support of their SBC teaching. All five individuals cared deeply about their students, and they exhibited an insatiable curiosity about their students' thinking and learning. The combination of these personality characteristics and personal beliefs, in addition to the participants' association with inspirational mentors and their devotion to professional development, sustained them on their mathematical journey. However, the participants' students played a vastly influential role in each of the participants' use and development of their SBC teaching practice.

Unique theme: Students' influences. The five participants' students performed a dramatic role in their development as teachers. In the interviews, the participants revealed that their students' observations about the mathematics curriculum and their teaching methods influenced their future actions both inside and outside the classroom. In the classroom, each participant used their students' suppositions about their teaching and the curriculum to create changes in their instructional methods and a course's mathematical content. This result is not surprising considering that one of the principles of constructivism, as noted in the literature review, is to adapt teaching or curriculum to the suppositions of students. However, outside the classroom, each participant used the students' classroom comments as the catalyst for professional growth. In other words, the participants honored their students' classroom input and used it to determine which areas of professional growth they would further pursue. 
Common theme: Influences. All the participants acknowledged that they started their teaching career using a teacher-directed pedagogy and that their main methods of teaching were lecturing and problem demonstration. The participants in this study opted at some point in their career to convert to teaching using an SBC pedagogy. It was the influence of family, mentors, teachers or professors, and mathematics teaching organizations that facilitated each participant's pedagogical change.

Gregg (1995) maintained that changing from a teacher-directed pedagogy to SBC pedagogy involves a difficult transformation. Most teachers who attempt such a conversion eventually revert back to teacher-directed instruction (Educational Resources Information Center, 1997). College students in mathematics education, like the research participant Mitch, who received intensive training in constructivist teaching, have had a difficult time using constructivist teaching methods in their initial teaching position (Cavanagh \& Prescott, 2010). According to Kilpatrick (2009), an estimated 10\% of United States mathematics teachers use reformist, NCTM standards-based pedagogy in their classroom, which implies that $90 \%$ of the nation's mathematics teachers use a traditional, teacher-directed pedagogy. Despite the culture of mathematics teaching in the United States, the five research participants elected to practice the use of SBC pedagogy in their classrooms, and the following influences helped them do so successfully.

Common theme: Family. All five participants spoke about the ways family influenced their choice to enter into the education field. Their families were instrumental in helping them develop personality characteristics that were significant to the participants' teaching. The most common and significant trait was a passion for learning. 
Murray (2011) asserted in a study of high school mathematics students' thoughts on what makes a "good mathematics teacher" that a teacher's passion for learning plays a vital role in student learning.

In this research study, the participants' passion for learning served the participants well when transforming their teaching to an SBC pedagogy by continuously updating both mathematical concept knowledge and SBC teaching methods. They felt that in doing this, they better prepared themselves to help their students understand mathematics. However, as noted earlier, none of the participants initially went to college to be an educator. Furthermore, once they began their teaching, they taught using the same methods they encountered as students, using a teacher-directed pedagogy.

Common theme: Mentors. Each of the five research participants sought out mentors, who ultimately played a significant role in the participant's teaching career. For example, each of the participants had mentors who convinced them to join both the NCTM and their state's mathematics teaching organization. Meredith, Cole, and Rachael's mentors also involved them in NSF-funded workshops and programs. All of the five participants' subsequent involvement in their state mathematics teaching organizations and the NCTM led to further professional development, which dramatically changed their classroom teaching.

Feiman-Nemser (2001) wrote that schools' use of mentoring to help new teachers has been common in the United States since the early 1980s, but that the practice has received mixed reviews. Ball and Cohen (1999) contended that for mentoring to be effective, it must help cultivate in a beginning teacher an interest in an inquiry that is 
focused on student thinking and understanding, as well as help foster disciplined talk about problems of practice with colleagues in and out of school. In particular, a mentor needs to continuously expose the beginning teacher to professional development outside of the school.

Common theme: Education. As noted in chapter 4, all of the participants experienced only teacher-directed teaching in all of the Precollege and undergraduate mathematics classes. They all stated that the Precollege mathematics education did not prepare them for mathematics courses in college since the learning styles they developed in high school consisted of mimicking their teachers' demonstrations and memorizing mathematic procedures. They did not develop much understanding of the mathematical concepts behind the procedures. Four of the participants stated that this lack of mathematical understanding caught up with them in the mathematics courses they enrolled in after completing calculus. In the case of Cole, he experienced difficulty with all of his undergraduate mathematics courses. Four of the participants continued on with their education in mathematics even without the mathematical understanding they felt was needed. All the participants realized they lacked a deep understanding of mathematical concepts, and, with the help of their mentors, they actively sought out educational opportunities that increased their mathematical conceptual knowledge. The five participants' pursuit of mathematical conceptual knowledge followed different routes. For Meredith, Cole, and Rachael, the development of mathematical conceptual understanding began in graduate school and continued with their involvement in professional development during the early years of their teaching careers. Mitch and 
Damon's graduate school educational experience had little effect on their development of mathematical conceptual understanding. Instead, their progress began when they later sought out professional development in terms of workshops and conferences.

In a recent study, Harwell, Post, Medhanie, Dupuis, and Lebeau (2013) found that students who were taught mathematics by teacher-directed methods were not prepared for college mathematics courses beyond calculus. These students had not developed the mathematical knowledge needed to understand the concepts of these advanced courses. The authors of this multi-institutional study of both high school curricula and college mathematics achievement found that students who had a traditional teacher-directed mathematics education achieved high grades in Calculus, but that their grades declined in mathematics courses beyond calculus. Furthermore, a high percentage $(63.7 \%)$ of these students failed to continue on to higher mathematics courses.

Cobb, Wood, Yackel, \& McNeal (1992) and Gregg (1995) asserted that prior to the 1960s a successful mathematics teacher was defined by his or her effective teaching of mathematical procedures and skills using a teacher-directed pedagogy consisting of lecturing and problem demonstration. As noted in the literature review, Kilpatrick (2009) contended that the vast majority (approximately 90\%) of today's United States mathematics teachers still adheres to teacher-directed teaching methods as their mode of instruction. All of the research participants experienced a traditional Precollege mathematics education in which all of their mathematics instruction was teacher-directed. All of the participants, with the exception of Cole, experienced a drop in their grades in their college mathematics courses beyond calculus. The participants attributed this drop 
to the lack of deep understanding of conceptual mathematics. However, all five of the participants continued their pursuit of mathematics teaching careers and they eventually developed a deep mathematical conceptual understanding. As noted in the literature review, a deep understanding of mathematics concepts and procedures is requisite for teaching using an SBC pedagogy. All five of the participants developed their mathematical understanding through their involvement in professional development.

Common theme: Professional development. For all five participants, the gaining of further knowledge through professional development was an integral part of their teaching. All five enthusiastically attributed their success as a teacher to their involvement with professional development.

Shulman (1987) outlined the essential types of knowledge needed to be an effective teacher: (a) mathematical knowledge and its presentation to students, (b) knowledge of students' behaviors and thinking, and (c) knowledge in the classroom. He asserted that teachers must commit themselves to acquiring and continuously improving upon these forms of knowledge to employ an SBC pedagogy.

Ball and Cohen (1999) maintained that teachers who wish to transform their teaching from a traditional teacher-directed pedagogy to an SBC pedagogy need to continually modify their classroom practices to better promote student understanding of mathematics. McGee, Wang, and Polly (2013) concurred with the above and added that the implementation of an SBC pedagogy in the classroom involves a commitment of the teacher to professional development. 
Common theme: NCTM standards. All five participants stated that they were made aware of the NTCM standards at different points in their careers. As noted previously, the five participants began their teaching careers using teacher-directed pedagogy. However, they then began to make incremental changes to their teaching pedagogy using the standards as their guide. Eventually, all five participants sought out and taught from curricula that were designed around the standards. In discussing her transformation to SBC teaching, Rachael recalled a quote by James Rubio, past Executive Director of the NCTM, who counseled teachers changing their teaching to reflect the NCTM standards that a reasonable goal is "seeking incremental improvement rather than postponing perfection" (Vennebush, 2013). This quote summed up her and the other research participants' attitudes about implementing the NCTM standards.

LaBerge and Sons (1999), in their research on five beginning high school mathematics teachers, noted that all of them were aware of the NCTM standards, but that as learners none of them had been influenced by those standards. All five beginning teachers felt that it was difficult to teach using the standards because their major concerns were classroom management and discipline. They viewed the standards as admirable goals, but thought of their application as an incremental process. Furthermore, according to Burrill (1997), teachers who follow the principles advocated by the NCTM confront barriers in the form of cultural, conceptional, and political obstacles from administrators, colleagues, parents, and students. This was the case with the five research participants.

Common theme: Obstacles to teaching. As noted above and in chapter 4, all five participants confronted obstacles to their teaching, such as being required to teach 
with traditional textbooks that emphasized the acquisition of procedural mathematical skills. They also encountered both conceptual and political opposition from students, colleagues, administrators, and parents arising from these groups' concept of mathematical rigor.

Windschitl $(1999,2002)$ stated that teachers who adhere to an SBC pedagogy face numerous obstacles from different groups of stakeholders. As was reported in the literature review, these groups of people based their beliefs regarding mathematical rigor on their own mathematical education, which had been traditional and teacher-directed (Phillips, 1995; Simon, 1995). Cohen and Ball (1990) reported that unless obstacles to teachers' use of SBC teaching are addressed and overcome, teachers will convert back to a teacher-directed pedagogy. This conversion is particularly common among beginning teachers. In a study of 58 beginning teachers attempting to teach using an SBC pedagogy, Simmons et al. (1999) found that $80 \%$ of the teachers had converted to a teacher-directed pedagogy by their third year. All five of the research participants felt pressure to use a teacher-directed pedagogy during their teaching career. In spite this pressure and the other obstacles they encountered during their teaching careers, all five of the participants made the conversion to SBC teaching. However, none of them started their teaching career using SBC teaching methods.

Common theme: Teaching style—beginning, current, or end of career. At the beginning of their teaching careers, all five of the research participants taught the way they had been taught, using a teacher-directed pedagogy. This finding is supported by previously noted research stating that approximately $90 \%$ of United States mathematics 
teachers instruct using a teacher-directed pedagogy (Kilpatrick, 2009). Over the course of their career, through making the acquaintance of mentors and attending highly influential professional development, the participants began the process of changing their teaching to better reflect the NCTM standards. In doing so, the participants altered their thinking about how people learn mathematics; they began to view learning in terms of a constructivist framework. Their reformed beliefs regarding how students learn guided their choice of teaching methods and curricula, and informed their use of technology. These beliefs also changed their view of the student/teacher relationship. At the beginning of their career, the participants viewed this relationship in a traditional manner. Each participant viewed him or herself as the dispenser of information, the manager of the classroom, and the assessor of their students' knowledge of mathematics. Over the course of their careers, all five participants adopted a constructivist view of the student/teacher relationship. According to this view, student knowledge is developed by students themselves, with the teacher providing mathematics materials, technology, and guidance during the process of constructing knowledge.

Sherin (2002) contended that teachers are able to use SBC pedagogy in their classroom if they increase their understanding of the subject matter, of the curriculum materials, and of student learning. J. A. Thomas and Monroe (2006) maintained that changing to a standards-based teaching pedagogy is a commitment to continuous growth, not a final destination. All five participants in this research study continually went about incrementally changing their teaching methods during their teaching career. 


\section{Conclusion}

Both the common and unique findings of this research study give rise to recommendations that have significance to educational leaders at the local and state levels. Also, with the introduction of the Mathematics Common Core Standards in 45 of the 50 states of the United States, a case could be made that the findings of this study have implications nationally. The following Common Core process standards emphasize many of the problem-solving strategies stressed by SBC teaching:

- CCSS.Math.Practice.MP1: Make sense of the problems and persevere in solving them.

- CCSS.Math.Practice.MP2: Reason abstractly and quantitatively.

- CCSS.Math.Practice.MP4: Model with mathematics.

- CCSS.Math.Practice.MP5: Use appropriate tools strategically.

- CCSS.Math.Practice.MP7: Look for and make use of structure.

- CCSS.Math.Practice.MP8: Look for and express regularity in repeated reasoning.

Edenfield (2012) contended that Common Core Process Standards align with the NCTM standards and principles, and that using SBC pedagogy in the classroom would benefit students in terms of developing problem-solving skills that in turn would improve their chances of doing well on the Common Core mathematics assessments that are administered to public school students in all 45 states. Based on the findings of this research, both in terms of themes and the applicable literature, the following recommendations are being offered. 


\section{Recommendations}

\section{Effective Mentoring}

As noted earlier, Ball and Cohen (1999) contended in their research that successful mentoring involves the fostering of a desire in beginning teachers to examine their students' mathematical understanding. They further noted that for this to occur the mentor needs to promote involvement with fellow mathematics teachers both inside and outside the teacher's school. The involvement outside of school should include membership in teaching professional organizations, enrollment in workshops, and conference attendance. Friedrichsen, Chval, and Teuscher (2007) concurred with the idea that beginning mathematics teachers should focus on their students' mathematical understanding, and they maintained that for this to happen there needs to be collaboration with fellow teachers and teachers outside of the school. All five of this research study's participants benefitted extensively from their association with a mentor. Along with learning the day-to-day running of a classroom, all participants, with the urging of their mentors, became involved with both their state mathematics teaching organization and the NCTM. This form of mentoring has significant implications for school administrators, for teacher educators, and for educational researchers.

Implications for school administrators. Beginning teachers are overwhelmed by the amount of learning that is required to effectively manage and teach in their classroom (Feiman-Nemser, 1992; Gratch, 1998; Windschitl, 1999). Ingersoll (2001) estimated that $40 \%$ to $50 \%$ of beginning teachers quit the profession before their fifth year of teaching, and roughly $17 \%$ of beginning teachers quit after one year of teaching. According to 
Ingersoll (2003), beginning teacher attrition dramatically affects the performance of schools. In a review of the literature on teacher attrition and retention, Borman and Dowling (2008) cited studies on beginning teachers in the United States that contended beginning teachers were frequently given the most difficult assignments, and provided limited class resources compared to veteran teachers. These novice teachers often confronted these conditions with little support from either their administration or colleagues. The authors maintained that these factors contribute to the nation's high beginning teacher turnover rate relative to other developed nations. The authors also noted that school districts that provide beginning teachers with support in the form of mentoring programs have decreased the attrition of their novice teachers.

School administrators aware of these statistics and their implications have turned to mentoring in the recent years. However, the results of mentoring have been mixed. Ball and Cohen (1999) observed that mentoring programs that lessened teacher attrition involved mentor promotion of professional development opportunities for beginning teachers. Furthermore, data obtained in this research study strongly support that an effective mentoring program must have the following components: (a) the mentor actively collaborating with the mentored teacher on day-to-day management of classroom, (b) the mentor and mentored teacher collaborate and reflect on teaching pedagogy and curriculum, (c) the mentor and mentored teacher are members of the state mathematics teaching organization and NCTM, and (d) the mentor and mentored teacher are active participants in both in-district and out-of-district professional development. 
Based on the above research, school administrators need to allot time and money to allow both the mentor and mentored teachers to attend professional development opportunities both inside and outside of the school district. Furthermore, time should be allotted to the mathematics department to regularly meet and discuss the teaching of students. In this research study, Damon experienced such opportunities in his first high school job. His mathematics department chairman insisted that all of the mathematics teachers have the same preparation period and lunch. This common time allowed the department to continually collaborate with each other. Damon cited this circumstance as the main reason he continued teaching. Meredith and her mentor, John, were given money and time by their school administrator to attend a 2-week NSF-funded workshop. Meredith stated that this workshop dramatically changed her teaching pedagogy and significantly increased her appetite for professional development opportunities. Cole and his mentor, Janice, were given both time and money to attend and participate in training for an NSF-funded curriculum in problem-solving. This collaboration between Cole and Janice led to other opportunities for Cole to advance his knowledge of SBC teaching methods. In the above research examples, the participants benefitted from their administrators' support in terms of money and time. It should also be pointed out that their administrators also benefitted because they were developing better teachers.

Implications for teacher educators. In the past, once students graduated from a university or college teacher education program, their development as a teacher was viewed as discrete steps of professional development. This professional development was frequently left to the teacher to navigate, with little assistance. In some cases, a new 
beginning teacher received mentoring, and as noted above, but this approach has produced mixed results throughout the United States. Barnes-Ryan (2010) maintained that mentoring needs to be reconceptualized, and school districts should partner with outside sources such as local universities and colleges to help with the mentoring process. Creating a mentoring program involving school districts and universities would allow beginning teachers to create beneficial connections in the school district's mentor program and access to future professional development. Guise (2013) argued that universities and colleges can play an important role in developing mentoring prior to graduation. For example, she suggested current students could form mentoring relationships with alumni currently teaching. In redefining the mentoring process, current preservice education students will begin their teaching careers with a concept of what a good mentoring program entails.

Implications for education researchers. The mentoring process involves a complex relationship between the mentor and beginning teacher. Each has countless personal needs and numerous interactions that enter into the mentoring process. Waterman and $\mathrm{He}$ (2011) asserted that, given this fact, it is not possible to consider the mentoring process a linear one. If the beginning teacher leaves the profession, it is very hard to establish the cause of his or her departure. Instead, the authors suggest a more apt use of research would be studying: (a) the quality of a mentoring program with in-depth qualitative research, (b) the "how" and "in what context" of the mentoring program, and (c) the mentoring process rather than the program. In adhering to these research 
recommendations, educators, when considering a mentoring program, can access research that addresses the question, "What works?"

\section{Successful High School SBC Teaching}

The research participants in this study were successful high school mathematics teachers who received the PAEMST. They all evolved from teaching using a teacherdirected pedagogy to an SBC pedagogy. All had taught various high school classes ranging from pre-algebra to calculus. Mitch, Rachael, and Damon successfully taught AP mathematics courses. As noted in the literature review, there have been multiple research studies on the use of SBC teaching at the elementary and middle school levels. There also have been studies of the effectiveness of SBC teaching on students' achievement in terms of written objective tests (Harwell et al., 2013; McCaffrey et al., 2001). According to Slavin, Lake, and Groff (2009), there have been numerous studies on the effectiveness of NSF-funded SBC curricula, but very little research on SBC teaching methods. Both the $\operatorname{NCTM}(1989,2000)$ and the National Research Council (2004) advocated the use of SBC teaching methods. In this research study the participants used SBC teaching methods. For example, Rachael, Mitch, and Damon used mathematically rich tasks to initiate a class, and Cole emphasized helping his students with metacognition. However, I feel this research study points to the fact that there needs to be more research on identifying successful high school mathematics teachers using the SBC teaching methods. As previously noted, there has been a large amount of research on the successful application of SBC mathematics teaching methods in the elementary and middle school levels, but little research on the successful use of SBC mathematics teaching methods at the high 
school level. According to Weiss and Raphael (1996), 97\% of PAEMST high school mathematics teachers use SBC teaching methods. These high school teachers, by virtue of being PAEMST recipients, are noted successful and effective mathematics teachers. As such, further research that involves this group could provide vital information on such topics as their SBC teaching methods, their classroom environments, their leadership skills inside and outside of the classroom, and their relationships with students. Such research findings would have implications for high school mathematics teachers attempting to teach utilizing SBC teaching methods, school administrators who wish to incorporate SBC teaching in their school, and teaching educators who are teaching SBC teaching methods in their teacher preparation courses.

Implications for high school mathematics teachers. As noted above, there is little research on effective SBC teaching methods (Slavin et al., 2009). All five of the research participants benefitted from their exposure to the SBC teaching methods they encountered in professional development. Frequently, they would go back to their classroom and apply what they learned from these educational opportunities. The research participants did so speculating that these teaching methods helped their students create an understanding of mathematical concepts and processes. All the participants evaluated the effectiveness of these new teaching methods using summative assessments of their students' mathematical understanding and seeking out their students' personal evaluation of their teaching techniques. For example, Rachael and Mitch, as noted earlier, ended up taking summer courses on teaching calculus using SBC teaching methods. The following fall, both teachers applied their newly-acquired SBC teaching methods to their 
AP Calculus classes. They immediately noticed that their students became engaged in developing an understanding of the calculus concepts and procedures. Throughout the remainder of the year, both Rachael and Mitch continued to use the SBC teaching techniques. These teachers evaluated both their students' mathematical understanding and their observations regarding the SBC teaching methods utilizing formative assessment techniques. At the end of the year, all of their students passed the AP Calculus examination. Teachers who wish to develop and use an SBC teaching pedagogy would benefit from being exposed to success stories like those of Rachael and Mitch. Cole, David, and Meredith reported gains for their students on state test scores, which they contributed to their students developing mathematical understanding. Based on these encouraging successes of the five research participants, I propose further research on noted, successful high school mathematics teachers (possibly PAEMST recipients) who employ SBC mathematics teachers' teaching methods. Such research could possibly supply data that could be used by current and future high school mathematics teachers who wish to use an SBC teaching pedagogy in their classrooms.

Implications for school administrators. The implications of the successful SBC teaching of high school mathematics teachers are considerable. As noted above, with 45 of the 50 states adopting the Common Core Standards, administrators must adjust their thinking about educational leadership. According to Marsh and LeFever (2004), principals/heads need to rethink their management style. A collaboration between teachers and administration needs to be created that allows for focusing on restructuring learning and teaching in the schools. 
In this research, all the participants had to work with their school's administrators to develop their understanding of SBC teaching pedagogy. Except for Damon, none of the participants' administrators came from a mathematics teaching background. These administrators' concepts of a mathematics classroom were based on the traditional teacher-directed pedagogy they had experience as students. Each participant educated their administrators about their SBC teaching pedagogy. In Cole's case, two of his administrators became very excited about what was happening in his classroom, and they became supporters of his mathematics leadership. The benefits of the research participants' collaboration with their administrators were reciprocal, as the principals were exposed to successful teaching methods, and the participants developed powerful allies and advocates.

Implications for teacher education. Preservice mathematics teachers go through a long process to become teachers. Typically, these teachers go through an apprenticeship of observation that might resemble their own K-12 education (Cohen \& Ball, 1999; Sowder, 2007). This apprenticeship can lead to a traditional view of mathematics teaching based on teacher-directed pedagogy. Teachers who go through this type of preparation program enter the teaching profession teaching the way they were taught. In this research study, all five of the participants started their teaching career using a traditional teacher-directed pedagogy. For future mathematics teachers to enter the teaching profession using an SBC teaching pedagogy, preservice instruction must involve classroom activities in which future mathematics teachers experience instruction that emphasizes SBC teaching methods (Huffman, Lawrenz, \& Thomas, 2008). Frykholm 
(1999) found that 58 beginning teachers viewed the NCTM Standards as fragmented topics pertaining to teacher performance instead of student learning. Based on this finding, he recommended that students in preservice education and mathematics need to experience the standards as students rather than teachers. Meredith, Rachael, and Cole took classes in graduate school that exposed them to SBC teaching methods. All three reported that these classes had a dramatic effect on their teaching practice. Meredith stated that the courses were highly influential in changing her teaching pedagogy to one based on SBC philosophy. Rachael spoke favorably of a Probability/Statistics teacher's use of mathematically rich tasks to teach the topics of the class, and she adopted the use of mathematically rich tasks in all her classes. Cole felt that the emphasis on his metacognition in his graduate classes inspired him to work on his own students' abilities to examine their cognitive processes when engaged in learning. He contended that he gained a deep insight into how to approach a mathematical task, to examine comprehension, and to evaluate the process of his task through its completion. He felt that this process made him a stronger mathematics student, and he wanted his students to have similar experiences.

Though it was not an area of study in this research, the following is a discussion of possible changes in education policy that might affect the use of SBC teaching pedagogy in classrooms. If implemented, such policy changes could dramatically support its usage. 


\section{Policy and SBC Teaching}

As detailed in the literature review, mathematics teachers who utilize an SBC teaching pedagogy actively provide tools, such as problem-solving and inquiry-based learning activities, with which students may formulate and test their ideas, draw conclusions and inferences, and pool and convey their knowledge in a collaborative learning environment. In doing so, the mathematics teachers' role in the classroom dramatically changes. The activities guide their students toward developing a conceptual understanding of mathematics. This teaching pedagogy significantly changes the roles of both the teacher and the students in a classroom. Instead of lecturing and demonstrating isolated mathematical procedures, SBC mathematics teachers engage their students in solving mathematically rich tasks. To accomplish this, teachers must develop teaching methods and skills that are unique to such a classroom environment. As noted in the literature review, some of these skills are: (a) learning to manage a classroom of student collaborative groups, (b) promoting problem-solving and sense-making skills, (c) asking probing questions to students to advance their thinking, and (d) insisting that students demonstrate and defend their thinking. An SBC mathematics classroom looks radically different from a traditional teacher-directed classroom, and to support such a learning environment requires new school policies.

\section{SBC Teaching and Student Equity}

The five research participants believed in the idea of equity. That is, they had faith that all of their students were capable of learning mathematics, and they acted on that belief. The concept of equity is a one of the six guiding principles advocated by the 
NCTM in its 1989 Principles and Standards for School Mathematics. The authors of the publication maintained that the Equity Principle calls for high expectations for all students, communicated through words and actions to all students. The authors added that, to achieve equity, resources and support need to be allocated to all classrooms and all students. Research has shown that all students, including those typically underserved, can learn mathematics when they have access to mathematics programs that support their learning (Silver \& Stein, 1996). However, according to Darling-Hammond (2004), students of different races and social-class backgrounds have disparate access to quality instruction compared to socially advantaged groups of students. Based on research on the Chicago Public School system, Diamond and Spillane (2007) contended that the majority of students of minority groups and those who are economically underprivileged received traditional, teacher-directed mathematics instruction, while their white counterparts received mathematical instruction more in line with SBC pedagogy. He went on to assert that the policies that ambitiously promote SBC instruction failed when teachers, who were more comfortable teaching using a teacher-directed pedagogy, made superficial changes that blended into their established teacher-directed teaching methods. Diamond concluded from his research that change in the classroom is seldom motivated by educational policy unless the policy is supported by tools that affect change. Accordingly, teachers who have traditionally used a teacher-directed pedagogy must have access to ongoing professional development that allows them to experience and reflect on SBC teaching methods in order to adopt and use such methods in their classroom. 


\section{SBC Teaching and Professional Development Support}

The five research participants attributed their growth as SBC teachers to their commitment to professional development. All the participants were the beneficiaries of support in terms of money and time from their school districts, professional teaching organizations such as the NCTM, and the federal government in the form of prize money from the PAEMST and Eisenhower grant money. S. M. Wilson, Darling-Hammond, and Berry (2001) studied the State of Connecticut Department of Education's (CDE) implementation of a series of quality policies intended to support student learning. The authors chose to study Connecticut because their students led the nation in reading and mathematics scores in the fourth and eighth grades in 1998. The state's high school students ranked number two in the world in science, behind Singapore, on the 1998 Third International Math and Science Study. The authors attributed these results to the CDE's ongoing investment in improving teaching, and particularly the CDE policies seeking improvement in teaching pedagogy, emphasizing the development of students' problemsolving skills and conceptual knowledge. Similar policies that promote ongoing professional development in SBC teaching methods for high school mathematics need to be enacted in all states. As noted in the literature review, without such support, the majority of high school mathematics teachers continue to teach using traditional teacherdirected methods.

\section{SBC Teaching and Smaller Class Size}

The policy of reducing class size has been historically viewed as serving two goals: (a) increasing the academic achievement of all students, and (b) closing the 
achievement gap between low- and high-achieving students (Konstantopoulos \& Chung, 2009). Research has shown that a reduction in class size grades 1-8 does improve student achievement (Graue, Oen, Hatch, Rao, \& Fadali, 2005). Rice (1999) found that as the population of a high school mathematics classroom increases teachers spend less time on: (a) innovative instructional practices, (b) small group collaboration, and (c) whole-group discussions. As noted in the literature review, these three teaching practices are integral parts of SBC mathematics teaching. However, Rice noticed that teachers assigned to teach more advanced mathematics classes in high school were more likely to use both innovative instruction and small group collaboration if the class size was reduced. This was not true for classes where the ability level of the students was judged to be low. However, based on her findings, Rice advocated for the policy of decreasing class size in high school mathematics because, in doing so, teachers were likely to spend more time on the above three teaching processes.

It should be noted here that the five research participants employed SBC teaching methods in all of their courses, regardless of the level of mathematical knowledge of their students. According to these teachers, all students were capable of learning mathematics. Decreasing class sizes were viewed by the participants as having a positive impact on their SBC teaching, because it allowed them to better attend to each student's needs.

\section{Limitations of the Research Study}

Elliot (1995) maintained that the aim of qualitative research is understanding participants' perspective in terms of a particular phenomenon. Researchers cannot set aside their own perspective totally. However, qualitative researchers believe that their 
own values allow them to understand and represent their participants' perspectives and experiences with validity. Nonetheless, qualitative researchers realize that they enter into their research with certain predispositions and preconceptions. This research has such biases, and the following is a discussion of these biases, which include (a) owning my perspective, (b) situating the research sample, (c) the study's methodology, and (d) the reliability of the data.

\section{Owning My Perspective}

This research study examines teachers who have developed and employed SBC teaching pedagogy in their classroom. The research participants are high school mathematics teachers who are both PAEMST recipients and CPAM members. I was a high school mathematics teacher, PAEMST recipient, and CPAM member, and, as such, I came to this research study with certain predispositions and preconceptions. Like all the participants, I started teaching using teacher-directed teaching methods, and over the course of my teaching career, I evolved into a mathematics teacher who employed SBC pedagogy in my classroom. As noted in the Introduction section, this teaching transformation created a desire to study similar high school mathematics teachers' journeys.

\section{Situating the Research Sample}

The participants in this research study are five high school mathematics teachers who either are currently teaching or retired. All five of the participants were chosen because they are high school mathematics teachers who are PAEMST recipients and members of CPAM. The participants are all Caucasian, two females and three males, 
with ages ranging from 45 to 64 . They all taught in predominately white suburban or rural private and public schools. All the participants self-reported that during their teaching career they transformed their teaching practice from one based on the traditional teaching of mathematics using a teacher-directed pedagogy to teaching using an SBC pedagogy. No successful high school mathematics teachers that either used a teacherdirected pedagogy or employ SBC pedagogy, but were not former PAEMST recipients and CPAM members, were involved in this research study. Including such teachers was beyond the scope of this research study.

\section{The Research Study's Methodology}

Critics of qualitative research have asserted that the research methodology is too subjective, in large part because the researcher is both the data collector and interpreter. Furthermore, according to Patton (1990), the methodology involves personal contact with the research participants, which could lead to misinterpretation of the data. In this study, contact and collaboration with the research participants were an integral part of the research methodology, narrative inquiry. Connelly and Clandinin (1990) likened the collaboration that exists in narrative inquiry to friendship. According to the authors, “friendship implies a sharing, an interpenetration of two or more persons' sphere of experience" (p. 4). This type of collaboration is an integral part of narrative inquiry, and informed the present study's approach to collecting narratives.

For this study, I conducted a personal one-on-one interview with each participant. The purpose of the interview was to collect the participant's story about the journey he or she took to become recognized as a successful high school mathematics teacher. I used 
both open-ended and leading questions. I also used my experiences as a high school mathematics teacher and former PAEMST recipient to elicit more information in the interviews. I was an active collaborator in the interview, which, as noted above, is a vital part of the narrative inquiry methodology. A collaboration between the participant and myself continued in the next part of the narrative inquiry process, in which, after collecting the initial data from the one-on-one interviews, I created narratives for all of the participants that summarized the journeys they had traveled to become nationally recognized, successful mathematics teachers. I sent each participant his or her narrative and we collaborated on it via telephone. Once again, I relied on my personal experience as a high school mathematics teacher, former PAEMST recipient, and CPAM member. Based on this collaboration, I rewrote their narratives, adding and removing information from the initial written narrative. This process assured me that I had written a valid, credible narrative of their journey. However, in assuring validity, I lost some reliability.

\section{Reliability of the Data}

According to Merriam (1995), the real question about reliability in qualitative research, such as narrative inquiry, is not whether the results of one study are the same as subsequent studies, but "whether the results of a study are consistent with the data collected" (p. 56). One method for assuring this is using the triangulation process.

In this study, data were collected from all of the participants' PAEMST application forms that addressed both their concept of learning and how they applied it in their classroom. I used these documents to create questions for the one-on-one interview, and as a source of data for this research. I also explored the documents for possible 
research themes. Having used the documents in this manner, I also elected to use the narratives as a further source of data. However, I did not have a third piece of information, for example, a survey like the Constructivist Learning Environment Survey, that would enable the process of triangulation, and as a result the reliability of the research study was compromised.

Despite these limitations, the reader can be assured that the procedures for narrative inquiry as mapped out in the Methodology section of this paper were followed faithfully. The results of the study can be viewed by the reader as valid because close attention was given to the perspectives of the research participants.

\section{Conclusion}

\section{Discussion}

This study examined the stories of five high school mathematics teachers who were both PAEMST recipients and CPAM members. Over the course of their teaching careers the participants had transformed their teaching pedagogy from a teacher-directed to an SBC approach. The qualitative methodology of narrative inquiry was chosen for this research because it was best suited to address the three research questions:

1. What are the paths SBC secondary mathematics teachers who received the PAEMST pursued to become highly effective?

2. What obstacles and challenges did they encounter and how were these obstacles overcome?

3. What sustained them on their journeys?

As noted in the above Limitations section, this narrative lacks reliability.

However, the use of narrative inquiry in this research study was purposeful because it guaranteed internal validity. According to Merriam (1995), the use of qualitative research 
assumes the belief that reality is relatively true; it is ever-changing. For the qualitative researcher, there is no such thing as a completed reality waiting to be studied. Both the researcher and the participant can offer their own interpretations of reality. The five research participants presented their own understanding of their reality, and in writing the first narrative from the one-on-one interviews, I wrote my own interpretation of each participant's reality. Sending each participant my interpretative narrative allowed me to ascertain if my interpretative narrative was plausible and accurate in terms of the participant's reality. Merriam asserted that this method, called "member check" (p. 54), is utilized to strengthen the internal validity of a qualitative research study. Ensuring the research had internal validity provided a foundation for looking for research themes in the five final narratives, as it assured me that data the narratives created addressed the three research questions.

\section{Implications of the Research}

The implications of this research study are based on the concept of the external validity, or generalization. When looking at research, most people associate generalization with a "statistical sense of extrapolating from a sample to a population" (Merriam, 1995, p, 57). Qualitative research studies, with their smaller, less random populations, have results that cannot be generalized. However, as noted earlier in chapter 5, the findings from this research have implications for high school mathematics teachers, school and district administrators, college educators, and educational researchers. In particular, I had hoped that this research could be used as a source of information for high school mathematics teachers who wish to begin the process of developing SBC teaching 
pedagogy. Realizing that this is one of the first studies of highly successful high school mathematics teachers, it is anticipated that there will be further research on the subject.

\section{Further Research}

Based on the limitations of this research study, additional research is recommended. The five research participants are from the western and upper Midwestern states; further research is recommended for identifying highly effective, high school mathematics teachers who use SBC teaching pedagogy from different demographic areas of the United States. Since the five participants in this study were Caucasian, research that involves non-white high school mathematics teachers who are successful at employing SBC teaching methods is recommended. Increasing the number of participants in future research would add further insight regarding the development and use of successful SBC pedagogy.

Both the common and unique findings of this research study indicate the need for more research. In particular, the unique findings regarding personality traits and student influence could be studied further. For example, research on personality traits of PAEMST recipients might yield information that to be used by education researchers as the foundation for further studies. The influence of students on the five participants is important because educational research at this point has devoted little attention to the topic. The vast amount of research on influence has focused on the influence teachers have on their students. This imbalance implies the teacher-student relationship is onesided. The findings regarding common themes require further study. There has been little 
research on the effect these themes have on high school mathematics teachers using SBC pedagogy in their classroom.

The findings of this research study may be considered to have minimal external validity because of the size of the research population. However, this research study points to a glaring hole in the research on what makes a successful high school mathematics teacher. This study should be viewed as a catalyst for a discussion at the local, state, and national levels about the concept of effective high school mathematics teaching. Is it to be defined, as has been for the last century, as the teaching of a set of isolated skills and procedures, or as the use of problem-solving, collaboration, and reason-making on mathematical rich tasks? It is this researcher's hope that the present research study will promote discussion and further research on this question.

\section{Personal Reflections}

I started this research study with the intention of shedding light on the teachers, like myself, who developed and used an SBC approach to teaching in their high school mathematics classroom. I felt that my research initiated the conversation on what constitutes effective mathematics instruction at the high school level.

Going through the process of writing a dissertation, I learned many invaluable lessons. I became knowledgeable about what it meant to be a scholar and researcher. Through my extensive research for my literature review, I became acquainted with the leaders in the field of mathematics education who advocate the use an SBC pedagogy in high school mathematics classrooms. Twice I conferred with several of these leaders. In doing so, I entered into the world of academic research. Throughout my dissertation 
process, my conversations with professors at my institution were both eye-opening and gratifying. The information these professors provided was rewarding, but more important to me, I came away from these conversations with the feeling that I was viewed as a legitimate academic equal.

With my choice of using the narrative inquiry methodology in my research study, I became an active collaborator with the research participants. I was able to create five narratives that address their mathematical teaching journeys, and was surprised to find that their journeys were similar to the one I made. This insight made me realize that our journeys were valuable, and that there needs to be further studies of high school mathematics teachers like this study's five participants.

Finally, through taking part in the dissertation process, I developed a deep respect for research and what it can mean to the field of mathematics education. As a mathematics teacher, I had little time to delve into research. My knowledge of pertinent research in the field of mathematics education came at conferences and workshops. I frequently tried to use findings from my classroom, but I never sought out research on my own. Now that I know what a research study entails, I will return to researching subjects related to the present study in order to aid fellow mathematics teachers. 


\section{REFERENCES}

American Educational Research Association. (1990). Educational evaluation and policy analysis. Washington, DC: Author.

Anderson, R. (2007). Being a mathematics learner: Four faces of identity. The Mathematics Educator 17(1), 7-14.

Anghileri, J. (2006). Scaffolding practices that enhance mathematics learning. Journal of Mathematics Teacher Education, 9(1), 33-52.

Applefield, J. M., Huber, R., \& Moallem, M. (2000). Constructivism in theory and practice: Toward a better understanding, The High School Journal, 84(2), 35-53.

Appleton, K., \& Asoko, H. (1996). A case study of a teacher's progress toward using a constructivist view of learning to inform teaching in elementary science. Science Education, 80(2), 165-180.

Ausubel, D. P. (2000). The acquisition and retention of knowledge: A cognitive view. Dordrecht, Netherlands: Kluwer Academic Publishers.

Balacheff, N. (1990). Towards a problématique for research on mathematics teaching. Journal for Research in Mathematics Education, 21(4), 258-272.

Ball, D. L. (1990a). Breaking with experience in learning to teach mathematics: The role of a preservice methods course. For the Learning of Mathematics, 10(2), 10-17.

Ball, D. L. (1990b). The mathematical understandings that prospective teachers bring to teacher education. The Elementary School Journal, 90(4), 449-466.

Ball, D. L. (1993). With an eye on the mathematical horizon: Dilemmas of teaching elementary school mathematics. Elementary School Journal, 93(4), 373-397.

Ball, D. L. (1996). Teacher learning and the mathematics reforms: What we think we know and what we need to learn. Phi Delta Kappan, 77(7), 500-508.

Ball, D. L. (1997). From the general to the particular: Knowing our own students as learners of mathematics. Mathematics Teacher, 90(9), 732-737.

Ball, D. L., \& McDiarmid, G. W. (1988). Research on teacher learning: Studying how teachers' knowledge changes. Action in Teacher Education, 10(2), 17-23. 
Ball, D. L., Thames, M. H., \& Phelps, G. (2008). Content knowledge for teaching: What makes it special? Journal of Teacher Education, 59(5), 389-407.

Ball, D. L., \& Cohen, D. (1999). Developing practice, developing practitioners: Toward a practice based theory of professional education. In G. Sykes \& L. DarlingHammond (Eds.), Teaching as the learning profession: Handbook of policy and practice (pp. 3-32). San Francisco, CA: Jossey-Bass.

Ball, D. L., Lubienski, S., \& Mewborn, D. (2001). Research on teaching mathematics: The unsolved problem of teachers' mathematical knowledge. In V. Richardson (Ed.), Handbook of research on teaching ( $4^{\text {th }}$ ed.; pp. 433-456). New York, NY: Macmillan.

Bandura, A. (1996). Multifaceted impact of self-efficacy beliefs on academic functioning. Child Development, 67(3), 1206-1222.

Banner, J. M., \& Cannon, H. C. (1997). The elements of teaching. New Haven, CT: Yale University Press.

Barnes-Ryan, S. G. (2010), The first two years of teaching. English Journal, 99(3), 84-86.

Baroody, A. J. (1993). Problem-solving, reasoning, and communicating, K-8: Helping children think mathematically. New York, NY: Merrill.

Bartell, T. G., \& Meyer, M. R. (2008). Addressing the equity principle in the mathematics classroom. Mathematics Teacher, 101(8), 604-608.

Battista, M. T. (1999). The mathematical miseducation of America's youth: Ignoring research and scientific study in education. Phi Delta Kappan, 80(6), 424-433.

Beck, J., Czerniak, C. M., \& Lumpe, A. T. (2000). An exploratory study of teachers' beliefs regarding the implementation of constructivism in their classrooms. Journal of Science Teacher Education, 11(4), 323-343.

Bell, A. (2003). A narrative approach to research. Canadian Journal of Environmental Education, 8(1), 95-110.

Benander, L., \& Clement, J. (1985). Catalog of error patterns observed in courses on basic mathematics: Working draft. Washington, DC: U.S. Dept. of Education, Office of Educational Research and Improvement, Educational Resources Information Center.

Black, P., \& Wiliam, D. (1998). Assessment and classroom learning, Education: Principles, Policy and Practice, 5(1), 7-74. 
Black, P., \& Wiliam, D. (1998). Inside the black box: Raising standards through classroom assessment. Phi Delta Kappan, 80(2), 139-144.

Boaler, J. (1998). Open and closed mathematics: Student experiences and understandings. Journal for Research in Mathematics Education, 29, 41-62.

Boaler, J., \& Greeno, J. G. (2000). Identity, agency, and knowing in mathematics worlds. In J. Boaler (Ed.), Multiple perspectives on mathematics teaching and learning (pp. 171-200). Westport, CT: Ablex.

Bogdan, R. C., \& Biklen, S. K. (2006). Qualitative research for education: An introduction to theory and methods. Boston, MA: Pearson.

Borko, H., \& Livingston, C. (1989). Cognition and improvisation: Differences in mathematics instruction by expert and novice teachers. American Educational Research Journal, 26(4), 473-498.

Borko, H., Eisenhart, M., Brown, C. A., Underhill, R. G., Jones, D., \& Agard, P. C. (1992). Learning to teach hard mathematics: Do novice teachers and their instructors give up too easily? Journal for Research in Mathematics Education, 23(3), 194-222.

Borman, G. D., \& Dowling, N. M. (2008). Teacher attrition and retention: A metaanalytic and narrative review of the research. Review of Educational Research, 78(3), 367-409.

Bosworth, K. (1995). Caring for others and being cared for: Students talk caring in school. Phi Delta Kappan, 76(9), 686-693.

Brendehur, J., \& Frykholm, J. (2000). Prompting mathematical communication in the classroom: Two preservice teachers' conceptions and practices. Journal of Mathematics Teacher Education, 3, 125-153.

Brooks, J. G., \& Brooks, M. G. (1999). In search of understanding: The case for constructivist classrooms. Alexandria, VA: Association for Supervision and Curriculum Development.

Brophy, J. (1982). Successful teaching strategies for the inner-city child. The Phi Delta Kappan, 63(8), 527-530.

Bruner, J. S. (1961). The act of discovery. Harvard Educational Review, 31, 21-32.

Burrill, G. (1997). The NCTM Standards: Eight years later. School Science and Mathematics, 97(6), 335-339. 
Carlsen, W. S. (1992). Closing down the conversation: Discouraging student talk on unfamiliar science content. Journal of Classroom Interaction, 27(2), 15-21.

Carter, K (1993). The place of story in the study of teaching and teacher education. Educational Researcher, 22(1), 5-12.

Cavanagh, M., \& Prescott, A. (2010). The growth of reflective practice among three beginning secondary mathematics teachers. Asia-Pacific Journal of Teacher Education, 38(2), 147-159. doi:10.1080/13598661003678968

Chazan, D., \& Ball, D. (1999). Beyond being told not to tell. For the Learning of Mathematics, 19(2), 2-10.

Chiu, M. S., \& Whitebread, D. (2011). Taiwanese teachers' implementation of a new "constructivist mathematics curriculum": How cognitive and affective issues are addressed. International Journal of Educational Development, 31(2), 196-206.

Clandinin, D. J., Pushor, D., \& Orr, A. M. (2007). Navigating sites for narrative inquiry. Journal of Teacher Education, 58(1), 21-35.

Cobb, P. (1988). The tension between theories of learning and instruction in mathematics education. Educational Psychologist, 23(2), 87-103.

Cobb, P., Boufi, A, McClain, K., \& Whitenack, J. (1997). Reflective discourse and collective reflection. Journal for Research in Mathematics Education, 28(3), 258-277.

Cobb, P., Wood, T., \& Yackel, E. (1990). Chapter 9: Classrooms as learning environments for teachers and researchers. Journal for Research in Mathematics Education. Monograph, 4, 125-146.

Cobb, P., Wood, T., Yackel, E., \& McNeal, B. (1992). Characteristics of classroom mathematics traditions: An interactional analysis. American Educational Research Journal, 29(3), 573-604.

Cobb, P., Yackel, E., \& Wood, T. (1992). A constructivist alternative to the representational view of mind in mathematics education. Journal for Research in Mathematics Education, 23(1), 2-33.

Cohen, D. K. (1987). Educational technology, policy, and practice. Educational Evaluation and Policy Analysis, 9(2), 153-170.

Cohen, D. K. (1990). A revolution in one classroom: The case of Mrs. Oublier. Educational Evaluation and Policy Analysis, 12(3), 311-329. 
Cohen, D. K., \& Ball, D. L. (1990). Policy and practice: An overview. Educational Evaluation and Policy Analysis, 12(3), 233-239.

Coles, R. (1989). The call of stories: Teaching and the moral imagination. Boston, MA: Houghton Mifflin.

Colvin, R. L. (1999). Math wars: Tradition vs. real-world applications. School Administrator, 56(1), 26-31.

National Research Council, \& National Research Council. (1989). Everybody counts: A report to the nation on the future of mathematics education. Washington, DC: National Academy Press.

Confrey, J. (1990). Chapter 8: What constructivism implies for teaching. Journal for Research in Mathematics Education. Monograph, 4, 107-122.

Connelly, F. M., \& Clandinin, D. J. (1988). Teachers as curriculum planners: Narratives of experience. New York, NY: Teachers College Press.

Connelly, F. M., \& Clandinin, D. J. (1990). Stories of experience and narrative inquiry. Educational Researcher, 16(5), 2-14.

Cook-Sather, A., \& Shultz, J. (2001). Starting where the learner is: Listening to students. In J. Shultz \& A. Cook-Sather (Eds.), In our own words: Students' perspectives on school (pp. 1-17). Lanham, MD: Rowman \& Littlefield

Cooney, T. J. (1988). The issue of reform: What have we learned from yesteryear? Mathematics Teacher, 81(5), 352-363.

Coulter, C. A., \& Smith, M. L. (2009). The construction zone: Literary elements in narrative research. Educational Researcher, 38(8), 557-590.

Council of Presidential Awardees in Mathematics. (2009). Background of the Presidential Awards Program. Retrieved from http://www.cpam.teachersdg.org/

Covey, S. R., \& Gulledge, K. A. (1994). Principle-centered leadership and change. The Journal for Quality and Participation, 17(2), 12-21.

Creswell, J. W. (2008). Educational research: Planning, conducting, and evaluating quantitative and qualitative research. Upper Saddle River, NJ: Pearson/Merrill Prentice Hall.

Crites, S. (1986). Storytime: Recollecting the past and projecting the future. In T. R. Sarbin (Ed.), Narrative psychology: The storied nature of human conduct (pp. 152-167). New York, NY: Praeger. 
Cuban, L. (1990). Reforming again, again, and again. Educational Researcher, 19(1), 3-13.

Cuban, L. (1993). How teachers taught: Constancy and change in American classrooms, 1890-1990. New York, NY: Teachers College Press.

Dahl, K. (1995). Challenges in understanding the learner's perspective. Theory into Practice, 43(2), 124-130.

Dangel, J. R., Guyton, E., \& McIntyre, C. B. (2004). Constructivist pedagogy in primary classrooms: Learning from teachers and their classrooms. Journal of Early Childhood Teacher Education, 24(4), 237-245.

Darling-Hammond, L. (1997). School reform at the crossroads: Confronting the central issues of teaching. Educational Policy, 11(2), 151-166.

Darling-Hammond, L. (2004). Standards, accountability, and school reform. Teachers College Record 106, 1047-1085.

Davis, B., \& Sumara, D. (2002). Constructivist discourses and the field of education: Problems and possibilities. Educational Theory, 52(4), 409-428.

Delpit, L. D. (1995). Other people's children: Cultural conflict in the classroom. New York, NY: New Press.

Delpit, L. D. (2006). Lessons from teachers. Journal of Teacher Education, 57(3), 220-231.

Desimone, L. M., Smith, T., Baker, D., \& Ueno, K. (2005). Assessing barriers to the reform of U.S. mathematics instruction from an international perspective. American Educational Research Journal, 42(3), 501-535.

Dewey, J. (1916). Democracy and education: An introduction to the philosophy of education. New York, NY: MacMillian.

Diamond, J. B., \& Spillane, J. P. (2004). High-stakes accountability in urban elementary schools: Challenging or reproducing inequality? Teachers College Record, 106, 11451176.

Dole, S. (2003). Applying psychological theory to helping students overcome learning difficulties in mathematics: An alternative approach to intervention. School Psychology International, 24(1), 95-114.

Dolgos, K. A. (1990). Discrete mathematics in the high school curriculum. International Journal of Mathematical Education in Science and Technology, 2(3), 439-442. 
Dossey, J. A. (1990). Discrete mathematics and the secondary mathematics curriculum. Reston, VA: National Council of Teachers of Mathematics.

Doyle, W. (1988). Work in mathematics classes: The context of students thinking during instruction. Educational Psychologist, 23(2), 167-180.

Driscoll, M. J., Confrey, J., \& Martz, E. (1987). Teaching mathematics: Strategies that work, $K-12$. Chelmsford, MA: Northeast Regional Exchange.

Edenfield, K. W. (2012May 1). The common core and inverse functions. Mathematics Teacher, 105(9), 672-678.

Educational Resources Information Center. (1997). Secondary science and mathematics teacher preparation programs: Influences on new teachers and their students: Instrument package and user's guide: Supplement to the final report of the Salish I Research Project. Washington, DC: U.S. Dept. of Education, Office of Educational Research and Improvement, Educational Resources Information Center.

Eisenhart, M. (1993). Conceptual knowledge falls through the cracks: Complexities of learning to teach mathematics for understanding. Journal for Research in Mathematics Education, 24(1), 8.

Elliott, J (2005). Using Narrative in Social Research, London, Engling: SAGE Publications Ltd.

Elliott, B., \& MacLennan, D. (1994). Education, modernity and neo-conservative school reform in Canada, Britain and the US. British Journal of Sociology of Education, 15(2), 165-185.

Elliott, R., Fischer, C. T., \& Rennie, D. L. (1999). Evolving guidelines for publication of qualitative research studies in psychology and related fields. The British Journal of Clinical Psychology / the British Psychological Society, 38, 215-229.

Elmore, R. F. (2002). Hard questions about practice living with a bad school situation is like living with bad wallpaper: If we don't notice it, we don't change it. Educational Leadership, 59, 22-25.

Elmore, R. F., National Academy of Sciences, \& National Research Council. (1997). Learning from TIMSS: An NRC symposium on the results of the Third International Mathematics and Science Study. Washington, DC: National Academy of Sciences/National Research Council.

Elmore, R. F., Peterson, P. L., \& McCarthey, S. J. (1996). Restructuring in the classroom: Teaching, learning, and school organization. San Francisco, CA: Jossey-Bass. 
Engle, R. A., \& Conant, F. C. (2002). Guiding principles for fostering productive disciplinary engagement: Explaining an emergent argument in a community of learners' classroom. Cognition and Instruction, 20(4), 399-348.

Fairhurst, A. M., \& Fairhurst, L. L. (1995). Effective teaching, effective learning: Making the personality connection in your classroom (1st ed). Palo Alto, CA: DavisBlack.

Fang, Z., \& Ashley, C. (2004). Pre-service teachers: Interpretations of a field-based reading block. Journal of Teacher Education, 55(1), 39-54.

Feiman-Nemser, S. (1992). Helping novices learn to teach: Lessons from an experienced support teacher (Research Report 91-6). East Lansing, MI: National Center for Research on Teacher Learning. (ERIC Document Reproduction Service No. ED 343 887)

Feiman-Nemser, S. (2001), From preparation to practice: Designing a continuum to strengthen and sustain teaching. Teachers College Record, 103(6), 1013-1055.

Fennema, E., \& Nelson, B. S. (1997). Mathematics teachers in transition. Mahwah, NJ: Lawrence Erlbaum Associates.

Ferrini-Mundy, J., \& Gaudard, M. (1992). Secondary School Calculus: Preparation or Pitfall in the Study of College Calculus?. Journal for Research in Mathematics Education, 56-71.

Fogarty, R. (1999). Architects of the intellect. Educational Leadership, 57(3), 76-78.

Fosnot, C. T. (1993). Learning to teach, teaching to learn: The center for constructivist teaching-teacher preparation project. Teaching Education, 5(2), 69-78.

Fosnot, C. T. (1996). Constructivism: Theory, perspectives, and practice. New York, NY: Teachers College Press.

Fraivillig, J. L., Murphy, L. A., \& Fuson, K. C. (1999). Advancing children's mathematical thinking in everyday mathematics classrooms. Journal for Research in Mathematics Education, 30, 148-170.

Freire, P. (1974). Pedagogy of the oppressed. New York, NY: Continuum.

Freire, P. (1982). Education for critical consciousness. New York, NY: Continuum.

Freire, P., \& Macedo, D. P. (1987). Literacy: Reading the word and the world. South Hadley, MA: Bergin \& Garvey. 
Friedrichsen, P., Chval, K. B., \& Teuscher, D. (2007). Strategies and sources of support for beginning teachers of science and mathematics. School Science and Mathematics, 107(5), 169-181.

Frykholm, J. A. (1999). The impact of reform: Challenges for mathematics teacher preparation. Journal of Mathematics Teacher Education, 2(1), 79-105.

Garelick, B. (2005). The new, a-maze-ing approach to math. Education Next 5(2), 28-36.

Glasgow, N. A., \& Hicks, C. D. (2009). What successful teachers do: 101 research-based classroom strategies for new and veteran teachers. Thousand Oaks, CA: Corwin.

Glassman, M. (2001). Dewey and Vygotsky: Society, experience, and inquiry in educational practice. Educational Researcher, 30(4), 3-14.

Glesne, C. (2011). Becoming qualitative researchers: An introduction. Boston, MA: Pearson.

Goertz, M. E., Floden, R. E., \& O'Day, J. A. (1996). Studies of education reform: Systemic reform. Washington, DC: U.S. Dept. of Education, Office of Educational Research and Improvement, Office of Reform Assistance and Dissemination.

Gojak, L. M. (2013). What's all this talk about rigor? Retrieved from http://www.nctm.org/about/content.aspx?id=35428

Goodlad, John I. (1984). A Place Called School. Prospects for the Future. New York, NY: McGraw-Hill Book Company.

Goos, M. (1995, Oct). How do you know when you understand? Using explanation to monitor and construct mathematical understanding. Paper presented at the Postgraduate Research Conference Commemorating 50 Years of Education Studies at University of Queensland, Brisbane, Queensland, Australia. Abstract retrieved from http://files.eric.ed.gov/fulltext/ED404177.pdf

Goos, M. (2004). Learning mathematics in a classroom community of inquiry. Journal for Research in Mathematics Education, 35(4), 258-291.

Gordon, M. (2008). Between constructivism and connectedness. Journal of Teacher Education 59(4) 322-331.

Gordon, M. (2009a). The misuses and effective uses of constructivist teaching. Teachers and Teaching: Theory and Practice, 15(6), 737-746.

Gordon, M. (2009b). Toward a pragmatic discourse of constructivism: Reflections on lessons from practice. Educational Studies: Journal of the American Educational Studies Association, 45(1), 39-58. 
Gordon, S. (1985). Discrete Topics in the Undergraduate Mathematics Curriculum: How Big a Step Should We Take? New York, NY: Springer New York.

Gottesman, I. (2010). Sitting in the waiting room: Paulo Freire and the critical turn in the field of education. Educational Studies, 46(4), 376-399.

Gratch, A. (1998). Beginning teacher and mentor relationships. Journal of Teacher Education, 49(3), 220-227.

Graue, E., Oen, D., Hatch, K., Rao, K., \& Fadali, E. (2005, April 12). Perspectives on class size reduction. Paper presented at the annual meeting of the American Educational Research Association, Montreal, Canada.

Gregg, J. (1995). The tensions and contradictions of the school mathematics tradition. Journal for Research in Mathematics Education, 26(5), 442-466.

Gregory, M. R. (2002). Constructivism, standards, and the classroom community of inquiry. Educational Theory, 52(4), 397-408.

Grouws, D. A., \& Cebulla, K. J. (2000). Improving student achievement in mathematics. Geneva, Switzerland: International Academy of Education.

Guise, M. (2013). Forming university and teacher partnership in an effort to reframe and rethink mentoring programs. English Journal, 102(3), 65-70.

Hackenberg, A. J. (2010). Mathematical caring relations in action, Journal for Research in Mathematics Education, 41(3), 236-273.

Hamann, D. L., Baker, D. S., McAllister, P. A., \& Bauer, W. I. (2000). Factors affecting university music students' perceptions of lesson quality and teaching effectiveness. Journal of Research in Music Education, 48, 102-113.

Hammerness, K. (2008). "If you don't know where you are going, any path will do": The role of teachers' visions in teachers' career paths. The New Educator, 4(1), 1-22.

Handal, B., \& Herrington, A. (2003). Mathematics teachers' beliefs and curriculum reform. Mathematics Education Research Journal, 15, 59-69.

Haney, J. J., Lumpe, A. T., \& Czerniak, C. M. (2003). Constructivist beliefs about the science classroom learning environment: perspectives from teachers, administrators, parents, community members, and students. School Science and Mathematics, 103(8), 366-377.

Harwell, M. R., Post, T. R., Medhanie, A., Dupuis, D. N., \& LeBeau, B. (2013). A multiinstitutional study of high school mathematics achievement and course taking. Journal of Research in Mathematics Education, 44(5), 742-774. 
Heaton, R. M. (2000). Teaching mathematics to the new standards: Relearning the dance. New York, NY: Teachers College Press.

Heitin, L. (2012, June 28). Re: Texas GOP: No more critical thinking in schools [Web log message]. Retrieved from: http://blogs.edweek.org/teachers/ teaching_now/2012/06/ texas_gop_no_more_critical_thinking.html

Heller, J. I., \& M. Gordon, A. (1992). Lifelong learning. The Educator, 6(1), 4-19.

Herbst, P. G. (2003). Using novel tasks in teaching mathematics: three tensions affecting the work of the teacher. American Educational Research Journal, 40(1), 197-238.

Hiebert, J. (1997). Making sense: Teaching and learning mathematics with understanding. Portsmouth, NH: Heinemann.

Hiebert, J., Gallimore, R., \& Stigler, J. W. (2002). A knowledge base for the teaching profession: What would it look like and how can we get one? Educational Researcher, 31(5), 3-15.

Hiebert, J., Stigler, J. W., Jacobs, J. K., Givvin, K. B., Garnier, H., Smith, M., Hollingsworth, H., Manaster, A., Wearne, D., \& Gallimore, R. (2005). Mathematics teaching in the United States today (and tomorrow): Results From the TIMSS 1999 video study. Educational Evaluation and Policy Analysis, 27(2), 111-132.

Hill, H. C., \& Ball, D. L. (2004). Learning mathematics for teaching: Results from California's mathematics professional development institutes. Journal for Research in Mathematics Education, 35(5), 330-351.

Hodge, L. L., \& Cobb, P. (2003, April). Classrooms as design spaces for supporting students' mathematical learning and engagement. Paper presented at the annual meeting of the American Educational Research Association, Chicago. IL.

Huberman, M. (1995). Networks that alter teaching: conceptualizations, exchanges and experiments. Teachers and Teaching, 1(2), 193-211.

Huffman, D., Lawrenz, F., \& Thomas, K. (2008). Science and mathematics instruction in a reform-based teacher preparation program. School Science and Mathematics, $108(4), 137-145$.

Hyslop-Margison, E. J., \& Strobel, J. (2007). Constructivism and education: misunderstandings and pedagogical implications. Teacher Educator, 43(1), 72-86.

Hytten, K. (2000). The resurgence of Dewey: are his educational ideas still relevant? Journal of Curriculum Studies 32(3), 453-466. 
Ibarra, H. (2005). Constructivist teaching behaviors of recipients of Presidential Awards for Excellence in Mathematics and Science Teaching (Doctoral dissertation). Retrieved from Dissertations and Theses: Full Text. (Publication No. AAT 3172406)

Ingersoll, R. M. (2001). Teacher turnover and teacher shortages: An organizational analysis. American Educational Research Journal, 38(3), 499-534.

Ingersoll, R. M. (2003). Is there a shortage among mathematics and science teachers? Science Educator, 12(1), 1-9.

Ingvarson, L. (1998). Professional development as the pursuit of professional standards: The standards-based professional development system. Teaching and Teacher Education, 14(1), 127-40.

Jamar, I., \& Pitts, V. R. (2005). High expectations: A "how" of achieving equitable mathematics classrooms. The Negro Educational Review, 56(2-3), 127-134.

Jones, K., \& Whitford, B. L. (1997). Kentucky's conflicting reform principles: HighStakes school accountability and student performance assessment. Phi Delta Kappan, 79(4), 276-281.

Kazemi, E., \& Franke, M. (2004). Teacher learning in mathematics: Using student work to promote collective inquiry. Journal of Mathematics Teacher Education, 7(3), 203-235.

Kazemi, E., \& Stipek, D. (2001). Promoting conceptual thinking in four upperelementary mathematics classrooms. Elementary School Journal, 102(1), 59-80.

Kenney, M. J., \& Hirsch, C. R. (1991). Discrete mathematics across the curriculum, K-12: 1991 yearbook. Reston, VA: National Council of Teachers of Mathematics.

Kilpatrick, J. (1987). Problem formulating: Where do good problems come from? In A. H. Schoenfeld (Ed.), Cognitive science and mathematics education (pp. 123-128). Hillsdale, NJ: Erlbaum.

Kilpatrick, J. (2009). Tools of American mathematics teaching, 1800-2000. Science Education 93(3), 581-583.

Kilpatrick, J., Swafford, J., \& Findell, B. (Eds.). (2001). Adding it up: Helping children learn mathematics. Washington, DC: National Academy Press.

Kincheloe, J. L. (1991). Teachers as researchers: Qualitative inquiry as a path to empowerment. London, England: Falmer. 
Kivinen, O., \& Ristela, P. (2003). From constructivism to a pragmatist conception of learning. Oxford Review of Education, 29(3), 363-375.

Klein, D. (2000). Math problems: Why the department of education recommended math programs don't add up. American School Board Journal, 187(4), 52-57.

Klein, D. (2007). A quarter century of US 'math wars' and political partisanship. BSHM Bulletin: Journal of the British Society for the History of Mathematics, 22(1), 22-33. doi:10.1080/17498430601148762

Kohn, A. (1998). Only for my kid: How privileged parents undermine school reform. Phi Delta Kappan, 79(8), 568-577.

Konstantopoulos, S., \& Chung, V. (2009). What are the long-term effects of small classes on the achievement gap? Evidence from the lasting benefits study. American Journal of Education, 116(1), 125-154.

Kounin, J. S. (1969). Classroom management. New York, NY: Holt, Rinehart and Winston.

LaBerge, V. B., \& Sons, L. R. (1999). First-year teachers' implementation of the NCTM standards. PRIMUS, 9(2), 139-156.

Lampert, M. (1986). Knowing, doing and teaching multiplication. Cognition and Instruction, 3(4), 305-342.

Lampert, M. (1990). When the problem is not the question and the solution is not the answer: Mathematical knowing and teaching. American Educational Research Journal, 27(1), 29-63.

Lampert, M., \& Blunk, M. L. (1998). Talking mathematics in school: Studies of teaching and learning. Cambridge, England: Cambridge University Press.

Lee, B., Cawthon, S., \& Dawson, K. (2013, February). Elementary and secondary teacher self-efficacy for teaching and pedagogical conceptual change in a drama-based professional development program. Teaching and Teacher Education, 30, 84-98.

Leinhardt, G., \& Steele, M. D. (2005). Seeing the complexity of standing to the side: Instructional dialogues. Cognition and Instruction, 23(1), 87-163.

Leitzel, J. R. (1991). A Call for Change: Recommendations for the Mathematical Preparation of Teachers of Mathematics. An MAA Report. Mathematical Association of America, 1529 18th Street NW, Washington, DC. Abstract retrieved from http://eric.ed.gov/?id=ED412109 
Lewis, C. C., \& Tsuchida, I. (1999). A lesson is like a swiftly flowing river: How research lessons improve Japanese education. American Educator, 22(4), 12.

Lewis, C. C., Perry, R. R., Friedkin, S., \& Roth, J. R. (2012). Improving teaching does improve teachers: evidence from lesson study. Journal of Teacher Education, 63(5), 368-375.

Lewis, C., Perry, R., \& Murata, A. (2006). How should research contribute to instructional improvement? The case of lesson study. Educational Researcher, 35(3), 3-14.

Lincoln, Y. S., \& Guba, E. G. (1985). Naturalistic inquiry. Beverly Hills, CA: Sage.

Madsen, K., 2003. The effect on accuracy of instruction, teacher delivery, and student attentiveness on musicians' evaluation of teacher effectiveness. Journal of Research in Music Education 51, 38-51.

Manouchehri, A., \& Enderson, M. C. (1999). Promoting mathematical discourse: Learning from classroom examples. Mathematics Teaching in the Middle School, 4(4), 216-222.

Manouchehri, A., \& Goodman, T. (1998). Mathematics curriculum reform and teachers: Understanding the connections. Journal of Educational Research, 92(1), 27-41.

Manouchehri A., \& Goodman, T. (2000). Implementing mathematics reform: The challenge within. Educational Studies in Mathematics 42, 1-34.

Marlowe, B. A., \& Page, M. L. (2005). Creating and sustaining the constructivist classroom. Thousand Oaks, CA: Corwin.

Marriott, M. (1990, December 5). For fledgling teacher corps, hard lessons. New York Times (1923-Current File). Retrieved from http://search.proquest.com/ docview/108450210? accountid $=13265$

Marsh, D. D., \& LeFever, K. (2004). School principals as standards-based educational leaders: Looking across policy contexts. Educational Management Administration and Leadership, 32(4), 387-404.

Marshall, C., \& Rossman, G. B. (1995). Designing qualitative research. Thousand Oaks, CA: Sage.

Martin, C. (1997). Looking at type: The fundamentals. Gainesville, FL: Center for Application of Psychological Type. 
Matteson, S. M., Swarthout, M. B., \& Zientek, L. R. (2011). Student motivation: Perspectives from mathematics teachers. Action in Teacher Education, 33(3), 283-297.

Matthews, M. R. (2000). Appraising constructivism in science and mathematics education. In D. C. Phillips (Ed.), Constructivism in education: Opinions and second opinions on controversial issues (pp. 161-192). Chicago, IL: University of Chicago.

McCaffrey, D. F., Hamilton, L. S., Stecher, B. M., Klein, S. P., Bugliari, D., \& Robyn, A. (2001). ARTICLES - Interactions among instructional practices, curriculum, and student achievement: The case of standards-based high school mathematics. Journal for Research in Mathematics Education, 32(5), 493.

McCaffrey, D. F., Hamilton, L. S., Stecher, B. M., Klein, S. P., Bugliari, D and Robyn, A. (2001). Interactions among instructional practices, curriculum, and student achievement: The case of standards-based high school mathematics. Journal for Research in Mathematics Education, 32(5), 493-517.

McEwan, H., \& Egan, K.(1995). Narrative in teaching, learning, and research. New York, NY: Teacher College Press.

McEwan, H., \& Egan, K. (1997). Narrative in teaching, learning and research. The Journal of General Education, 46(2), 165-168.

McEwan, E. K. (2002). 10 traits of highly effective teachers: How to hire, coach, and mentor successful teachers. Thousand Oaks, CA: Corwin Press.

McGee, J. R., Wang, C., \& Polly, D. (2013). Guiding teachers in the use of a standardsbased mathematics curriculum: teacher perceptions and subsequent instructional practices after an intensive professional development program. School Science and Mathematics, 113(1), 16-28.

Meier, D., \& Wood, G. H. (2004). Many children left behind: How the No Child Left Behind Act is damaging our children and our schools. Boston, MA: Beacon.

Mercer, N. (1995). The guided construction of knowledge: Talk amongst teachers and learners. Clevedon, Avon, England: Multilingual Matters.

Merriam, S. B. (1995). What can you tell from an $\mathrm{n}$ of 1?: Issues of validity and reliability in qualitative research. PAACE Journal of Lifelong Learning, 4, 51-60.

Middleton, J. A., \& Spanias, P. A. (1999). Motivation for achievement in mathematics: Findings, generalizations, and criticisms of the research. Journal for Research in Mathematics Education, 30, 65-88. 
Miles, M. B., \& Huberman, M. A., (1994). Qualitative data analysis: An expanded sourcebook. Thousand Oaks, CA: Sage Publications.

Mirel, J. (2003). Old educational ideas, new American schools: Progressivism and the rhetoric of educational revolution. Paedagogica Historica, 39(4), 477-497.

Mullis, I. V. S., Dossey, J. A., Owen, E. H., \& Phillips, G. W. (1993). Executive summary of the NAEP 1992 mathematics report card for the nation: Data from the national and trial state assessments. Washington, DC: U.S. Department of Education.

Murray, S. (2011). Secondary students' descriptions of "Good" mathematics teachers. Australian Mathematics Teacher, 67(4), 14-21.

Nasir, N. S., Hand, V., \& Taylor, E. V. (2008). Culture and mathematics in school: Boundaries between "cultural" and "domain" knowledge in the mathematics classroom and beyond. Review of Research in Education, 32(1), 187-240.

Nathan, M. J., \& Knuth, E. J. (2003). A study of whole classroom mathematical discourse and teacher change. Cognition and Instruction, 21(2), 175-207.

National Center for Research on Teaching and Learning. (1992). Findings on learning to teach. Lansing, MI: Michigan State University.

National Center of Education Statistics.(2003). Teaching mathematics in seven countries: Result from the TIMSS video study. Washington, DC: U.S. Department of Education.

National Council of Teachers of Mathematics. (1989). Curriculum and evaluation: Standards for school mathematics. Reston, VA: Author.

National Council of Teachers of Mathematics. (1991). Professional standards for teaching mathematics. Reston, VA: Author.

National Council of Teachers of Mathematics. (1995). Assessment standards for school mathematics. Reston, VA: Author.

National Council of Teachers of Mathematics. (2000). Principles and standards for school mathematics. Reston, VA: Author.

National Research Council. (1989). Everybody counts: A report to the nation on the future of mathematics education. Washington, DC: National Academy Press.

National Research Council. (1990). Reshaping school mathematics: A philosophy and framework for curriculum. Washington, DC: Mathematical Sciences Education Board, National Research Council. 
National Research Council. (2001). Educating teachers of science, mathematics, and technology: New practices for the new millennium. Washington, DC: National Academy Press.

National Research Council. (2004). On evaluating curricular effectiveness. Washington, DC: National Academies Press

Noddings, N. (1990). Chapter 1: Journal for Research in Mathematics Education. Monograph, 4, 7-18.

Noddings, N. (2001). The caring teacher. In V. Richardson (Ed.), The handbook of research on teaching (4th ed., pp. 99-105). Washington, DC: American Educational Research Association.

Oakes, J., Quartz, K. H., Ryan, S., \& Lipton, M. (2000). Becoming good American schools: The struggle for civic virtue in education reform. Phi Delta Kappan, 81(8), 568-575.

O’Conner, M. C., \& Michaels, S. (1996). Shifting participant frameworks: Orchestrating thinking practices in group discussion. In D. Hicks, (Ed.), Discourse, learning, and schooling (pp. 63-103). Cambridge, England: Cambridge University Press.

Oxford, R. (1997). Constructivism: Shape-shifting, substance, and teacher education applications. Peabody Journal of Education, 72, 35-66.

Pape, S. J., Bell, C. V., \& Yetkin, I. E. (2003). Developing mathematical thinking and self-regulated learning: A teaching experiment in a seventh-grade mathematics classroom. Educational Studies in Mathematics, 53(3), 179-202.

Patton, M. Q. (1990). Qualitative evaluation and research methods. London, England: Sage

Pedersen, S., \& Liu, M. (2003). Teachers' beliefs about issues in the implementation of a student-centered learning environment. Educational Technology Research and Development, 51(2), 57-76.

Perrone, V., \& Harvard University. (1996). Curriculum projects in mathematics: T-120. Cambridge, MA: The School.

Peterson, K. D., Bennet, B., \& Sherman, D.F. (1991). Themes of uncommonly successful teachers of at-risk students. Urban Education, 26(2), 176-194.

Phillips, D. C. (1995). The good, the bad, and the ugly: The many faces of constructivism. Educational Researcher, 24(7) 5-12.

Piaget, J. (1965). The child's conception of number. New York, NY: W. W. Norton. 
Piaget, J. (1970). Science of education and the psychology of the child. New York, NY: Orion Press.

Piaget, J., \& Wells, P. A. (1973). Psychology and epistemology: Towards a theory of knowledge. London, England: Allen Lane.

Polk, J. A. (2006). Characteristics of effective teachers. Arts Education Policy Review, 107(4), 23-29.

Polkinghorne, D. E. (1988). Narrative knowing and the human sciences. Albany, NY: State University of New York Press.

Polkinghorne, D. E. (1991). Narrative and self-concept. Journal of Narrative and Life History, 1, 135-153.

P 1 ya, G. (1962). Mathematical discovery: On understanding, learning, and teaching problem-solving. New York, NY: Wiley.

Powell, K., \& Kalina, C. (2009). Cognitive and social constructivism: Developing tools for an effective classroom. Education 130(2), 241-250.

Prawat, R. S. (1992). Teachers' beliefs about teaching and learning: A constructivist perspective. American Journal of Education, 100(3), 354-395.

Prawat, R. S. (1995). Misreading Dewey: Reform, projects, and the language game. Educational Researcher, 24(7), 13-22.

Presidential Award for Excellence in Teaching Mathematics and Science. (2011a). About the award. Retrieved from https://www.paemst.org/about/view

Presidential Award for Excellence in Teaching Mathematics and Science. (2011c). The application packet—PAEMST. Retrieved from https://www.paemst.org/ public/files/2011 2012/PAEMST/Application/Packet.pdf

Presidential Award for Excellence in Teaching Mathematics and Science. (2011c). The award process. Rretrieved from https://www.paemst.org/award_process/view

Putnam, R. T. (1992). Teaching mathematics for understanding: Discussing cast studies of four fifth-grade teachers. Elementary School Journal, 93(2), 213-228.

Qing, L., \& Xi, M. (2010). A meta-analysis of the effects of computer technology on school students' mathematics learning. Educational Psychology Review, 22(3), 215-243. 
Rees, J., \& And, O. (1992). Addressing professional standards for the preparation of mathematics teachers. SRATE Journal, 1(1), 43-46.

Remillard, J. T. (1999). Curriculum materials in mathematics education reform: A framework for examining the teachers' curriculum development. Curriculum Inquiry, 29(3), 315-342.

Rice, J. K. (1999). The impact of class size on instructional strategies and the use of time in high school mathematics and science courses. Educational Evaluation and Policy Analysis, 21(2), 215-29.

Richardson, V. (2003). Constructivist pedagogy. Teachers College Record, 105(9), 1623-1640.

Ritchhart, R. (1999). Generative topics: Building a curriculum around big ideas. Teaching Children Mathematics, 5(8), 462-468.

Rogers, B. (1999). Conflicting approaches to curriculum: recognizing how fundamental beliefs can sustain or sabotage school reform. Peabody Journal of Education, 74(1), 29-67.

Romberg, T. A. (1992). Perspectives on scholarship and research methods. In D. A. Grouws (Ed.), Handbook of research on mathematics teaching and learning (pp. 49-64). New York, NY: Macmillan.

Rosenshine, B., \& Furst, N. (1971). Research on teacher performance criteria. In B. O. Smith (Ed.), Research in teacher education: A symposium (pp. 27-72. Englewood Cliffs, NJ: Prentice-Hall.

Rosiek, J., \& Atkinson, B. (2007). The inevitability and importance of genres in narrative research on teaching practice. Qualitative Inquiry, 13(4), 499-521.

Russell, T. (1993). Learning to teach science: Constructivism, reflection, and learning from experience. In K. Tobin (Ed.), The practice of constructivism in science education (pp. 247-258). Hillsdale, NJ: Lawrence Erlbaum.

Sanders, W. L., \& Rivers, J. C. (1996). Cumulative and residual effects of teachers on future student academic achievement. Knoxville, TN: University of Tennessee, Value Added Research and Assessment Center.

Schifter, D. (2005). A constructivist perspective on teaching and learning mathematics. In C. T. Fosnot (Ed), Constructivism: Theory, perspectives, and practices $\left(2^{\text {nd }}\right.$ ed.; pp. 80-109) New York, NY: Teachers College Press. 
Schifter, D., \& Fosnot, C. T. (1993). Reconstructing mathematics education: Stories of teachers meeting the challenge of reform. New York, NY: Teachers College Press.

Schoenfeld, A. H. (1987). Pólya, problem-solving, and education. Mathematics Magazine 60(5). 283-291. doi:10.2307/2690409

Schoenfeld, A. H. (1992). Learning to think mathematically: Problem-solving, metacognition, and sense making in mathematics. In D. A. Grouws (Ed.), Handbook of research on mathematics teaching and learning (pp. 334-371). New York, NY: Macmillan.

Schoenfeld, A. H. (1996). Mathematical thinking and problem-solving. Contemporary Psychology, 41(1), p. 76.

Schoenfeld, A. H. (1999). Looking toward the $21^{\text {st }}$ century: Challenges of educational theory and practice. Educational Researcher, 28(7), 4-14.

Scholes, R. (1980). Language, narrative, and anti-narrative. Critical Inquiry, 7(1), 204212.

Schorr, R. Y., Firestone, W. A., \& Monfils, L. (2003). State testing and mathematics teaching in New Jersey: The effects of a test without other supports. Journal for Research in Mathematics Education, 34(5), 373-405.

Schram, T. (2006). Conceptualizing and proposing qualitative research $\left(2^{\text {nd }} \mathrm{ed}.\right)$. Upper Saddle River, NJ: Pearson Education, Inc.

Seegers, G. \& Boekaerts, M. (1993). Task motivation and mathematics achievement in actual task situations. Learning and Instruction, 3(2), 133-150.

Sfard, A., Forman, E., \& Kieran, C. (2001). Guest editorial. Learning discourse: Sociocultural approaches to research in mathematics education. Educational Studies in Mathematics, 46(3), 1-12.

Sherin, M. G. (2002). When teaching becomes learning. Cognition and Instruction, 20(2), 119-150.

Sherin, M. G., Mendez, E. P., \& Louis, D. A. (2004). A discipline apart: The challenges of "fostering a community of learners" in a mathematics classroom. Journal of Curriculum Studies, 36(2), 207-232.

Shor, I. (1987). Freire for the classroom: A sourcebook for liberatory teaching. Portsmouth, NH: Boynton/Cook. 
Shulman, L. S. (1987). Knowledge and teaching: Foundations of the new reform. Harvard Educational Review, 57(1), 1-22.

Siebert, M. (1999, February 7). Educators often struck by voice ailments, The Des Moines Register, p. 4.

Silver, E.A., \& Stein, M. K. (1996) The QUASAR Project: The "Revolution of the Possible" in mathematics instructional reform in urban middle schools. Urban Education 30, 476-521.

Simmons, P. E., Emory, A., Carter, T., Coker, T., Finnegan, B., Crockett, D., Richardson, L., Labuda, K. (1999). Beginning teachers: Beliefs and classroom actions. Journal of Research in Science Teaching, 36(8), 930-954.

Simon, M. A. (1986). The teacher's role in increasing student understanding of mathematics. Educational Leadership, 43(7), 40-43.

Simon, M. A. (1993). Prospective teachers' knowledge of division. Journal for Research of Mathematics Education, 24, 233-254.

Simon, M. A. (1995). Reconstructing mathematics pedagogy from a constructivist perspective. Journal for Research in Mathematics Education, 26(2), 114-145.

Simon, M. A., \& Schifter, D. (1991). Towards a constructivist perspective: An intervention study of mathematics teacher development. Educational Studies in Mathematics, 22(4), 309-331.

Sirotnik, K. A. (1983). What you see is what you get-consistency, persistency, and mediocrity in classrooms. Harvard Educational Review, 53(1), 16-31.

Slavin, R., Lake, C., \& Groff, C. (2009). Effective programs in middle and high school mathematics: A best-evidence synthesis. Review of Educational Research, 79(2), 839-911.

Smerdon, B. A., Burkam, D. T., \& Lee, V. E. (1999). Access to constructivist and didactic teaching: Who gets it? Where is it practiced? Teachers College Record, 101(1), 5-34.

Smith, J. P. (1996). Efficacy and teaching mathematics by telling: A challenge for reform. Journal for Research in Mathematics Education, 27(4), 387-402.

Southall, J. K. (2003). Twelve ideas for professional excellence. Teaching Music 11(1), 48-53. 
Sowder, J. T. (2007). And development of teachers. Second handbook of research on mathematics teaching and learning: A project of the National Council of Teachers of Mathematics, 1, 157.

Spillane, J. P., \& Zeuli, J. S. (1999). Reform and teaching: Exploring patterns of practice in the context of national and state mathematics reforms. Educational Evaluation and Policy Analysis, 21(1), 1-27.

Stein, M. K., Engle, R. A, Smith, P. S., \& Hughes, E. K. (2008). Orchestrating productive mathematical discussions: Five practices for helping teachings move beyond show and tell. Mathematics Teaching and Learning, 10(4), 313-340.

Stein, M. K., Grover, B. W., \& Henningsen, M. (1996). Building student capacity for mathematical thinking and reasoning: An analysis of mathematical tasks used in reform classrooms. American Educational Research Journal, 33(2), 455-488.

Stigler, J. W., \& Hiebert, J. (2004). Improving mathematics teaching. Educational Leadership, 61(5), 12-16.

Stotsky, S. (2007). Massachusetts's math wars. Quarterly Review of Comparative Education, (37)4, 489-500.

Sullivan, P. (1989). Factors inhibiting change: A case study of a beginning primary teacher. Mathematics Education Research Journal, 1(2), 1-16.

Suurtamm, C., \& Graves, B. (2007). Mathematics education reform: The role of coherence within the complexity of change. PME Conference, 1, 535-539.

Tanner, L. N. (1997). Dewey's laboratory school: Lessons for today. New York, NY: Teachers College Press.

Teacher Development Group. (2014). Our mission. Retrieved from https://www.teachersdg.org/

Teddlie, C., Kirby, P. C., \& Stringfield, S. (1989). Effective versus ineffective schools: Observable differences in the classroom. American Journal of Education, 97(3), 221-236.

Theobald, P., \& Mills, E. (1995). Accountability and the struggle over what counts. Phi Delta Kappan, 76(6), 462-466.

Thomas, D. R. (, 2006). A general inductive approach for analyzing qualitative evaluation data. American Journal of Evaluation, 27(2), 237-246. 
Thomas, J. A., \& Monroe, E. E. (2006). Self-Study of a teacher's journey toward standards-based mathematics teaching. Studying Teacher Education, 2(2), 169181.

Tobin, K. G. (1993). The practice of constructivism in science education. Hillsdale, NJ: Erlbaum.

Traina, R. P. (1999). What makes a good teacher? Education Week, 18, 19.

Upward bound program (2012). Program description. Retrieved February 27, 2014, from http://www2.ed.gov/programs/trioupbound/index.html

Van de Walle, J. A. (1999). Reform mathematics vs. the basics: Understanding the conflict and dealing with it. Retrieved from http://www.mathematicallysane.com/ analysis/reformvsbasics.asp

Van Oers, B. (2001). Educational forms of initiation in mathematical culture. Educational Studies in Mathematics, 46(1/3), 59-85

Vennebush, P. (2013, April 9). Re: Jim Rubillo - lifetime achievement award [Power Point Presentation]. Retrieved from http://www.authorstream.com/ Presentation/patrickvennebush-1766831-jim-rubillo-lifetime-achievement-award/

Vinner, S. (1990). Inconsistencies: Their causes and function in learning mathematics. Focus on Learning Problems in Mathematics, 12, 85-98.

Vogler, K. E., \& Burton, M. (2010). Mathematics teachers' instructional practices in an era of high-stakes testing. School Science and Mathematics, 110(5), 247-261.

Vygotsky, L. S., \& Cole, M. (1978). Mind in society: The development of higher psychological processes. Cambridge, MA: Harvard University Press.

Wachob, P. (2011). Critical friendship circles: The cultural challenge of cool feedback. Professional Development in Education, 37(3), 353-372.

Walshaw, M., \& Anthony, G. (2008). The teacher's role in classroom discourse: A review of recent research into mathematics classrooms. Review of Educational Research, 78(3), 516-551.

Ward, B. B., Campbell, S. R., Goodloe, M. R., Miller, A. J., Kleja, K. M., Kombe, E. M., \& Torres, R. E. (2010). Assessing a mathematical inquiry course: Do students gain an appreciation for mathematics? Primus, 20(3), 183-203.

Wasley, P. A., Hampel, R. L., \& Clark, R. W. (1997). Kids and school reform. San Francisco, CA: Jossey-Bass. 
Waterman, S., \& He, Y. (2011). Effects of mentoring programs on new teacher retention: A literature review. Mentoring \& Tutoring: Partnership in Learning, 19(2), 139156.

Watson, A. (2001). Instances of mathematical thinking among low attaining students in an ordinary secondary classroom. Journal of Mathematical Behavior, 20(4), 461475.

Webb, N., Coxford, A. F., \& National Council of Teachers of Mathematics. (1993). Assessment in the mathematics classroom. Reston, VA: National Council of Teachers of Mathematics.

Wehmeyer, M. (2001). Assessment in self-determination: Guiding instruction and transition planning. Assessment for Effective Intervention, 26(4), 41-49.

Weiss, I. R., \& Raphael, J. B. (1996). Characteristics of presidential awardees: How do they compare with science and mathematics teachers nationally? Chapel Hill, NC: Horizon Research.

White, D. Y. (2003). Promoting productive mathematical classroom discourse with diverse students. Journal of Mathematical Behavior, 22(1), 37-53.

White, H. (1980). The value of narrativity in the representation of reality. Critical Inquiry, 7(1), 5-27.

Wilson, B.G. (1996). Constructivist learning environments: Case studies in instructional design. Englewood Cliffs, NJ: Educational Technology Publications.

Wilson, P., Cooney, T., \& Stinson, D. (2005). What constitutes good mathematics teaching and how it develops: Nine high school teachers' perspectives. Journal of Mathematics Teacher Education, 8, 2, 83-111.

Wilson, S. M., Darling-Hammond, L., \& Berry, B. (2001). A case of successful teaching policy: Connecticut's long-term efforts to improve teaching and learning: A research report. Seattle, WA: University of Washington, Center for the Study of Teaching and Policy.

Windschitl, M. (1999). The challenges of sustaining a constructivist classroom culture. Phi Delta Kappan, 80(10), 751-755.

Windschitl, M. (2002). Framing constructivism in practice as the negotiation of dilemmas: An analysis of the conceptual, pedagogical, cultural, and political challenges facing teachers. Review of Educational Research, 72(2), 131-175.

Wood, T. (2002). What does it mean to teach mathematics differently? In B. Barton, K. Irwin, M. Pfannkuch, \& M. Thomas (Eds.), Mathematics education in the South 
Pacific (Proceedings of the $25^{\text {th }}$ annual conference of the Mathematics Education Research Group of Australia (pp. 61-67). Sidney, AU: MERGA.

Wood, T., Cobb, P., \& Yackel, E. (1991). Change in teaching mathematics: A case study. American Educational Research Journal, 28(3), 587-616.

Wood, T., Williams, G., \& McNeal, B. (2006). Children's mathematical thinking in different classroom cultures. Journal for Research in Mathematics Education, $37(3), 222-255$.

Wrenn, J., \& Wrenn, B. (2009). Enhancing learning by integrating theory and practice. International Journal of Teaching and Learning in Higher Education, 21(2), 258265.

Yackel, E., \& Cobb, P. (1996). Sociomathematical norms, argumentation, and autonomy in mathematics. Journal for Research in Mathematics Education, 27(4), 458-477.

Zimmerman, B. J. (1982). Piaget's theory and instruction: How compatible are they? Contemporary Educational Psychology, 7(3), 204-216.

Zuckerman, J. T. (2007). Classroom management in secondary schools: A study of student teachers' successful strategies. American Secondary Education, 35(2), 4-16. 
APPENDIX A

INITIAL RECRUITMENT EMAIL 


\section{Initial Recruitment/Permission Email}

You are invited to participate in a research study conducted by Gerald Young from Portland State University's Education Department. The researcher hopes to study the stories of high school mathematics teachers who use SBC pedagogy in their classrooms. The following three questions are addressed in the study: (1) What are the paths standards-based, constructivist high school mathematics teachers pursued to become identified as highly effective mathematics teachers?, (2) What obstacles and challenges did they encounter and how were they met?, and (3) What sustained them on their journeys? The study is being conducted as part of the requirements for the doctoral degree at Portland State University, and is supervised by Dr. Ron Narode, Associate Professor of Curriculum and Instruction at Portland State University. You were selected as a possible participant in this study because, like the researcher, you are a recipient of the Presidential Award for Excellence in Mathematics and Science Teaching (PAEMST), a member of Council of Presidential Awardees (CPAM), and you have been identified as a high school mathematics teacher who uses standards-based, constructivist (SBC) pedagogy in your classroom. Please refer the attachment to this email to see the requirements for this research study.

\section{Email Attachment}

If you decide to participate, you will be asked to provide the following: (1) a copy of either the Evidence of Learning section (PAEMST recipient prior to 2004) or Narrative Prompt section (PAEMST recipient, 2004 to the present) of your PAEMST application, and (2) demographic information, including your name and gender, current high school teaching position, years of teaching mathematics, and the name of your high school and the city and state it is located in.

You will be asked to send the researcher a copy of either the Evidence of Learning section (PAEMST recipient prior to 2004) or Narrative Prompt section (PAEMST recipient, 2004 and on) of your PAEMST application via an attachment on an email message. You will be asked to include in the same email the above demographic information. The Evidence of Learning or the Narrative Prompt will be used to learn about the ways you use reformist, constructivism in the classroom.

Any information obtained in this study that could possibly be linked to you or identify you will be kept confidential. The Evidence of Learning or Narrative Prompt section of the PAEMST application and demographic information will be viewed only by the researcher and Dr. Ron Narode; no information you provide will be released to any other persons. All the documents will be kept in a locked file cabinet from the time of their arrival until three years after the completion of the researcher's dissertation. At that time, all of the research documents will be destroyed.

Your participation in this research study is voluntary. You are under no obligation to take part in this study, and it will not affect your relationship with Portland State 
University. Furthermore, you may withdraw from this study at any time without affecting your relationship with Portland State University.

If you have questions or concerns about your participation in this study, contact the researcher at either his home address: Gerald Young at 12528 SE Imperial Crest St., Happy Valley, OR 97086; internet address: young5688@comcast.net; home phone: (503) 698-4089; or cell phone: (503) 708-1464. If you have concerns about your rights as a research participant, please contact Research and Strategic Partnerships, Market Center Building $6^{\text {th }}$ floor, Portland State University, (503) 725-4288.

Your submission of your Evidence of Learning or Narrative Prompt section of PAEMST application and your demographic information indicates that you have read and understand the above information and agree to take part in this study. 
APPENDIX B

PAEMST-NARRATIVE PROMPT SECTION 


\title{
The Five Dimensions of Outstanding Teaching-Narrative Prompts Dimension One: Mastery of mathematics or science content appropriate for the
}

\author{
grade level taught.
}

The narrative for Dimension One should be about four pages.

1a. Discuss the mathematical or scientific ideas that are fundamental to understanding the chosen topic or concept.

1b. Explain why this topic or concept is important for students to learn and how it relates to more complex concepts that students will encounter in subsequent lessons, grades, or courses.

1c. Discuss the misconceptions or misunderstandings that students typically have with regard to

this topic or concept.

Dimension Two: Use of instructional methods and strategies that are appropriate for the students in the class and that support student learning.

The narrative for Dimension Two should be about four pages.

2a. Describe the instructional approaches you used in the video to help students understand the topic or concept chosen in Dimension One.

2b. Explain how you identify and build on students' prior knowledge, and how this knowledge

is addressed in your video and in your general teaching strategies.

2c. Discuss the instructional strategies and techniques you use to meet the learning needs of all students, challenging those with a strong knowledge while ensuring learning for less accomplished students.

\section{Dimension Three: Effective use of student assessments to evaluate, monitor, and improve student learning.}

The narrative for Dimension Three should be about three pages.

3a. Describe how you assessed student learning and achievement for the topic discussed in Dimension One and shown on the video, and how you use what you learned from the assessment to improve your teaching.

3b. Discuss other specific ways that you routinely assess and guide student learning. You may include examples of formative or summative techniques, including student presentations, projects, quizzes, unit exams, or other methods.

3c. Provide evidence of your teaching effectiveness as measured by student achievement on school, district or state assessments, or other external indicators of student learning or achievement. 


\section{Dimension Four: Reflective practice and lifelong learning to improve teaching and student learning.}

The narrative for Dimension Four should be about three pages.

4a. Discuss the more successful and less successful aspects of the instructional activities shown in the video and describe what you might do differently to improve student learning

4b. Describe how reflection on your teaching practices helps you improve your classroom instruction. You may provide examples of lessons or activities you revised based on this reflection.

4c. Using one or two of the professional development experiences cited in your résumé, describe how your participation in these activities has improved your teaching and enhanced student learning.

\section{Dimension Five: Leadership in education outside the classroom.}

The narrative for Dimension Five should be about one page.

5a. Describe how you have supported other teachers, student teachers or interns through activities such as induction, mentoring, leading professional development activities, or coteaching.

5b. Describe how you contribute to educational excellence at the school, district, state or national level.

Adapted from "Presidential Award for Excellence in Mathematics and Science Teaching: 2012-2013 Application Packet for Middle and High School Teachers (Grades 7-12) by National Science Foundation, Directorate for Education and Human Resources, Division of Undergraduate Education, Division of Research on Learning in Formal and Informal Settings, p. 7. 
APPENDIX C CONSENT FORM 


\section{Consent to Participate in a Research Study}

"The Criteria for a Successful Career as a High School Mathematics Teacher"

\section{INTERVIEW}

Principal Investigator: Gerald Young, Doctoral Student, Portland State University, Portland Oregon

You are invited to participate in the interview portion of a research study that explores the journey of a highly effective, high school mathematics teachers using a reformist teaching paradigm in their classroom. The purpose of the study is to differentiate themes and patterns from yours' and other participants' narratives. This information will provide guideposts and inspiration to other mathematics teachers who are developing and using a reformist teaching paradigm in their classrooms. I am asking you to participate because you are identified as a highly effective mathematics teacher who is a past recipient of the Presidential Award for Excellence in Mathematics and Science Teaching (PAEMST). Another reason for my interest is that you employ a reformist teaching paradigm in your mathematics classroom.

If you agree to take part in this section of the research study, you will be asked to participate in one face-to-face interview at a location agreed on by both you and the researcher. The interview should take about two hours. I would like to audiotape the interview to make sure that our conversation is recorded accurately. The discussion topics include your experiences developing and using a reformist teaching paradigm in your high school mathematics classroom.

From this interview, I will write a narrative of your experiences as highly successful mathematics. I will send the completed written narrative to you, and ask that you read the narrative. Two weeks after I send you the narrative, I will contact you to set up a time to have either a Skype or Face Time conference. During this conference, you and I will collaborate of the written narrative. During this collaboration, you will have a chance to add information to and delete information from the narrative. If you choose, you will have a chance to write a reflection paper about your teaching. Both the edited narrative and the reflection paper will be included in my dissertation.

While you may not receive a direct benefit from participating in this research, some people find sharing their stories to be a valuable experience. I hope that this study will contribute to an understanding of the use of a reformist teaching paradigm in a high school mathematics classroom.

I plan to publish the results of this study, but will not include any information that would identify you or your school, school district, town, or state. To keep your information safe, the audio tape and notes from of your interview will be placed in a locked file cabinet for the duration of three years after my dissertation is completed. As soon as these three 
years elapse, the tapes and notes will be destroyed. I will enter the study data on a computer that is password-protected and uses special coding of the data to further protect the information. To protect confidentiality, your real name or your school, school district, town, and state will not be used in the written copy of the discussion; a different pseudonym will be assigned to you, your school, school district, town, and your state.

There are entities other than the researchers that may need to see the information you provided as part of the study. These include organizations responsible for making sure the research is done safely and properly, including the Portland State University's Research and Strategic Partnerships, and my doctoral advisor, Dr. Ron Narode, Ph.D., of Portland State University's Education Department, Curriculum and Instruction.

If you have questions about this research, including questions about the scheduling of the interview, you may contact Gerald Young at 12528 SE Imperial Crest St., Happy Valley, OR 97086; internet address: young5688@comcast.net; home phone: (503) 698-4089; or cell phone: (503) 708-1464. You may also contact my faculty advisor, Dr. Ron Narode, Ph.D., Portland State University, Education Department, Curriculum and Instruction, PO Box, Portland, OR 97207, naroder@pdx.ed, (503) 725-4798. If you have concerns about your rights as a research participant, please contact Research and Strategic Partnerships, Market Center Building $6^{\text {th }}$ floor, Portland State University, (503) 725-4288.

By signing this document, you are agreeing to be included in the study. Participating in this research is completely voluntary. Even if you decide to participate now, you may change your mind and stop at any time. You will be given a copy of this document for your records, and a copy will be kept with the study records. Be sure that questions you may have about the study have been answered and that you understand what you are being asked to do. You may contact the researcher if you think of a question later.

I agree to participate in the study.

Signature Date

I agree to be audiotaped as part of the study.

Signature Date 
APPENDIX D

INTERVIEW PROTOCOL 
"The Criteria for a Successful Career as a High School Mathematics Teacher" Interview Protocol

Participant

School

City

State

Beginning Script

Thank you for your participation today. My name is Gerald (Jerry) Young; I am former recipient of PAEMST award (Oregon, 2001) and a doctoral student at Portland State University. I am conducting this interview as part of my dissertation research. Thank you for sending the Narrative Prompt (2004 to present) or Evidence of Learning (prior to 2004) section of your PAEMST application to me. Those data gathering sources and this interview will be used in my research study on the effective use of constructivism in high school mathematics classrooms. This one-on-one interview will take approximately 60 minutes and will include questions regarding your experiences of the development of reformist/constructivist teaching paradigm in your classroom.

I would like your permission to tape record this interview, so I may accurately document the information you convey. I will be using both a digital recorder and a digital recording pen. If at any time during the interview you wish to discontinue the use of these recording devices or the interview itself, please feel free to let me know. All of your responses are confidential. Your responses will remain confidential and will be used to develop a better understanding of how you developed your constructivist teaching philosophy and teaching strategies. The purpose of this study is to distinguished themes and patterns in data supplied by you and other study participants that will allow for the development of a road map for mathematics teachers who want to use a constructivist teaching paradigm in their classroom.

At this time I would like to remind you of your written consent to participate in this study. I am the responsible investigator, specifying your participation in the dissertation research study: The Criteria for a Successful Career as a High School Mathematics Teacher. You and I have both signed and dated each copy, certifying that we agree to continue this interview. You will receive one copy and I will keep the other under lock and key, separate from your reported responses.

I want to reassure you that your participation in this study will be confidential and any data are gathered from the data gathering sources (PAEMST narrative prompts, demographic information, and interview) will only be viewed by you, me, and my doctoral advisor, Associate Professor Ron Narode from Portland State University, Education Department. The electronically-store data gathered from this study will be stored on a computer that is password protected. Hardcopy data will be kept under lock 
and key for a period of three years after my receiving my doctorate degree. At the time, both the hardcopy and electronic data information will be destroyed.

Your participation in this interview is completely voluntary. If at any time you need to stop, take a break, or return a page, please let me know. You may also withdraw your participation at any time without consequence. Do you have any questions or concerns before we begin? Then, with your permission, we will begin the interview.

\section{Demographic questions:}

Script

This first part of the interview is set up to gather needed demographic information about you in terms of teaching mathematics.

How many years have you taught mathematics?

How many years have you taught mathematics at different levels of schooling?

How many years have you taught mathematics at your current school?

What mathematics subjects have you taught at the high school level?

\section{Open-ended questions:}

Script

This study concerns the experiences of high school mathematics teachers applying the reformist constructivist teaching paradigm in their classroom. There is little research involving reformist mathematics teachers at the high school. This goal of this study is to 'shed light' on this topic, and your experiences with reformist mathematics teaching will be significant.

1. Tell me why you chose the teaching profession.

2. Why did you choose mathematics as your subject of study in college?

3. What influenced you toward mathematics teaching? 
4. Tell me about your early experiences of teaching.

5. Can you remember your beliefs about teaching prior to going into your first classroom? After several years of teaching? Now?

6. What were the obstacles you confronted with teaching during the years?

7. How did you overcome these obstacles?

8. Why did you begin to use reformist mathematics teaching strategy in your classroom?

9. Tell me about your use of reformist (constructivism) pedagogy in your mathematics classroom?

10. How did you develop the teaching skills (i.e., questioning) needed with constructivist teaching.

11. What led you to the philosophy of constructivism?

\section{Possible motivational prompts:}

- Tell me about...

- Could you tell me more about....

According to the literature on the subject, using constructivism in a high school mathematics classroom is frequently controversial, and many mathematics teachers using constructivism are confronted with obstacles.

1. Tell me about any obstacles you confronted using constructivism in your classroom.

2. How did you "overcome" these obstacles?

3. I frequently was surprised by my students in my classroom. Could you tell me about some of your surprises when you first began using constructivist teaching strategies in your classroom?

4. Why are you still using constructivism in your mathematics classroom?

\section{Additional motivational prompts:}

- Could you tell me more about...?

- Would you elaborate more on...? 
- What was your thinking about...?

- I not sure of your thinking here, could you elaborate further on...?

\section{Ending Script}

Thank you for participating in this interview. The information from your interview, PAEMST Narrative Prompt or Evidence of Learning section of your application will allow me to construct a written narrative of your development on standards-based, constructivist mathematics teaching paradigm. Once I have written this narrative I will send you a copy via email. At that point, I would like you to review the narrative and note any corrections or additions needed. I will give you a week to review the narrative then we will set up a second session via email and, using either Skype or telephone, we will review the written narrative together. From this collaboration, I will rewrite the narrative with the added corrections and additions. Furthermore, you may choose to write a written reflection about your development of constructivist mathematics teaching paradigm, and send it to me. I will include this written reflection into my dissertation verbatim.

Again, the data I collected will be kept confidential. No one except you, me, and my doctoral advisor, Dr Ron Narode will see any of this data and reflection. 
APPENDIX E

DATA GATHERING MATRIX 


\begin{tabular}{|c|c|c|c|}
\hline $\begin{array}{c}\text { Themes/ } \\
\text { Participant }\end{array}$ & Influence-Family & Influence-Mentors & $\begin{array}{c}\text { Influence-Teachers \& } \\
\text { Professors }\end{array}$ \\
\hline Meredith & $\begin{array}{l}\text { *Father engrained the idea } \\
\text { that "a problem was an } \\
\text { opportunity" } \\
\text { *Mother helped her in her } \\
\text { classroom. This "planted a } \\
\text { seed" Love teaches her } \\
\text { younger siblings }\end{array}$ & $\begin{array}{l}\text { John-colleague } \\
\text { Helped her through student } \\
\text { teaching \& getting job Got } \\
\text { her to go to NW Math } \\
\text { Conf., OML \& NSF- } \\
\text { sponsored workshop that } \\
\text { "change her life" }\end{array}$ & $\begin{array}{l}\text { Jr \& Sr High Math } \\
\text { Teachers- gave her } \\
\text { challenging problems. } \\
\text { Topology Professor-used } \\
\text { visual \& physical models } \\
\text { to explain Topology } \\
\text { concepts "Change her } \\
\text { teaching" }\end{array}$ \\
\hline Rachael & $\begin{array}{l}\text { *Father- History Prof. } \\
\text { *Mother-English Teacher } \\
\text { Felt she would be a teacher } \\
\text { at an early age. Love } \\
\text { teaching her younger } \\
\text { siblings }\end{array}$ & $\begin{array}{l}\text { A professor who headed the } \\
\text { SIMMS project. } \\
\text { Teachers who were fellow } \\
\text { writers for the SIMMS } \\
\text { project. }\end{array}$ & $\begin{array}{l}\text { Honors Geometry- made } \\
\text { students defend thoughts } \\
\text { English-“different starting } \\
\text { points" in essay } \\
\text { Prob./Stats Prof-taught } \\
\text { using rich math tasks. }\end{array}$ \\
\hline Mitch & $\begin{array}{l}\text { *Father-"engineer \& very } \\
\text { technical" Started Mitch } \\
\text { early with computer \& } \\
\text { calculator. This developed } \\
\text { Mitch's love for technology } \\
\text { that created learning. }\end{array}$ & $\begin{array}{l}\text { A teacher who met him at } \\
\text { his state math teacher } \\
\text { conference. } \\
\text { When troubled with math, } \\
\text { went to workshop \& } \\
\text { conferences \& sought out } \\
\text { mentors }\end{array}$ & $\begin{array}{l}\text { Math Methods, Prof-taught } \\
\text { using } 1989 \text { NCTM } \\
\text { publication as text. } \\
\text { Encourage prof. dev. for } \\
\text { her students join NCTM \& } \\
\text { use } \\
\text { Change Mitch on } \\
\text { constructivist teaching }\end{array}$ \\
\hline Damon & $\begin{array}{l}\text { *Father-Lutheran pastor } \\
* \text { Mother-reading teacher } \\
\text { *All of the } 7 \text { siblings went } \\
\text { into the teaching } \\
\text { *Wife-fellow math teacher }\end{array}$ & $\begin{array}{l}\text { Dept. Chairman of the first } \\
\text { school. Got him to join } \\
\text { state's math teaching Ass'n } \\
\text { \& NCTM. Got him to go to } \\
\text { NCTM regional where his } \\
\text { "life was changed" }\end{array}$ & $\begin{array}{l}\text { 1st grade teacher-1st to set } \\
\text { seed for teaching. } \\
\text { College Alg Prof-engaging } \\
\text { connections } \\
\text { Cooperating Teacher.-1st } \\
\text { time seeing constructivism } \\
\text { in teaching. }\end{array}$ \\
\hline Cole & $\begin{array}{l}\text { *Father-doctor } \\
\text { *Mother-Restaurant } \\
\text { Manager \& Dorm mother. } \\
\text { Sent to boarding school } \\
\text { classical education was } \\
\text { good. Strong regiment of } \\
\text { drill \& practice }\end{array}$ & $\begin{array}{l}\text { Janice \& Rich-LCMP } \\
\text { Sarah-IMP } \\
\text { Lydia-TDG \& OML \& } \\
\text { leadership } \\
\text { May-Equals \& Family Math }\end{array}$ & $\begin{array}{l}\text { Professors in Graduate } \\
\text { School. Created seed for } \\
\text { looking at student learning. }\end{array}$ \\
\hline Meredith & $\begin{array}{l}\text { Standards-based teaching } \\
\text { - Used, LCMP, Connected } \\
\text { Math } \\
\text {-Teaching pedagogy } \\
\text { Student centered } \\
\text {-Definition of math rigor \& } \\
\text { Prob Solving }\end{array}$ & $\begin{array}{l}\text { Instrumental in teaching } \\
\text {-New curricula } L C M P \& \\
\text { Connected Math } \\
\text {-Mentors } \\
\text {-Leadership } \\
\text {-Use of technology -TI- } \\
\text { graphing calculators }\end{array}$ & $\begin{array}{l}\text { Upward Bound-positive } \\
\text { teaching experience } \\
\text { NSF-funded inspirational } \\
\text { 2- week workshop \& } \\
\text { curricula } \\
\text { State Math Teacher Ass'n- } \\
\text { sponsored Conferences } \\
\text { NCTM }\end{array}$ \\
\hline
\end{tabular}




\begin{tabular}{|c|c|c|c|}
\hline $\begin{array}{c}\text { Themes/ } \\
\text { Participant }\end{array}$ & Influence-Family & Influence-Mentors & $\begin{array}{c}\text { Influence-Teachers \& } \\
\text { Professors }\end{array}$ \\
\hline Rachael & $\begin{array}{l}\text { Standards-based teaching } \\
\text { Curricula used SIMMS } \\
\text {-Teaching pedagogy } \\
\text { Constructivism } \\
\text {-Definition of math rigor. } \\
\text { Students construct meaning }\end{array}$ & $\begin{array}{l}\text { Instrumental in teach. } \\
\text { New curricula-SIMM, } \\
I M P A C T \\
\text {-Mentors } \\
\text {-Leadership } \\
\text {-Use of technology in } \\
\text { teaching-TI-graphing } \\
\text { calculators }\end{array}$ & $\begin{array}{l}\text { Peace Corps- } \\
\text { metacognition realization } \\
\text { NSF-grant for master's \& } \\
\text { writing for SIMMS } \\
\text { SIMMS-discovered } \\
\text { mentors \& curricula \& } \\
\text { constructivism }\end{array}$ \\
\hline Mitch & $\begin{array}{l}\text { Standards-based teaching } \\
\text {-Curricula \& Technology - } \\
\text { Geom Sketchpad \& } \\
\text { Discovering Geom } \\
\text {-Teaching pedagogy } \\
\text { Constructivism }\end{array}$ & $\begin{array}{l}\text { Instrumental in teach. } \\
\text {-New curricula-Discovering } \\
\text { Geometry, IMPACT } \\
\text {-Mentors } \\
\text {-Leadership } \\
\text {-Use of technology in } \\
\text { teaching, Sketchpad }\end{array}$ & $\begin{array}{l}\text { State Math Teacher Ass'n- } \\
\text { discovered mentors \& } \\
\text { curricula } \\
\text { NSF-funded calculus } \\
\text { Impact program } \\
\text { Key Curriculum-curricula } \\
\text { \& software-Geo Sketchpad }\end{array}$ \\
\hline Damon & $\begin{array}{l}\text { Standards-based teaching } \\
\text { - Curricula used, wrote his } \\
\text { own Discrete Math based on } \\
\text { the Standards } \\
\text {-Teaching pedagogy } \\
\text { Constructivism } \\
\text { 1991-Publication }\end{array}$ & $\begin{array}{l}\text { Instrumental in teach } \\
\text {-New curricula-Discrete } \\
\text { Math } \\
\text {-Mentors } \\
\text {-Leadership } \\
\text {-Use of technology in } \\
\text { teaching } \\
\text { TI-graphing calculators }\end{array}$ & $\begin{array}{l}\text { State Math Teacher Ass'n- } \\
\text { discovered useful ideas } \\
\text { Key Curriculum-used } \\
\text { Discovering Algebra } \\
\text { NCTM-regional } \\
\text { conferences changed his } \\
\text { teaching pedagogy }\end{array}$ \\
\hline Cole & $\begin{array}{l}\text { Standards-based teaching } \\
\text { - Curricula-used Connected } \\
\text { Math, Family Math, \& IMP } \\
\text {-Teaching pedagogy } \\
\text { Constructivism } \\
\text {-Math rigor, definition }\end{array}$ & $\begin{array}{l}\text { Instrumental in teach } \\
\text {-New curricula IMP, } \\
\text { Connected Math, Family } \\
\text { Math } \\
\text {-Mentors \& leadership } \\
\text {-Use of technology in } \\
\text { teaching, TI-graphing } \\
\text { calculators }\end{array}$ & $\begin{array}{l}\text { Teacher Core-master's } \\
\text { prog. } \\
\text { NSF-Programs \& curricula } \\
\text { TDG-leadership } \\
\text { State Math Teacher Ass'n- } \\
\text { acquired mentors }\end{array}$ \\
\hline Meredith & $\begin{array}{l}\text { All math teachers taught } \\
\text { using teacher-directed } \\
\text { pedagogy } \\
\text {-Good at replicating math } \\
\text { procedures \& skills }\end{array}$ & $\begin{array}{l}\text { Good at calculus, then } \\
\text { struggle with advance math } \\
\text { subjects } \\
\text { Student Teaching-not good } \\
\text { Math Methods class-poor }\end{array}$ & $\begin{array}{l}\text { Topology-Prof taught } \\
\text { using visual/physical } \\
\text { models, Calculus for } \\
\text { Middle School Teachers- } \\
\text { highly influential in } \\
\text { changing teaching } \\
\text { pedagogy }\end{array}$ \\
\hline
\end{tabular}




\begin{tabular}{|c|c|c|c|}
\hline $\begin{array}{c}\text { Themes/ } \\
\text { Participant }\end{array}$ & Influence-Family & Influence-Mentors & $\begin{array}{c}\text { Influence-Teachers \& } \\
\text { Professors }\end{array}$ \\
\hline Rachael & $\begin{array}{l}\text { All math Teachers taught } \\
\text { using teacher-directed } \\
\text { pedagogy } \\
\text {-Good at replicating math } \\
\text { procedures \& skills }\end{array}$ & $\begin{array}{l}\text { Good at calculus, then } \\
\text { struggle with advance math } \\
\text { subjects because of lack of } \\
\text { math conceptual } \\
\text { understanding } \\
\text { Student Teach-not good. } \\
\text { Math Methods class- } \\
\text { horrible }\end{array}$ & $\begin{array}{l}\text { Master's work was great! } \\
\text { Prof that developed } \\
\text { SIMMS } \\
\text {-Become involved with } \\
\text { IMPACT program, } \\
\text { constructivism, \& Calculus }\end{array}$ \\
\hline Mitch & $\begin{array}{l}\text { All math teachers taught } \\
\text { using teacher-directed } \\
\text { pedagogy } \\
\text {-Good at replicating math } \\
\text { procedures \& skills ("mimic } \\
\text { math") }\end{array}$ & $\begin{array}{l}\text { Good at calculus, then } \\
\text { struggle with advance math } \\
\text { subjects Student Teaching- } \\
\text { great constructivist } \\
\text { cooperative teacher } \\
\text { Math Methods class- } \\
\text { GREAT }\end{array}$ & $\begin{array}{l}\text { Uneventful master's } \\
\text { program. } \\
\text {-Did "mimic math" in math } \\
\text { classes } \\
\text {-Worked with Geometry } \\
\text { Sketchpad in on a class }\end{array}$ \\
\hline Damon & $\begin{array}{l}\text { All math teachers taught } \\
\text { using teacher-directed } \\
\text { pedagogy } \\
\text {-Good at replicating math } \\
\text { procedures \& skills }\end{array}$ & $\begin{array}{l}\text { College Alg.Prof changed } \\
\text { his thinking about teaching } \\
\text { math. Inspirational teacher } \\
\text { Student Teaching- Witness } \\
\text { constructivism teaching \& } \\
\text { used it in class. Older } \\
\text { brother mentored him }\end{array}$ & $\begin{array}{l}\text { Master's program was } \\
\text { great } \\
\text {-Worked in a cohort of } 18 \\
\text { teachers } \\
\text {-Great collaboration } \\
\text { environment } \\
\text {-Developed Discrete Math } \\
\text { curriculum }\end{array}$ \\
\hline Cole & $\begin{array}{l}\text { ll math teachers taught using } \\
\text { teacher-directed pedagogy } \\
\text {-Not good at replicating } \\
\text { math procedures \& skills, } \\
\text { wondered about the "why" }\end{array}$ & $\begin{array}{l}\text { Did not start out in } \\
\text { education, majored in } \\
\text { International Relations } \\
\text {-Struggled with math } \\
\text { because he wrestle with the } \\
\text { "why" \& prof taught "how" }\end{array}$ & $\begin{array}{l}\text { Participating in Teacher } \\
\text { Core program. } \\
\text {-Great program that } \\
\text { fostered, "sued for } \\
\text { teaching, for student } \\
\text { learning"" }\end{array}$ \\
\hline Meredith & $\begin{array}{l}\text { 1st yr of teaching was } \\
\text { "strictly lectures \& } \\
\text { demonstrations," } \\
\text {-"Boring \& skill-based"Did } \\
\text { use projects } \\
\text {-Cared for students } \\
\text {-Regional conference } \\
\text { changed her teaching }\end{array}$ & $\begin{array}{l}\text { Developed student-centered } \\
\text { teaching approach } \\
\text {-Problem-solving } \\
\text {-Attitude, "all students can } \\
\text { learn math!" } \\
\text {-Sought out teaching } \\
\text { methods to help }\end{array}$ & $\begin{array}{l}\text { CU-1st yr teaching-taught } \\
\text { using teacher-directed. } \\
\text { CO-Changing pedagogy } \\
\text { PE-Curriculum change in } \\
\text { schools } \\
\text { PO-colleague, parents, \& } \\
\text { students complained }\end{array}$ \\
\hline
\end{tabular}




\begin{tabular}{|c|c|c|c|}
\hline $\begin{array}{c}\text { Themes/ } \\
\text { Participant }\end{array}$ & Influence-Family & Influence-Mentors & $\begin{array}{c}\text { Influence-Teachers \& } \\
\text { Professors }\end{array}$ \\
\hline Rachael & $\begin{array}{l}\text { 1st years of teaching, } \\
\text { "oblivious to } \\
\text { understanding" } \\
\text {-Taught class with the goal } \\
\text { of, "to see if the students did } \\
\text { the things they needed to get } \\
\text { done in math class" }\end{array}$ & $\begin{array}{l}\text { Later years of teaching } \\
\text {-Emphasis on students } \\
\text { engaging in math rich tasks } \\
\text {-Emphasized equity } \\
\text {-Change was hard to SBC } \\
\text { teaching, but she persisted }\end{array}$ & $\begin{array}{l}\text { CU-Turned down for H.S. } \\
\text { teaching-middle school } \\
\text { teacher idea } \\
\text { CU \& PE-teachers did not } \\
\text { want to change to NSF } \\
\text { curriculum, colleagues \& } \\
\text { parents complained }\end{array}$ \\
\hline Mitch & $\begin{array}{l}\text { 1st years of teaching, } \\
\text {-Teacher-directed pedagogy } \\
\text {-"Rambled too much' \& } \\
\text { was a "yelling friend" }\end{array}$ & $\begin{array}{l}\text { High student expectations } \\
\text {-Start class rich task } \\
\text {-Work on constructivist } \\
\text { principles } \\
\text {-Students create their own } \\
\text { meanings of math concepts }\end{array}$ & $\begin{array}{l}\text { CU-Suffered initially a } \\
\text { lack of understanding } \\
\text { PO-Follow colleague } \\
\text { PE-Changing pedagogy to } \\
\text { student-learning } \\
\text { CU-Only member of } \\
\text { NCTM }\end{array}$ \\
\hline Damon & $\begin{array}{l}1 \text { st5 yr teacher-directed, } \\
\text { organized, cared about } \\
\text { students, passion for math, } \\
\text { Quirky behavior to keep } \\
\text { students engaged, } \\
\text { assessment summative } \\
\text { w/“ } 40 \text { one-step prob's" }\end{array}$ & $\begin{array}{l}\text { High student expectations } \\
\text {-Start class rich task } \\
\text {-Stress problem-solving \& } \\
\text { students creating } \\
\text { connections. } \\
\text {-Focus on student learning }\end{array}$ & $\begin{array}{l}\text { CU-Precollege math } \\
\text { PE-taught like he was } \\
\text { taught } \\
\text { CU-developed own } \\
\text { curriculum } \\
\text { PE-Winning over new } \\
\text { students to his "new" } \\
\text { pedagogy }\end{array}$ \\
\hline
\end{tabular}




\begin{tabular}{|c|c|c|c|}
\hline $\begin{array}{c}\text { Themes/ } \\
\text { Participant }\end{array}$ & Influence-Family & Influence-Mentors & $\begin{array}{c}\text { Influence-Teachers \& } \\
\text { Professors }\end{array}$ \\
\hline Cole & $\begin{array}{l}\text { First years of teaching } \\
\text {-"More quicker to tell" } \\
\text {-Used visual/physical } \\
\text { Manipulatives } \\
\text {-'Narrow scope" } \\
\text {-Worked from a fixed mind } \\
\text { set }\end{array}$ & $\begin{array}{l}\text { Last years of teaching } \\
\text {-Classroom "immersion into } \\
\text { math culture" } \\
\text {-"Culture of problem- } \\
\text { solving } \\
\text {-Work on students' } \\
\text { metacognition }\end{array}$ & $\begin{array}{l}\text { CU-Precollege math } \\
\text { CU \& CO-Teachers went } \\
\text { back to direct-teaching } \\
\text { abandoning } I M P \\
\text { PE-Changing teaching } \\
\text { pedagogy } \\
\text { PO-Parent opposition }\end{array}$ \\
\hline Meredith & $\begin{array}{l}\text { Problem solver, } \\
\text {-High expectations for } \\
\text { herself \& students } \\
\text {-Caring \&Highly intelligent } \\
\text {-Awareness of her strengths } \\
\text { \& weaknesses }\end{array}$ & $\begin{array}{l}\text { Faith in students to learn } \\
\text { mathematics } \\
\text {-Students help create } \\
\text { curriculum paths } \\
\text {-Students motivate her to } \\
\text { seek growth in teaching }\end{array}$ & \multirow{5}{*}{$\begin{array}{l}\text { In Obstacle Theme } \\
\text { CU-Cultural } \\
\text { PO-Political } \\
\text { PE-pedagogical } \\
\text { CO-Conceptional } \\
\text { *Personality Traits* \& } \\
\text { *Students' Influence* are } \\
\text { unique findings } \\
\text { The remainder of the } \\
\text { findings are classified as } \\
\text { "normal finding"; they are } \\
\text { supported by previous } \\
\text { research }\end{array}$} \\
\hline Rachael & $\begin{array}{l}\text { Faith in students to learn } \\
\text { mathematics } \\
\text {-Students help create } \\
\text { curriculum paths } \\
\text {-Students motivate her to } \\
\text { seek growth in teaching }\end{array}$ & $\begin{array}{l}\text { Faith in students to learn } \\
\text { mathematics } \\
\text {-Students help create } \\
\text { curriculum paths } \\
\text {-Students motivate her to } \\
\text { seek growth in teaching }\end{array}$ & \\
\hline Mitch & $\begin{array}{l}\text { Believes teaching was his } \\
\text { "deeper calling" "leave a } \\
\text { "footprint' that he was } \\
\text { around" } \\
\text {-Love of learning } \\
\text {-Caring \&Highly intelligent } \\
\text {-Highly motivated }\end{array}$ & $\begin{array}{l}\text { Faith in students to learn } \\
\text { mathematics } \\
\text {-Students help create } \\
\text { curriculum paths } \\
\text {-Students motivate him to } \\
\text { seek growth in teaching }\end{array}$ & \\
\hline Damon & $\begin{array}{l}\text { Problem solver } \\
\text {-Highly motivate- } \\
\text { perseverance } \\
\text {-Caring \&Highly intelligent } \\
\text {-High expectations for } \\
\text { herself \& students } \\
\text {-Highly motivated }\end{array}$ & $\begin{array}{l}\text { Faith in students to learn } \\
\text { mathematics } \\
\text {-Students help create } \\
\text { curriculum paths } \\
\text {-Students motivate him to } \\
\text { seek growth in teaching }\end{array}$ & \\
\hline Cole & $\begin{array}{l}\text { Problem solver } \\
\text {-Positive leadership traits } \\
\text {-Caring \&Highly intelligent } \\
\text {-Perseverance } \\
\text {-Curious about } \\
\text { metacognition }\end{array}$ & $\begin{array}{l}\text { Faith in students to learn } \\
\text { mathematics } \\
\text {-Students help create } \\
\text { curriculum paths } \\
\text {-Students motivate him to } \\
\text { seek growth in teaching }\end{array}$ & \\
\hline
\end{tabular}

